\title{
Investigation of HDDE exhaust flow mixing devices to enhance SCR performance
}

\author{
Venkata Reddy Sathi \\ West Virginia University
}

Follow this and additional works at: https://researchrepository.wvu.edu/etd

\section{Recommended Citation}

Sathi, Venkata Reddy, "Investigation of HDDE exhaust flow mixing devices to enhance SCR performance" (2010). Graduate Theses, Dissertations, and Problem Reports. 2135.

https://researchrepository.wvu.edu/etd/2135

This Thesis is protected by copyright and/or related rights. It has been brought to you by the The Research Repository @ WVU with permission from the rights-holder(s). You are free to use this Thesis in any way that is permitted by the copyright and related rights legislation that applies to your use. For other uses you must obtain permission from the rights-holder(s) directly, unless additional rights are indicated by a Creative Commons license in the record and/ or on the work itself. This Thesis has been accepted for inclusion in WVU Graduate Theses, Dissertations, and Problem Reports collection by an authorized administrator of The Research Repository @ WVU. For more information, please contact researchrepository@mail.wvu.edu. 


\title{
Investigation of HDDE Exhaust Flow Mixing Devices to Enhance SCR Performance
}

\author{
Venkata Reddy Sathi
}

Thesis Submitted to the

College of Engineering and Mineral Resources

at West Virginia University

in partial fulfillment of the requirements

for the degree of

Master of Science

in

Mechanical Engineering

Mridul Gautam, Ph.D., Chair

Benjamin C. Shade, Ph.D.

Hailin Li, Ph.D.

Gregory Thompson, Ph.D.

Department of Mechanical and Aerospace Engineering

Morgantown, West Virginia

2010 


\title{
Investigation of HDDE Exhaust Flow Mixing Devices to Enhance SCR Performance
}

\author{
Venkata Reddy Sathi
}

\begin{abstract}
The 2010 regulations implemented by the U.S. Environmental Protection Agency (EPA) require significant reduction in Oxides of Nitrogen $\left(\mathrm{NO}_{\mathrm{x}}\right)$ and Particulate Matter $(\mathrm{PM})$. These regulations have driven a significant amount of research and development into more advanced engine combustion strategies and after-treatment systems. This study focuses on $\mathrm{NO}_{\mathrm{x}}$ reduction in Heavy Duty Diesel Engines (HDDE) equipped with Diesel Particulate Filter (DPF) and Selective Catalytic Reduction (SCR) catalyst by optimizing the mixing of DPF out exhaust gas with urea injected upstream of the SCR. Proprietary wired mesh substrates were installed between the DPF and SCR system at three locations and showed further $\mathrm{NO}_{\mathrm{x}}$ reduction from the previous emissions results. Different wired mesh catalytic substrates of varying lengths were used in this study. Experiments were conducted on four of the 13 modes of the European Stationary Cycle (ESC), modes in which the engine yielded high $\mathrm{NO}_{\mathrm{x}}$ emissions. Results from these experiments show that the wired mesh substrates enhanced the mixing of the exhaust stream and urea, which improved the performance of the SCR catalyst. When the wired mesh was tested on ESC and Federal Transient Procedure (FTP), $\mathrm{NO}_{\mathrm{x}}$ emissions were reduced 20-25\% by introducing the wired mesh substrates in the exhaust flow for the ESC cycles. This study demonstrated that the wired mesh substrates enhanced the mixing of the exhaust gas and the injected urea. The mixing effect caused by the wired mesh improved the thermolysys of urea into ammonia $\left(\mathrm{NH}_{3}\right)$. This study draws a conclusion that using a wired mesh catalytic substrate in the exhaust upstream of the SCR catalyst improves the mixing of the exhaust with urea and gives additional $\mathrm{NO}_{\mathrm{x}}$ reduction for certain steady state modes, but showed no change for the $\mathrm{NO}_{\mathrm{x}}$ emissions for the FTP cycle.
\end{abstract}




\section{Acknowledgements}

I must express my gratitude to all the individuals who helped make my education a success. Without their support I would not have come so far.

I would first like to thank my parents for their constant love and support throughout my life.

I would like to thank Dr. Mridul Gautam for giving me the opportunity to receive a graduate education. You have allowed me to work under you, allowing me to gain valuable experience for my future

I thank Dr. Ben Shade for being in my committee and giving valuable feedbacks. I thank Dr. Hailin Li, Dr. Gregory Thompson for being in my committee and very helpful during the course of the project

I am very grateful to Vimala for being a great support and being a very very close friend for the past three years. I thank you for being besides me to share both my happiest moments and the troubled times

I would like to thank Raffaello Ardanese, Michelangelo Ardanese, Teddy Adams, Marc Besch, and Arvind Thiruvengadam for the constant support during the testing in EERC.

I would also like to thank my dearest friends Phani, Abhinav, Chaitanya, Nishit, Nikhil, Anvesh, Pradeep, Sathish, Praveen, Rajesh, and Vamshi for supporting me throughout my graduate studies. Words are not enough to express my thanks for all of my friends for their constructive criticism. 


\section{Table of Contents}

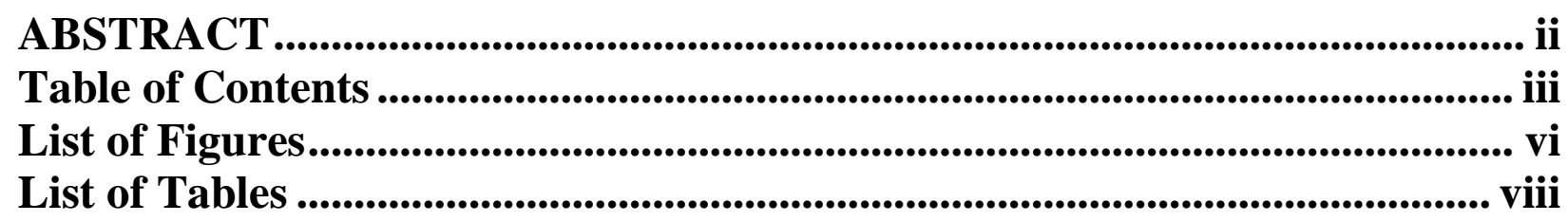

Chapter 1： Introduction.....................................................................................1

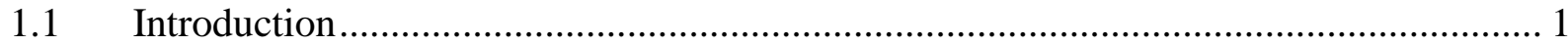

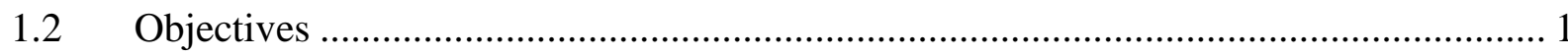

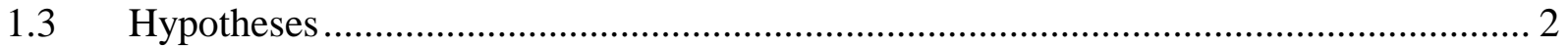

Chapter 2: Literature Review .....................................................................3

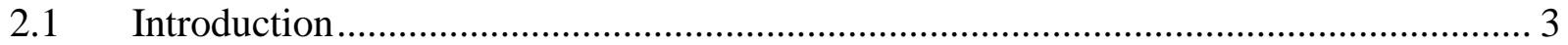

2.2 Previous Emission Testing and Scope for this Study ................................................... 4

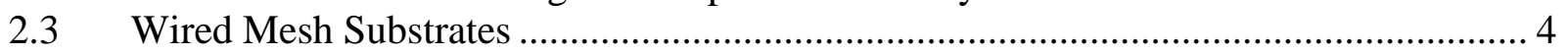

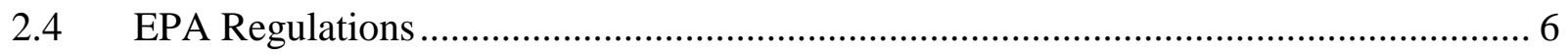

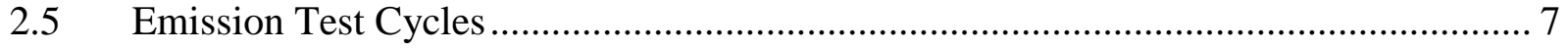

2.5.1 Federal Test Procedure ……………………............................................. 7

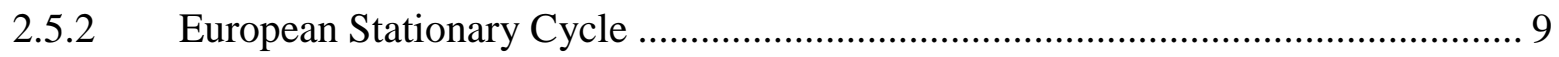

2.6 Exhaust After-treatment Devices ........................................................................ 11

2.6.1 Diesel Particulate Filters ................................................................................ 11

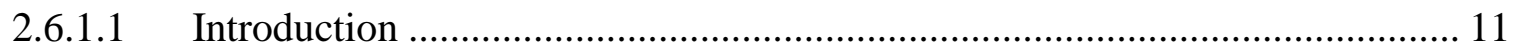

2.6.1.2 Filter Configuration ............................................................................. 13

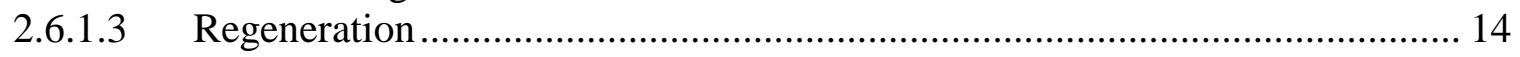

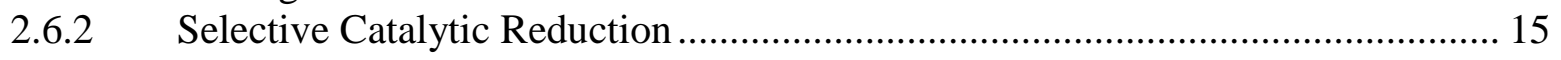

2.6.2.1 Introduction ...................................................................................... 15

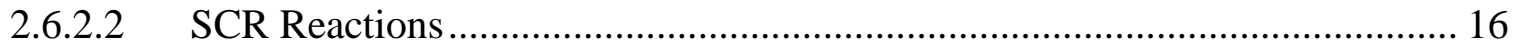

2.6.2.3 Catalysts and Reductants ........................................................................ 17

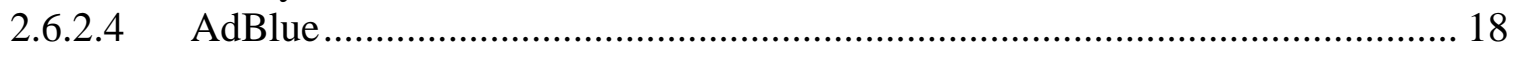

Chapter 3: Experimental Set Up..........................................................................19

3.1 Primary Exhaust Dilution Tunnel ...................................................................... 19

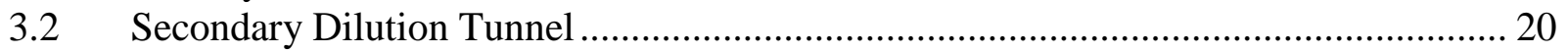

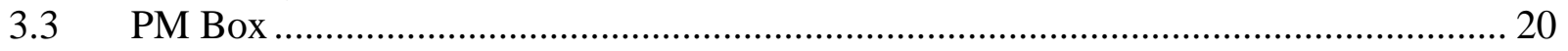

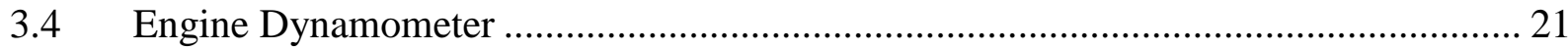

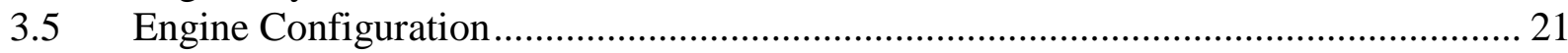

3.6 Gaseous Emission Sampling System ……………............................................... 22

3.6.1 Flame Ionization Detector Analyzers ……….................................................. 23

3.6.2 Non-Dispersive Infrared Analyzers ............................................................. 24

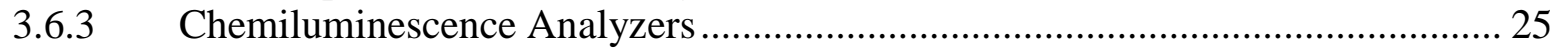

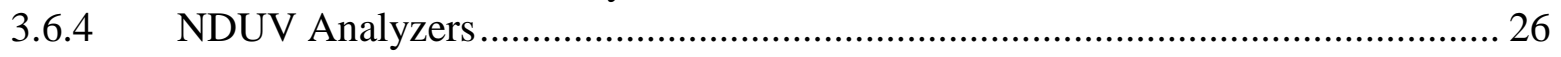



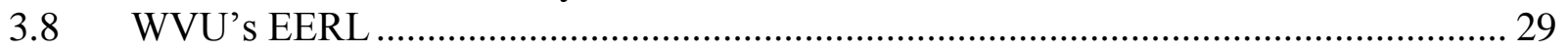


Chapter 4: Emission Testing Procedure ....................................................................30

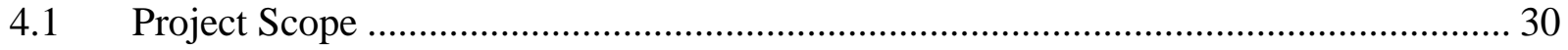

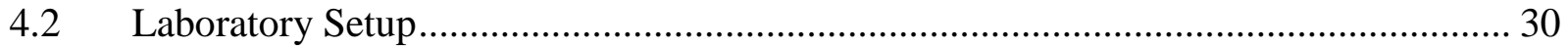

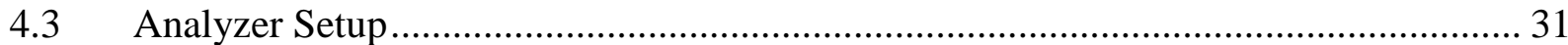

4.4 Previous Mixing Devices and Selection of Wired Meshes.......................................... 33

4.4.1 Mixing Device 1 ...................................................................................... 33

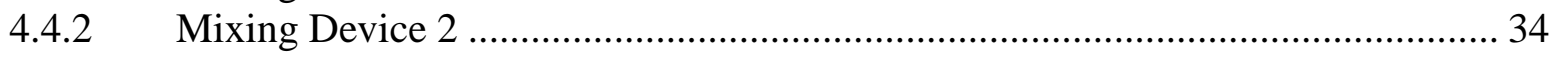

4.5 Different Kinds of Mesh Substrates Used ............................................................... 35

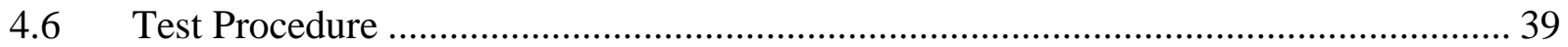

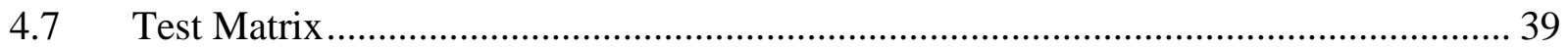

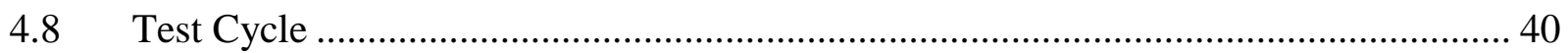

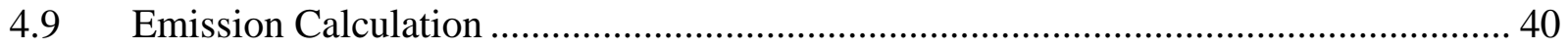

Chapter 5: Results and Discussion...................................................................41

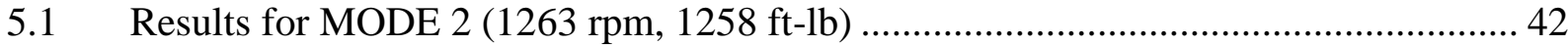

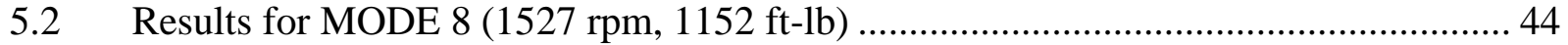



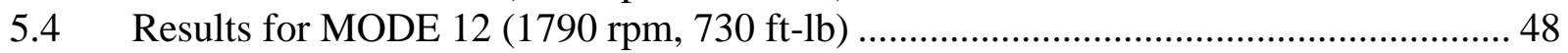

5.5 Correlation between $\mathrm{NO}_{\mathrm{x}}$ and Exhaust Temperatures ............................................... 50

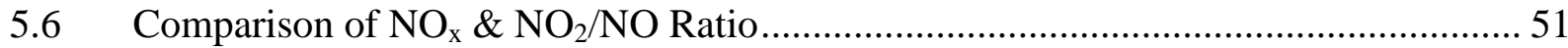

5.6.1 Comparison of Brake Specific Emissions of $\mathrm{NO}_{\mathrm{x}}$ …………………………....... 51

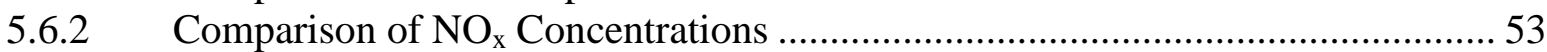

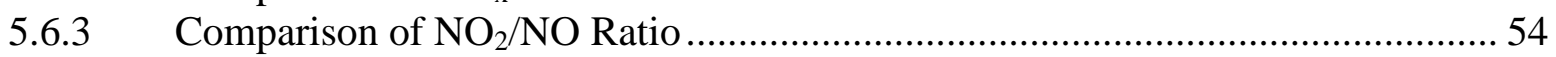

5.7 Comparison of Exhaust Temperature, $\mathrm{NO}_{\mathrm{x}}$, and $\mathrm{NH}_{3}$ Slip Concentrations .................. 56

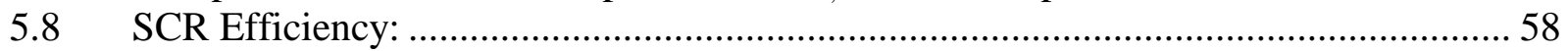

5.9 Back Pressure Comparisons:................................................................................. 59

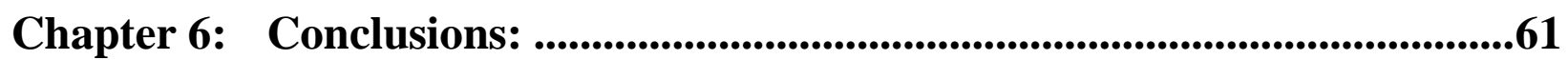

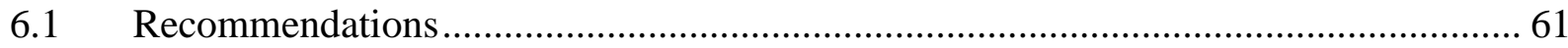

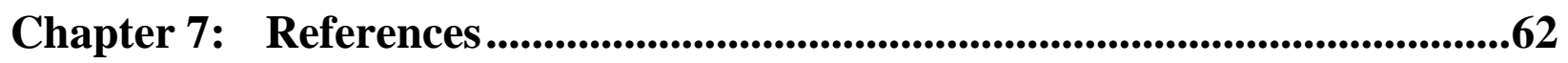

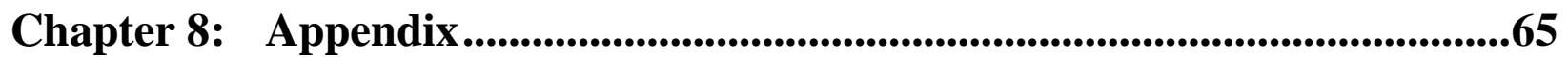

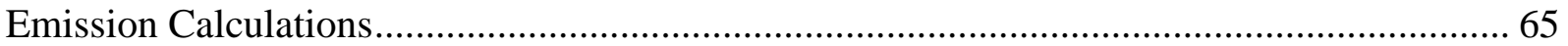




\section{List of Figures}

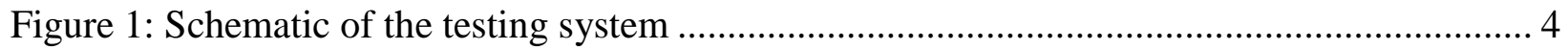



Figure 3: Plots for torque and speed during FTP cycle ................................................. 8

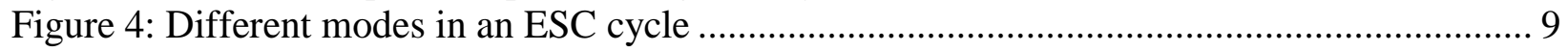

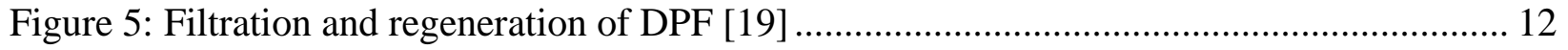

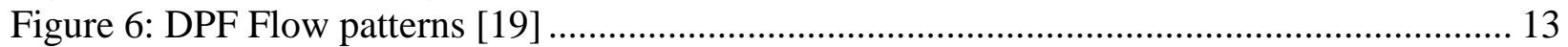

Figure 7: Process of Selective Catalytic Reduction [22] ..................................................... 15

Figure 8: Relationship between the $\mathrm{NH}_{3} / \mathrm{NO}_{\mathrm{x}}$ ratio, $\mathrm{NO}_{\mathrm{x}}$ conversion, temperature, and ammonia

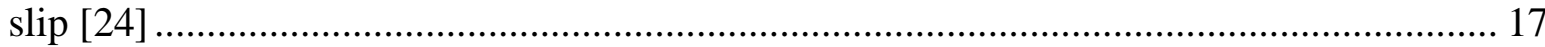

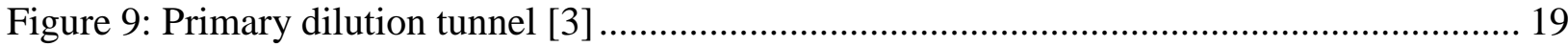

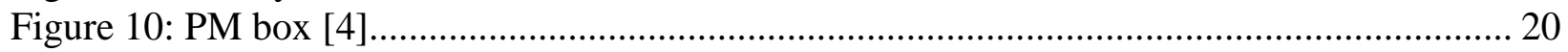

Figure 11: Engine dynamometer [3] .............................................................................. 21

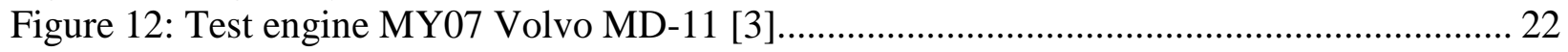

Figure 13: Rosemount analytical hydrocarbon analyzer model 402 ....................................... 24

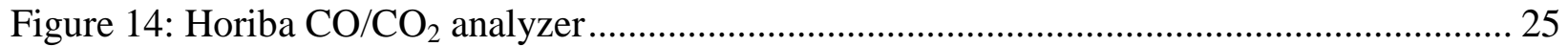

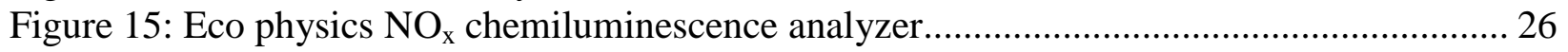

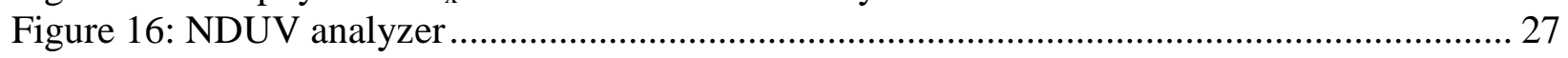

Figure 17: Fleetgard compact DPF system and Johnson Matthey SCR system [4] .................. 28

Figure 18: Urea tank and urea injector connected to the exhaust after-treatment system [4] ..... 28

Figure 19: Schematic diagram of clean tunnel sampling setup [35] ....................................... 29

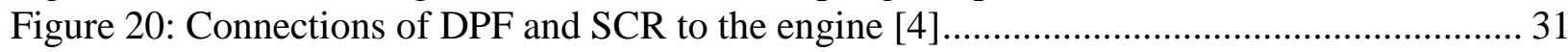

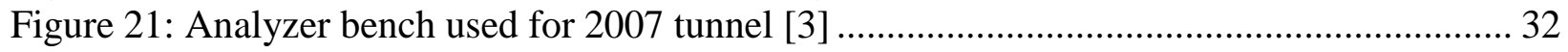

Figure 22: Mixing device 1 (Conical Turbulator)............................................................... 34

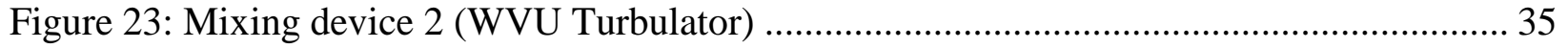

Figure 24: 11/2" Non-coated wired mesh substrate ............................................................... 36

Figure 25: 2" Non-coated wired mesh substrate .................................................................. 36

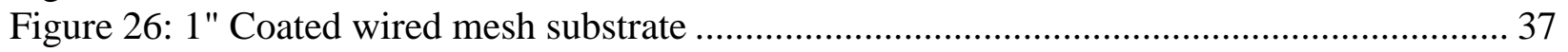

Figure 27: 11/2" Coated wired mesh substrate ................................................................... 37

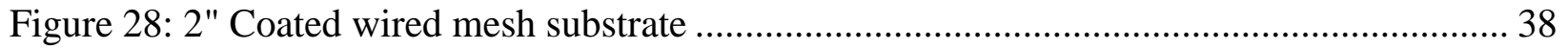

Figure 29 : Installation of wired mesh substrate in exhaust pipe ......................................... 38

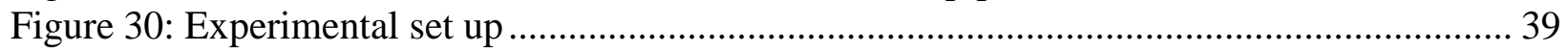

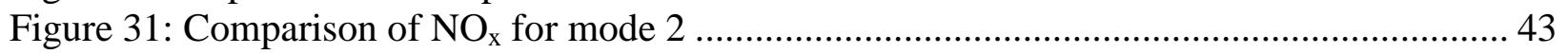

Figure 32: Comparison of SCR-in exhaust temperature measured at mode 2 ......................... 43

Figure 33: Comparison of $\mathrm{NO}_{\mathrm{x}}$ for mode 8 .................................................................. 45

Figure 34: Comparison of SCR-in exhaust temperature measured at mode 8 ........................... 45

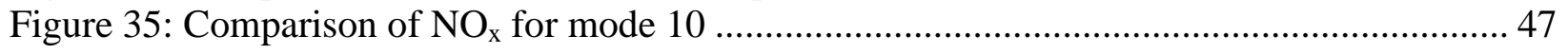



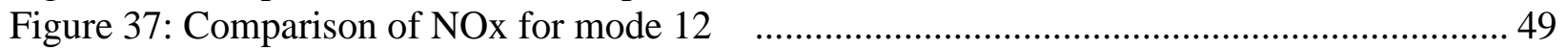

Figure 38: Comparison of exhaust temperature for mode 12 .............................................. 49

Figure 39: Correlation between $\mathrm{NO}_{\mathrm{x}}$ and exhaust temperatures........................................... 51

Figure 40: Comparison of SCR-out $\mathrm{NO}_{\mathrm{x}}$ in g/bhp-hr measured using ESC cycles .................... 52

Figure 41: Comparison of SCR-out $\mathrm{NO}_{\mathrm{x}}$ in $\mathrm{g} / \mathrm{bhp}$-hr measured using FTP cycles .................... 52

Figure 42: Comparison of SCR-Out $\mathrm{NO}_{\mathrm{x}}$ in ppm measured using ESC cycles......................... 53

Figure 43: Comparison of SCR-Out $\mathrm{NO}_{\mathrm{x}}$ in ppm measured using FTP cycles ......................... 54 
Figure 44: Comparison of $\mathrm{NO}_{2} / \mathrm{NO}$ ratio for ESC cycles .................................................. 55

Figure 45: Comparison of $\mathrm{NO}_{2} / \mathrm{NO}$ ratio for FTP cycles ................................................ 56

Figure 46: Exhaust temperature $\mathrm{Vs}_{\mathrm{NO}}$ and $\mathrm{NH}_{3}$ slip concentrations, ESC Cycles ................. 57

Figure 47: Exhaust temperature $\mathrm{Vs} \mathrm{NO}_{\mathrm{x}}$ and $\mathrm{NH}_{3}$ slip concentrations, FTP Cycles.................. 58

Figure 48: Comparison of SCR efficiency with and without mesh ....................................... 59

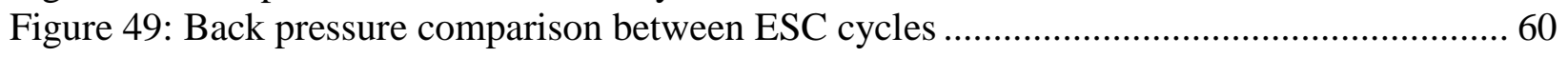

Figure 50: Back pressure comparison between FTP cycles................................................. 60 


\section{List of Tables}

Table 1: Federal emission standards for $\mathrm{NO}_{\mathrm{x}}$ and $\mathrm{PM}$ for heavy-duty engines [12] ................... 6

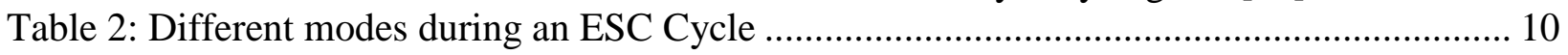

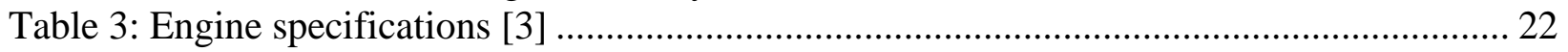

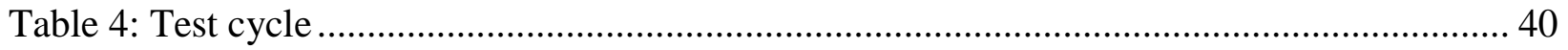

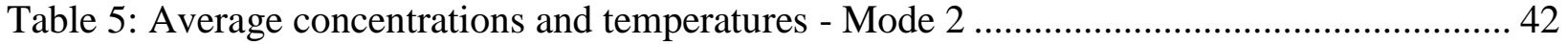

Table 6: Average concentrations and temperatures - Mode 8 ................................................. 44

Table 7: Average concentrations and temperatures - Mode 10 .............................................. 46

Table 8: Average concentrations and temperatures - Mode 12 ........................................... 48 


\section{Chapter 1: Introduction}

\subsection{Introduction}

The emission limit values for heavy duty engines are becoming stricter throughout the world. Exhaust after-treatment devices are necessary to meet the strict regulations set by the U.S. Environmental Protection Agency (EPA) to control engine out emissions levels in USA. Diesel Particulate Filter (DPF) and Selective Catalytic Reduction (SCR) have wide range of usage as exhaust after-treatment devices. DPF has the efficiency of filtering the Particulate Matter (PM) up to $99 \%$ [1]. SCR contains a catalyst which makes the oxides of nitrogen $\left(\mathrm{NO}_{\mathrm{x}}\right)$ react with injected urea, emitting nitrogen $\left(\mathrm{N}_{2}\right)$ and water vapor. This study mainly focused on enhancing the performance of SCR and improving the mixing of urea that is injected upstream of the SCR and the exhaust gas. Further $\mathrm{NO}_{\mathrm{x}}$ reduction can be achieved by improving the mixing of urea with the exhaust gas. This research is based on the investigation of the location of the wired mesh substrate in the exhaust pipe and the physical geometry, primarily the length of the wired mesh substrate, which will result in the maximum reduction of $\mathrm{NO}_{\mathrm{x}}$.

\subsection{Objectives}

DPF and SCR are currently the exhaust after-treatment systems of choice to mitigate Heavy Duty Diesel Engine (HDDE) emissions of PM and $\mathrm{NO}_{\mathrm{x}}$, respectively, to achieve the 2010 limits (0.20 g/bhp-hr of $\mathrm{NO}_{\mathrm{x}}$ and $0.01 \mathrm{~g} / \mathrm{bhp}-\mathrm{hr}$ of PM). This study employed wired mesh substrates in the exhaust stream, before SCR, to improve the mixing of the urea with the exhaust gas. The main objectives of this study are:

1. To investigate the effect of wired mesh substrates on the $\mathrm{NO}_{\mathrm{x}}$ emissions with urea distribution upstream of catalyst.

2. To optimize the location and length of the wired mesh substrates to achieve further $\mathrm{NO}_{\mathrm{x}}$ reduction than previous emission results from "Advanced Diesel Emission Control System" (ADECS) program.

3. To select a mesh substrate from the five coated and non-coated mesh substrates of different lengths that has the potential to result in $\mathrm{NO}_{\mathrm{x}}$ reduction.

4. To test the selected wired mesh on European Stationary Cycle (ESC) and Federal Transient Procedure (FTP) cycles and aiming at achieving further $\mathrm{NO}_{\mathrm{x}}$ reduction. 


\subsection{Hypotheses}

It was hypothesized that:

1. The stainless steel wired mesh substrate placed in the exhaust stream provides for enhanced mixing of exhaust gas with urea; hence, leads to increased SCR efficiencies.

2. Titanium dioxide $\left(\mathrm{TiO}_{2}\right)$ coating on the wire mesh will further improve the $\mathrm{NO}_{\mathrm{x}}$ reduction. 


\section{Chapter 2: Literature Review}

\subsection{Introduction}

In the past 30 years, the U.S. EPA maintained strict regulations on emissions from dieselfueled engines. A wide range of research has been taking place across the world in order to meet the requirements set forth by respective agencies in different countries. EPA's regulations are focused on the gaseous and solid emissions in the exhaust, primarily $\mathrm{NO}_{\mathrm{x}}$ and PM [2]. The majority of diesel-fueled engines produced today are electronically controlled. This feature has allowed the manufacturers to change engine parameters to reduce the amount of pollutants emitted by the engine.

Studies [3, 4, and 5] conducted in West Virginia University (WVU) Engine and Emissions Research Laboratory (EERL) in the ADECS program to meet the 2010 standards showed higher $\mathrm{NO}_{\mathrm{x}}$ levels when measured using the FTP cycle. $\mathrm{NO}_{\mathrm{x}}$ emissions, when measured using ESC, were reduced to the required limit (0.20 g/bhp-hr). Emissions standards for FTP cycle can be achieved by improving the mixing of the urea and the exhaust stream, upstream of the SCR performance.

Engine manufacturers use various approaches to test emissions. Engine emissions can be monitored on a continuous basis while the engine is operating or exhaust samples may be collected in bags and analyzed to obtain an integrated value. Data can be reported in actual concentration measurements (ppm or \% vol), in mass measurements (g), in terms of work output (g/bhp-hr), in terms of distance (g/mile), and in fuel-specific units (g/kgfuel). Most of the engine dynamometer tests report emissions in brake-specific terms (g/bhp-hr) [6].

The engine dynamometer testing approach was used for this study. The engine was fixed on the test bed and was connected to the engine dynamometer. The fuel to the engine, coolant, intake air, and the exhaust back pressure were controlled in the EERL, and all these arrangements were done according to the 40 CFR Part 1065 [7]. 


\subsection{Previous Emission Testing and Scope for this Study}

Emission testing was conducted at the WVUEERL for ADECS program [8 and 9] to reduce the $\mathrm{NO}_{\mathrm{x}}$ and PM emissions to the regulated limits. Standard FTP and ESC test cycles were used in this research. The engine was equipped with exhaust after-treatment devices, such as DPF and SCR. During this study, the PM was reduced lower than the required limit of 0.01 g/bhp-hr for both FTP and ESC test cycles.

The study was continued to reduce the $\mathrm{NO}_{\mathrm{x}}$ to the restricted limit of $0.20 \mathrm{~g} / \mathrm{bhp}-\mathrm{hr}$. A range of tests were conducted by changing the engine parameters and the urea injection map, and succeeded in decreasing the $\mathrm{NO}_{\mathrm{x}}$ emissions to the regulated limit for steady state cycles. But, the $\mathrm{NO}_{\mathrm{x}}$ emissions value in the case of FTP was not below the regulated limit.

This gives the scope for an extensive study in analyzing the behavior of the flow of exhaust gases. Introducing a wired mesh in the stream of the exhaust gases makes the flow uniform in all the directions thus providing enhanced mixing of the exhaust and injected urea.

\subsection{Wired Mesh Substrates}

A stainless steel wired mesh installed in the exhaust stream ensures a uniform flow pattern and can reduce the mixing distances. Single layer wire is rolled and knitted in the form of a mesh as shown in the Figure 2. These wired meshes can be made of different thicknesses depending on the requirement [10].

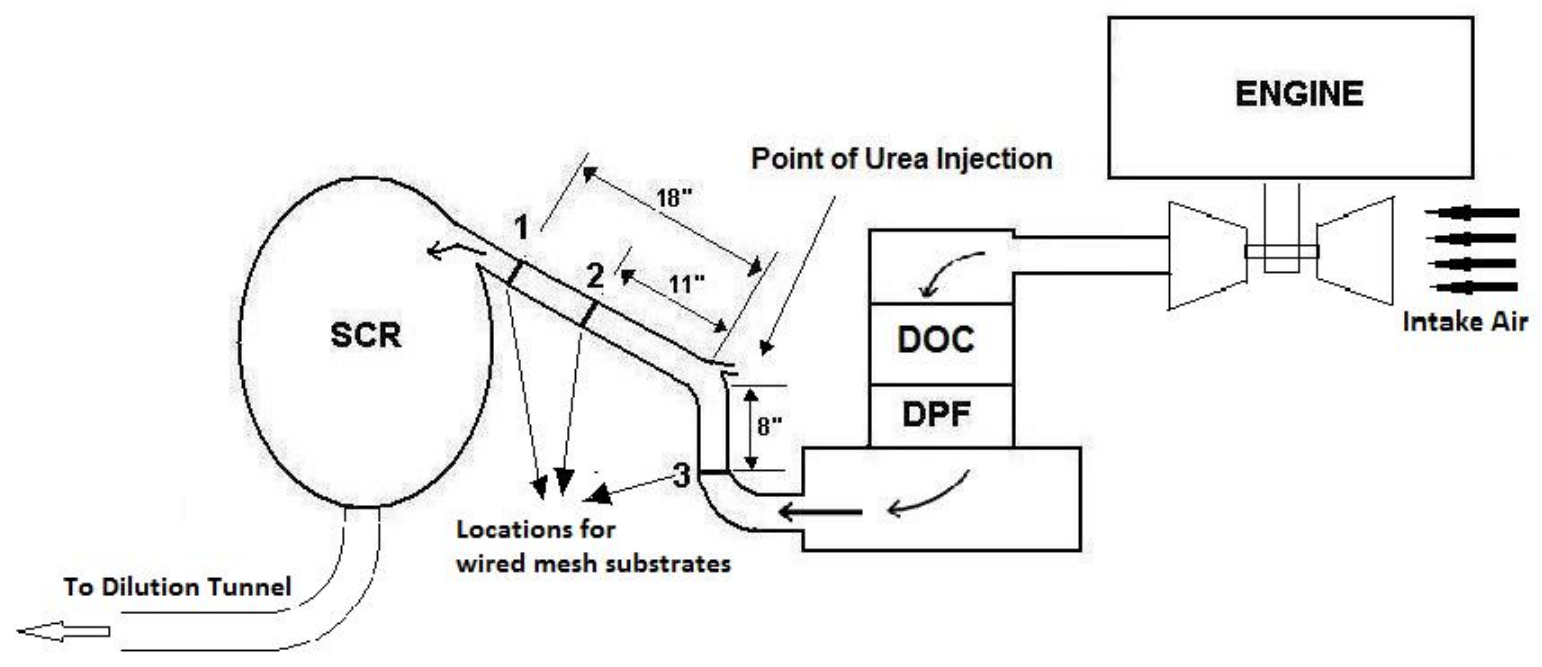

Figure 1: Schematic of the testing system 
When a wired mesh substrate is installed in the exhaust stream, the flow travels in both longitudinal and radial directions [10]. Thus, the injected urea disperses over a larger area. Wired mesh will provide increased contact time, good distribution of the urea, and increase the efficiency of the urea reaction. A typical wired mesh used in this study is shown in Figure 2.

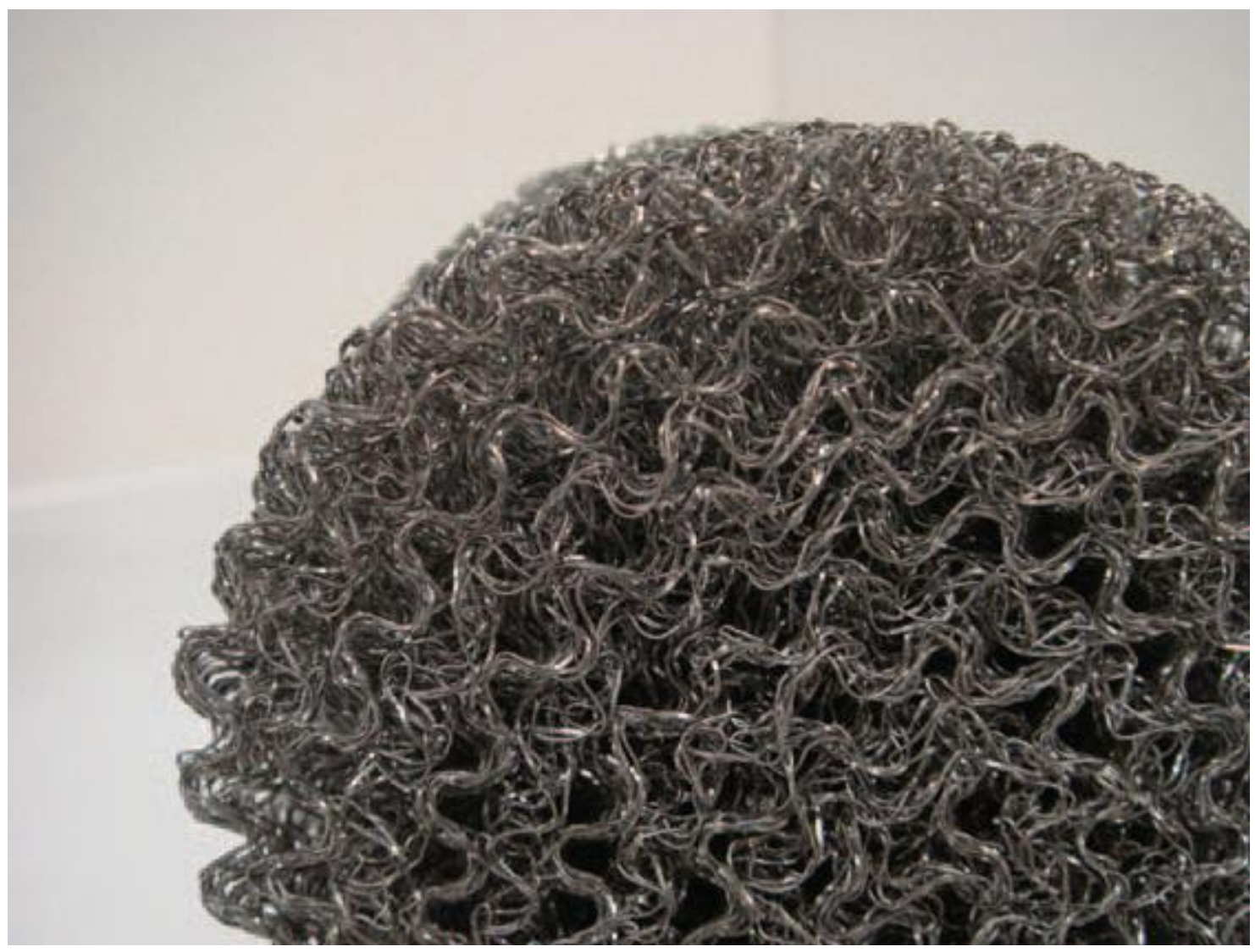

Figure 2 : Stainless steel wired mesh

Wired mesh substrates coated with Titanium dioxide $\left(\mathrm{TiO}_{2}\right)$ were also used in this study. The manufacturers of these wired meshes used electrophoretic deposition (EPD) to form a $\mathrm{Ti}$ layer on the surface of the mesh [11]. The Ti coated meshes were thermally treated in order to enhance the strength of the coating. Calcination of these wired meshes was done at a temperature of $600^{\circ} \mathrm{C}$ to form a thin layer of $\mathrm{TiO}_{2}$ on the outer surface of the wired mesh [11]. 


\subsection{EPA Regulations}

The EPA is a federal government organization in U.S. which regulates the levels of specific gases and particulate matter being emitted into the atmosphere and safeguards the natural environment. EPA sets the regulations to engine manufacturers to reduce the amount of pollutants in exhaust gases. This requires engine manufacturers to take necessary steps to design their engines according to the regulations. The first diesel exhaust emissions regulations were established by the EPA in 1971 as a result of the 1970 Clean Air Act [12]. These stringent requirements led to the development of diesel engines with significantly reduced emissions. A year-by-year certified levels of allowable emissions set by EPA from 1985 are shown in Table 1.

Table 1: Federal emission standards for $\mathrm{NO}_{\mathrm{x}}$ and PM for heavy-duty engines [12]

\begin{tabular}{|c|c|c|}
\hline $\begin{array}{c}\text { Engine } \\
\text { Model Year }\end{array}$ & $\begin{array}{c}\mathbf{N O}_{\mathbf{x}} \\
\text { g/bhp-hr }\end{array}$ & $\begin{array}{c}\mathbf{P M} \\
\text { g/bhp-hr }\end{array}$ \\
\hline 1985 & 10.7 & --- \\
\hline 1988 & 10.7 & 0.60 \\
\hline 1990 & 6.0 & 0.60 \\
\hline 1991 & 5.0 & 0.25 \\
\hline 1993 & 5.0 & 0.25 \\
\hline 1994 & 5.0 & 0.10 \\
\hline 1996 & 5.0 & 0.10 \\
\hline 1998 & 4.0 & 0.10 \\
\hline 2002 & 2.50 & 0.10 \\
\hline 2007 & 1.20 & 0.01 \\
\hline 2010 & 0.20 & 0.01 \\
\hline
\end{tabular}




\subsection{Emission Test Cycles}

To compare the emissions produced by different engines there should be a specific pattern in which the engine needs to be operated to determine the gaseous and PM levels. The emissions cycle has to resemble the actual operation of the engine in the real world in terms of speed and load on the engine during normal vehicle operation. Numerous test cycles were established to measure the pollutant levels emitted into the atmosphere from the engine exhaust. These tests were designed with the purpose of simulating real-time conditions. Steady state and transient tests were designed in order to test the performance of the engines. These test cycles specify the required speed and load conditions at which the engine needs to be operated. The set points of speed and load conditions differ from transient to the steady state operation [13].

These emission test cycles are sequences of speed and load conditions performed on a dynamometer. Emissions measured on a chassis dynamometer are usually expressed in mass of pollutant per unit of distance traveled. Emissions measured over an engine dynamometer test cycles are typically expressed in mass of pollutant per unit of mechanical energy delivered by the engine, such as $\mathrm{g} / \mathrm{kW}-\mathrm{hr}$ or $\mathrm{g} / \mathrm{bhp}-\mathrm{hr}$.

\subsubsection{Federal Test Procedure}

The FTP heavy-duty transient cycle is currently used to measure the exhaust emissions of heavy-duty engines in the USA [14]. The variety of heavy-duty trucks and buses in American cities, including traffic in and around the cities on roads and expressways, were taken into account in developing this transient cycle. It requires a DC or AC dynamometer capable of both absorbing and supplying power since the cycle also contains motoring segments.

The FTP cycle consist of four phases: New York Non Freeway (NYNF), Los Angeles Non Freeway (LANF), Los Angeles Freeway (LAFY) and the repetition of the first phase. These phases simulate real-world vehicle operation on these highways. This cycle comprises cold start, idling, acceleration and deceleration stages. A variety of different speeds and loads are sequenced to simulate real operation of the engine [14]. 
The cycle is carried out twice and the repetition is made with a hot start after a soak time of $1200 \mathrm{~s}(20 \mathrm{~min})$ on completion of the first cycle [15]. The variation of normalized speed and torque with time is shown in Figure 3.
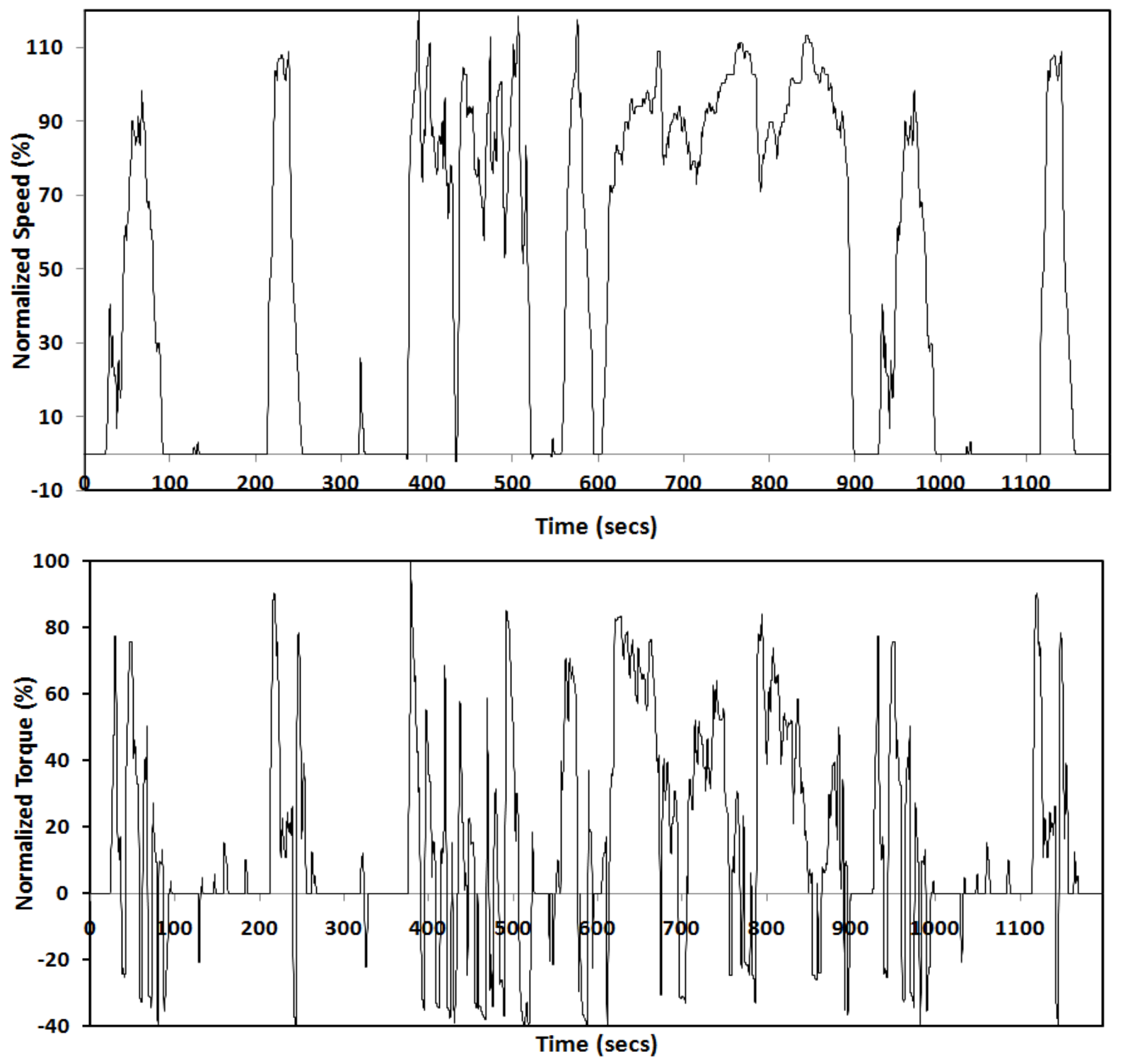

Figure 3: Plots for torque and speed during FTP cycle

Heavy duty diesel engines tested on the FTP cycle produce a range of exhaust temperatures. Generally, the temperature is between 250 and $350^{\circ} \mathrm{C}$, but there are some hot sections with temperatures reaching as high as $450^{\circ} \mathrm{C}$. 


\subsubsection{European Stationary Cycle}

The ESC test cycle has been introduced by the European Union to measure emissions from heavy-duty diesel engines. This cycle was introduced along with the European Transient Cycle (ETC) and European Load Response (ELR) tests. The ESC cycle is a steady state procedure with 13 different modes.

A sequence of steady state modes shown in Figure 4 and Table 2 were run using the engine dynamometer. The engine was run for a specific time interval in each mode. The speed and load changes occurred in the first 20 seconds of each mode. The engine speed and torque were maintained at $\pm 2 \%$ of the prescribed values. Each mode of ESC cycle has its own weighing factor. These weighing factors are considered while calculating the composite emissions levels for the entire cycle. Particulate matter was collected on a filter for the entire cycle and the brake specific emissions of PM were calculated from the mass of PM deposited on the filter. The final results are expressed in brake specific emissions [16].

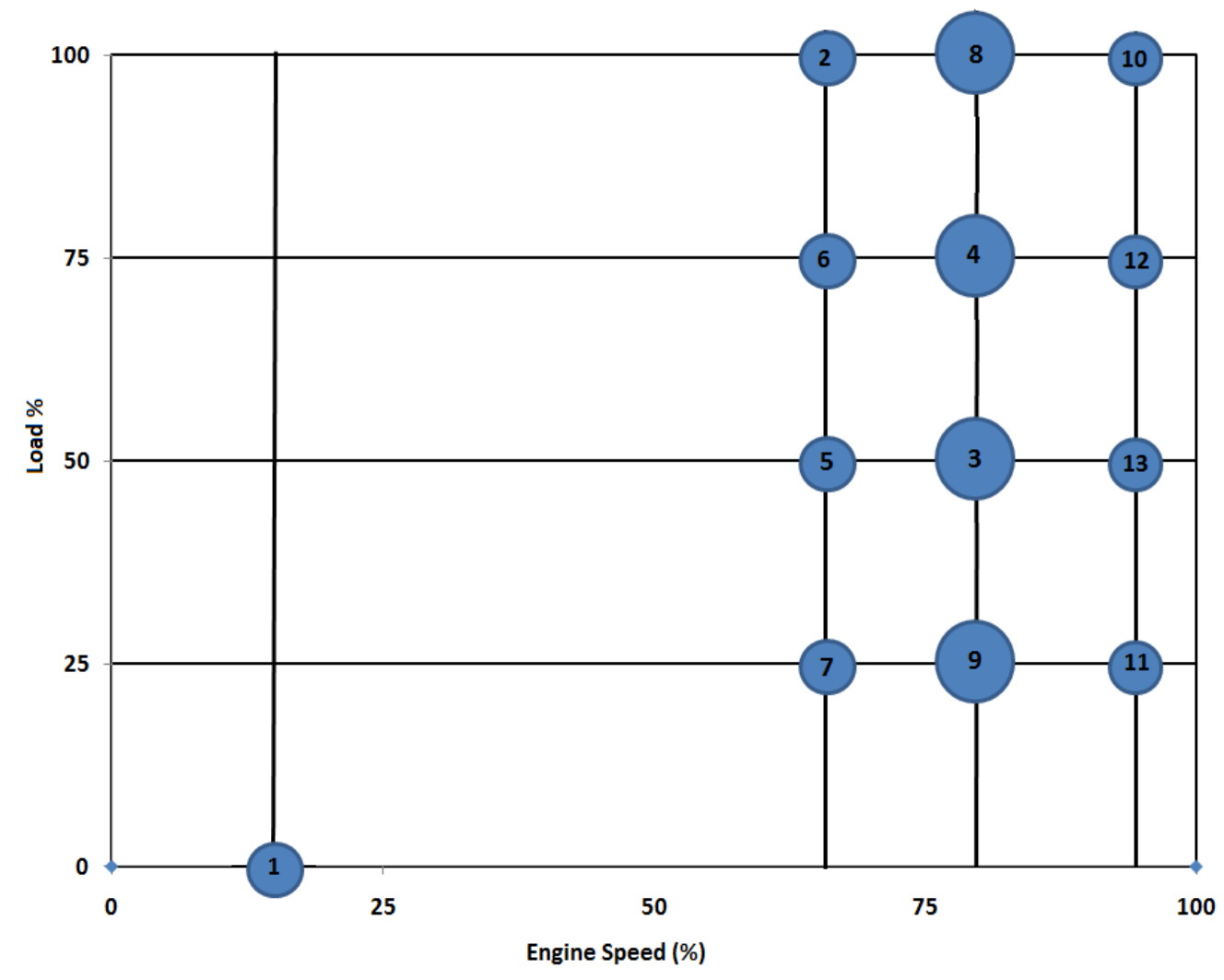

Figure 4: Different modes in an ESC cycle 
Table 2: Different modes during an ESC Cycle

\begin{tabular}{|c|c|c|c|c|}
\hline \multicolumn{5}{|c|}{ ESC Test Modes } \\
\hline MODE & Engine Speed & \% Load & Weight Factor \% & Duration \\
\hline 1 & Low Idle & 0 & 15 & 4 Minutes \\
\hline 2 & A & 100 & 8 & 2 Minutes \\
\hline 3 & B & 50 & 10 & 2 Minutes \\
\hline 4 & B & 75 & 10 & 2 Minutes \\
\hline 5 & A & 50 & 5 & 2 Minutes \\
\hline 6 & A & 75 & 5 & 2 Minutes \\
\hline 7 & A & 25 & 5 & 2 Minutes \\
\hline 8 & B & 100 & 9 & 2 Minutes \\
\hline 9 & B & 25 & 10 & 2 Minutes \\
\hline 10 & C & 100 & 8 & 2 Minutes \\
\hline 11 & C & 25 & 5 & 2 Minutes \\
\hline 12 & C & 75 & 5 & 2 Minutes \\
\hline 13 & C & 50 & 5 & 2 Minutes \\
\hline
\end{tabular}

The engine speeds A, B, and C was calculated from the power map of the engine. Maximum power generated from the engine during the power map was recorded. High speed and low speed of the engine were determined according to 40 CFR Part 1065.610 [17]. The high speed $\mathrm{N}_{\mathrm{hi}}$ of the engine is the speed (above rated speed) at which the engine produces $70 \%$ of the maximum rated power. The low speed $\mathrm{N}_{\mathrm{lo}}$ of the engine is the speed (below rated speed) at which the engine produces $50 \%$ of the maximum mapped power. The speeds $\mathrm{A}, \mathrm{B}$, and $\mathrm{C}$ were determined from the following equations.

$$
\begin{aligned}
& A=N_{l o}+0.25\left(N_{h i}-N_{l o}\right) \\
& B=N_{l o}+0.50\left(N_{h i}-N_{l o}\right) \\
& C=N_{l o}+0.75\left(N_{h i}-N_{l o}\right)
\end{aligned}
$$




\subsection{Exhaust After-treatment Devices}

Exhaust after-treatment devices are used to reduce engine out emissions from the engines. Exhaust after-treatment devices removes the unwanted emissions like $\mathrm{NO}_{\mathrm{x}}$ and $\mathrm{PM}$ after the exhaust were made to pass through them. These devices reduce the regulated gases and unwanted soot from the exhaust gases by using the catalyst. The exhaust after-treatment devices used in this study are DPF, used to filter the PM up to 98\%, and SCR, used to reduce the concentration of $\mathrm{NO}_{\mathrm{x}}$ in the exhaust up to $80 \%$. Diesel Oxidation Catalyst (DOC) reduces the emissions of carbon monoxide (CO) and hydrocarbons (HC) in the exhaust, and SCR oxidizes the $\mathrm{NO}_{\mathrm{x}}$ and converts it to $\mathrm{N}_{2}$ and water vapor.

\subsubsection{Diesel Particulate Filters}

\subsubsection{Introduction}

Diesel particulate filters are devices that capture diesel particulates and prevent them from entering the atmosphere. These filters show very good filtration efficiencies, greater than 90\% with mechanical and thermal durability. DPF's are made of porous media through which the gases will flow and the solid particles in the exhaust gases get trapped. Thermal regeneration is used to burn the collected particulates from the filter. DPF's are very effective in controlling the solid part of PM emissions, but they may be ineffective in controlling non-solid particulate fractions like volatile organic compounds [18].

Due to the particle deposition mechanisms used in these devices, DPFs are effective in controlling the solid fraction of diesel particulates, including elemental carbon (soot) and the related black smoke emissions. DPF can also filter the soluble organic fractions (SOF) and sulfate particles, but cannot regenerate SOF or sulfate particles or both. For this reason, DPFs designed to control the total PM emissions should make use of some additional components like oxidation catalysts or usage of ultra-low sulfur fuels in order to target the SOF emission and sulfate particulates reduction.

The DPFs cannot reduce the gaseous emissions in the exhaust, so additional devices must be used in order to reduce the $\mathrm{NO}_{\mathrm{x}}$ from the engine. The $\mathrm{NO}_{\mathrm{x}}$ emissions can also be reduced by using exhaust gas re-circulation (EGR). However using EGR increases the emissions of PM or soot [18]. Therefore, care must be taken in designing the DPF for EGR usage. The regeneration procedure should be done at frequently in such cases [18]. 
In addition to collecting the particulate matter, a procedure must be developed to burn the PM accumulated in the DPF system. The collected particulates would eventually cause an excessively high exhaust gas pressure drop in the filter, which would adversely affect the engine operation. Therefore, diesel filter systems have to provide a way of removing particulates from the filter to restore its soot collection capacity. Some filters are designed for single use whereas; the others are designed to burn off the accumulated particulates, either through a passive technology that makes use of a catalyst or through an active technology. A fuel burner is used which heats the filter to soot combustion temperatures in active technology. Burning off the accumulated soot particles is known as filter regeneration.

The DPF regeneration temperatures are usually in the range of $500^{\circ} \mathrm{C}$ to $600^{\circ} \mathrm{C}$ without the use of any catalyst. The regeneration temperatures can be reduced by using a catalytic coated DPF [19].

The filter regeneration can be performed either continuously during regular operation of the filter or periodically after a pre-determined quantity of soot has been accumulated. In both cases, the regeneration of filter systems should be carried out without involvement of the driver in the vehicle. In most cases, thermal regeneration of diesel filters is done by burning the collected PM particles in the filter converting them to gaseous particles, mainly carbon dioxide $\left(\mathrm{CO}_{2}\right)$ and ash. The thermal regeneration, schematically represented in Figure 5, is one of the cleanest and most attractive DPF regeneration methods [19].



Figure 5: Filtration and regeneration of DPF [19] 
The PM can be removed from the exhaust gas by the DPF by forcing the exhaust gas to flow through the filter and its walls. There is a wide variety of DPFs available in the market. These DPFs are designed according to requirements like low cost, durability, mass production suitability, minimum pressure drop, fine filtration, etc.

\subsubsection{Filter Configuration}

The wall-flow and flow-through DPF structure are the two main types of DPF structures available in the market. The most common design of the DPF structure is the wall-flow structure. It is a cylindrical ceramic structure containing small parallel channels running in the axial direction. The wall-flow monoliths are made of ceramic of higher porosity. The adjacent channels in the wall-flow filters are alternatively plugged at each end, thus forcing the gas to flow through the porous walls which act as a filter medium. Figure 6 shows the differences between the wall flow and flow through patterns.
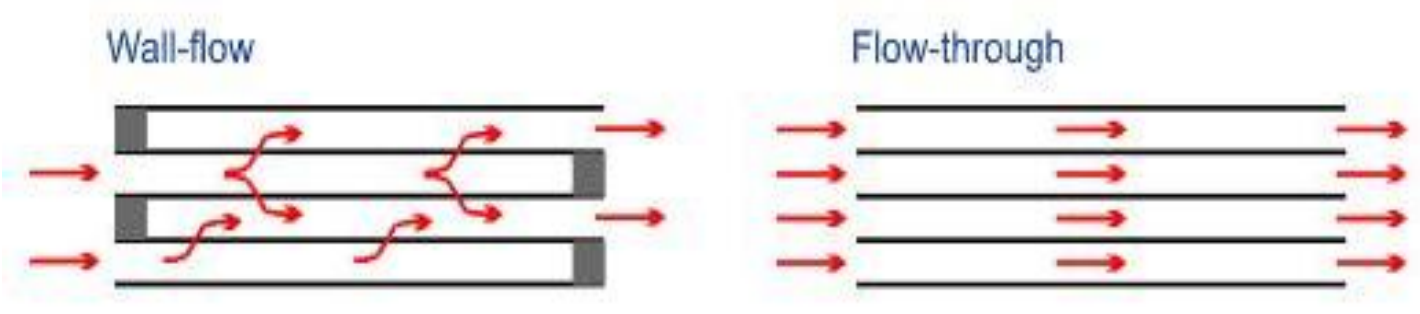

\section{Figure 6: DPF Flow patterns [19]}

The wall-flow filter looks like a checkerboard pattern by the alternate open and close cells at the inlet and outlet faces. They can be distinguished from the flow through patterns through the blocked passages. Plenty of other alternative designs and materials such as ceramic fibers and various types of metal structures were used in manufacturing the DPF. The efficiency of the filter to trap the particulate matter is high in the case of wall-flow mechanisms when compared to flow through patterns [19]. This is because the exhaust gas is permitted to flow through the walls of the filters due to a relatively high porosity but the solid matter cannot.

Finally, the filters are packed in a container and installed in the exhaust system of the vehicle. The DPF can be placed inside a muffler and installed in the exhaust path of the vehicle. 


\subsubsection{Regeneration}

The filters are designed to hold a certain quantity of soot. After considerable usage of the filter, the PM accumulated in DPF will raise the pressure drop in DPF system. The increase in back pressure will affect the normal operation of the engine. There must be a method to regenerate the filter in order to provide problem free operation. Most of the filter systems contain soot holding capacity for some hours or, at a maximum of, a few days. Some DPF systems regenerate continuously. Other DPFs need to be regenerated whenever they are clogged or if there is an increase in back pressure is observed.

There are two types of regeneration methods, active regeneration method and passive regeneration method. In active regeneration method, also called as periodical regeneration, electric heaters or burners are used to ignite the particles collected in the filter. Periodical regeneration can also be done by injecting fuel upstream of the DPF. The burning of fuel in $\mathrm{O}_{2^{-}}$ rich exhaust gas will increase the temperature of the DPF and enhance the burning of PM. In passive regeneration, catalytic DPF or catalytic additives are used, and the activation energy of the soot particles is decreased. Therefore, the oxidation of PM particles will occur at relatively low temperatures. This system is also called continuous regeneration. The passive regeneration technique is simpler and less expensive when compared to the active regeneration system [20].

The combustion of the diesel particulate matter starts at a temperature above $600{ }^{\circ} \mathrm{C}$ in active regeneration. Further increase in the temperature occurs due to the combustion of PM. When these temperatures are above the structural integrity threshold of the material, then failure of the filter media will occur. To reduce this risk of failure, use of fuel borne catalysts is required in the passive regeneration technique. The temperature of regeneration can be reduced to $350{ }^{\circ} \mathrm{C}$ to $450{ }^{\circ} \mathrm{C}$ by using a fuel borne catalyst [20].

"The catalyst reactivity in the DPF is based on the activation energy $\left(E_{a}\right)$. This activation energy is frequently used as a measure for the performance of the catalyst. The activation energy depends on numerous factors including soot composition, micro structure of soot, exhaust gas composition, and the type of catalyst. Therefore, the activation energy $\left(E_{a}\right)$ is not unique for all the DPFs. The effects of different catalysts or additives can be compared by using the activation energy of the combustion" [21].

Particulate filters also capture inorganic ash particles contained in the PM emission. These ash particles are incombustible and cannot be removed through thermal regeneration. The contribution of the ash in PM is very low when compared to the organic carbon, even though the 
accumulation of the ash particles will cause a gradual increase in the pressure drop over a period of time [21]. The ash particles captured in the filters can only be removed through dedicated maintenance procedures, such as cleaning with water (for Silicon Carbide substrates) or reversing the direction of flow through the filter. The frequency of the maintenance procedures depends on the micro-structure of the filter and the type of engine operation.

\subsubsection{Selective Catalytic Reduction}

\subsubsection{Introduction}

The oxides of nitrogen are converted into nitrogen, $\mathrm{N}_{2}$, and water, $\mathrm{H}_{2} \mathrm{O}$, when reacted with ammonia using SCR. Reductants like anhydrous ammonia, aqueous ammonia, or urea, are added to the exhaust gas, and they are absorbed onto a catalyst. Carbon dioxide, $\mathrm{CO}_{2}$, is a reaction product when urea is used as the reductant. A block diagram of the SCR reaction is shown in the Figure 7.

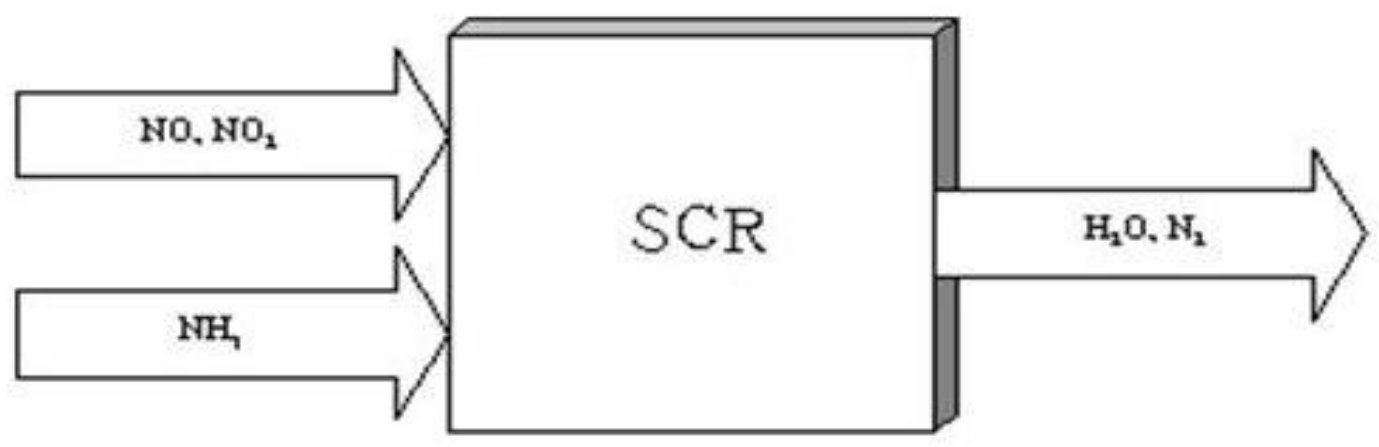

Figure 7 : Process of Selective Catalytic Reduction [22]

Ammonia is very harmful and there can be problems with its storage. Therefore, usage of urea is a common technology since it is non-hazardous and can be handled by the end user. The urea needs to be thermolyzed and hydrolyzed in order to avoid unwanted by-products like $\mathrm{CO}_{2}$ and water vapor [22].

Despite implementation problems of SCR technology in mobile diesel engines, it is a promising and proven technology for reducing the $\mathrm{NO}_{\mathrm{x}}$ emissions to the regulated level. UreaSCR technology is widely accepted by engine manufacturers in order to meet the regulations set 
forth by the EPA in the context of meeting the 2010 regulations to limit $\mathrm{NO}_{\mathrm{x}}$ emissions to 0.20 g/bhp-hr.

\subsubsection{SCR Reactions}

The exhaust gases are passed through the catalytic chamber in which the anhydrous ammonia reacts with the exhaust, and thus, the $\mathrm{NO}_{\mathrm{x}}$ reduction occurs. Before the gases pass through the catalytic chamber, ammonia is injected into the stream of the exhaust gases. The chemical equations for the SCR reaction are as shown below [23].

The chemical reactions that occur when urea is injected are shown below:

$$
\begin{aligned}
& 4 \mathrm{NO}+4 \mathrm{NH}_{3}+\mathrm{O}_{2} \longrightarrow 4 \mathrm{~N}_{2}+6 \mathrm{H}_{2} \mathrm{O} \\
& 2 \mathrm{NO}_{2}+4 \mathrm{NH}_{3}+\mathrm{O}_{2} \longrightarrow 3 \mathrm{~N}_{2}+6 \mathrm{H}_{2} \mathrm{O} \\
& \mathrm{NO}+\mathrm{NO}_{2}+2 \mathrm{NH}_{3} \longrightarrow 2 \mathrm{~N}_{2}+3 \mathrm{H}_{2} \mathrm{O}
\end{aligned}
$$

Several other reactions involved in this process are as follows:

$$
\begin{aligned}
& 2 \mathrm{SO}_{2}+\mathrm{O}_{2} \longrightarrow 2 \mathrm{SO}_{3} \\
& 2 \mathrm{NH}_{3}+\mathrm{SO}_{3}+\mathrm{H}_{2} \mathrm{O} \longrightarrow\left(\mathrm{NH}_{4}\right)_{2} \mathrm{SO}_{4} \\
& \mathrm{NH}_{3}+\mathrm{SO}_{3}+\mathrm{H}_{2} \mathrm{O} \longrightarrow \mathrm{NH}_{4} \mathrm{HSO}_{4}
\end{aligned}
$$

The reaction for urea:

$$
4 \mathrm{NO}+2\left(\mathrm{NH}_{2}\right)_{2} \mathrm{CO}+\mathrm{O}_{2} \longrightarrow 4 \mathrm{~N}_{2}+4 \mathrm{H}_{2} \mathrm{O}+2 \mathrm{CO}_{2}
$$

These ideal reactions take place at an optimal temperature range of $350{ }^{\circ} \mathrm{C}$ and $450{ }^{\circ} \mathrm{C}$. But with longer residence times, these reactions can also take place in the range of $230{ }^{\circ} \mathrm{C}$ to 460 ${ }^{\circ} \mathrm{C}$. Various fuels, gas constituents, and catalyst geometry effects the minimum temperature [23]. The ammonia injection rate should be precisely controlled to use the SCR process. An exact amount of ammonia needs to be injected into the stream of the exhaust gases. If less ammonia is injected than required, it may result in low NOx conversion efficiencies. At the same time, if a 
greater amount of ammonia is injected, it may result in release of undesirable ammonia into the atmosphere [23].

The emission of ammonia into the atmosphere from the SCR process is called ammonia slip. If the $\mathrm{NH}_{3} / \mathrm{NO}_{\mathrm{x}}$ ratio is higher, it will result in ammonia slip. The stoichiometric $\mathrm{NH}_{3} / \mathrm{NO}_{\mathrm{x}}$ ratio in the SCR system is about 1 . Ratios higher than 1 significantly increase ammonia slip and ratios below 1 will result in low $\mathrm{NO}_{\mathrm{x}}$ conversions. In order to minimize the ammonia slip and get satisfactory $\mathrm{NO}_{\mathrm{x}}$ conversions, the ratios between 0.9 and 1 are used in the SCR process. Figure 8 shows a relationship between the $\mathrm{NH}_{3} / \mathrm{NO}_{\mathrm{x}}$ ratio, $\mathrm{NO}_{\mathrm{x}}$ conversion, temperature, and ammonia slip. The ammonia slip decreases with increase in temperature. Depending on the temperature range, the $\mathrm{NO}_{\mathrm{x}}$ conversion in the SCR system may increase or decrease [23].



Figure 8: Relationship between the $\mathrm{NH}_{3} / \mathrm{NO}_{\mathrm{x}}$ ratio, $\mathrm{NO}_{\mathrm{x}}$ conversion, temperature, and ammonia slip [24]

\subsubsection{Catalysts and Reductants}

Titanium oxide, oxides of base metals like Vanadium and Tungsten, Zeolite, and various precious metals are used in manufacturing SCR catalysts. The catalyst compounds used for manufacturing the SCR catalysts have their own advantages and disadvantages. The base metal catalysts, such as the Vanadium and Tungsten, are lower in cost when compared to other metals. They also have the ability to operate in wide temperature ranges, but they lack high thermal durability. Thermal durability is very important in SCR applications in automobiles [25]. These metals also exhibit high catalytic potential to oxidize $\mathrm{SO}_{2}$ into $\mathrm{SO}_{3}$, which can be extremely 
damaging due to their acidic properties. Zeolite has the ability to withstand and operate at higher temperatures when compared to other catalysts. They can also withstand long-term operation at a temperature of $650{ }^{\circ} \mathrm{C}$ and up to $850^{\circ} \mathrm{C}$ in transient conditions [25].

Several reductants like anhydrous ammonia, aqueous ammonia, and urea are currently used in SCR applications. All these reductants are easily available in bulk quantities. There is no need for further conversion of pure anhydrous ammonia in order to use it in the SCR. Anhydrous ammonia is dangerous since it is very toxic. Large industrial SCR applications can use anhydrous ammonia since it requires no further conversion. Aqueous ammonia is safe to store and transport from one place to another, but it needs to be hydrolyzed in order to be used. Urea is required to convert it to ammonia through thermal decomposition.

\subsubsection{AdBlue}

AUS32 (Aqueous Urea Solution 32.5\%), simply known as AdBlue, is used in a process of selective catalytic reduction (SCR) in diesel fuel engines in order to reduce oxides of nitrogen from the exhaust. It is a $32.5 \%$ solution of highly purified urea in dematerialized water. AdBlue is a clear, non-toxic liquid that can be handled by the end user. Despite of the problems like corrosion effects, AdBlue can serve as a $\mathrm{NO}_{\mathrm{x}}$ reduction agent in SCR technology [26].

The AdBlue is carried onboard in SCR equipped trucks in specially designed tanks. It is dosed into the SCR system at a rate equivalent to 3-5\% of diesel consumption [26]. The refilling periods of the tanks will be longer because of the low dosing rates. It also occupies minimum chassis space in the vehicle. On-highway SCR systems are currently in use throughout the world. Trucks in North America are adopting the SCR dosing technology after 2010, as the US EPA's 2010 legislation imposed limits on $\mathrm{NO}_{\mathrm{x}}$ to levels to $0.20 \mathrm{~g} / \mathrm{bhp}$-hr. European truck manufacturers have implemented the SCR dosing systems because of the Euro VI emission standards. High quality standards should be maintained for AdBlue, because it is sensitive to chemical impurities in the solution [26]. 


\section{Chapter 3: Experimental Set Up}

The Volvo MY07 MD11 diesel-fueled engine was used for this study. All the required laboratory checks and maintenance work were done prior to the testing. This section describes the different stages used in the experimentation. All the tests were carried out according to the 40 CFR 1065 (1-25-2008).

\subsection{Primary Exhaust Dilution Tunnel}

The dilution tunnel was used to dilute the exhaust gas sample with ambient air in order to simulate real world conditions. Thus, exhaust emissions that are emitted in to the atmosphere by the engine can be measured accurately. The dilution tunnel is a 20 inch diameter duct made up of stainless steel, as shown in Figure 9. A temperature controlled air mixed with exhaust was pulled through the tunnel using subsonic venturi which provides a constant mass flow rate. An orifice is placed three feet from the entrance in order to mix the exhaust gas with dilution air. Sample probes were placed 15 feet downstream from the inlet to send a portion of the mixture into the analyzers. The design of the primary dilution tunnel used in EERL was done according to the 40 CFR Part 1065 regulations [27].

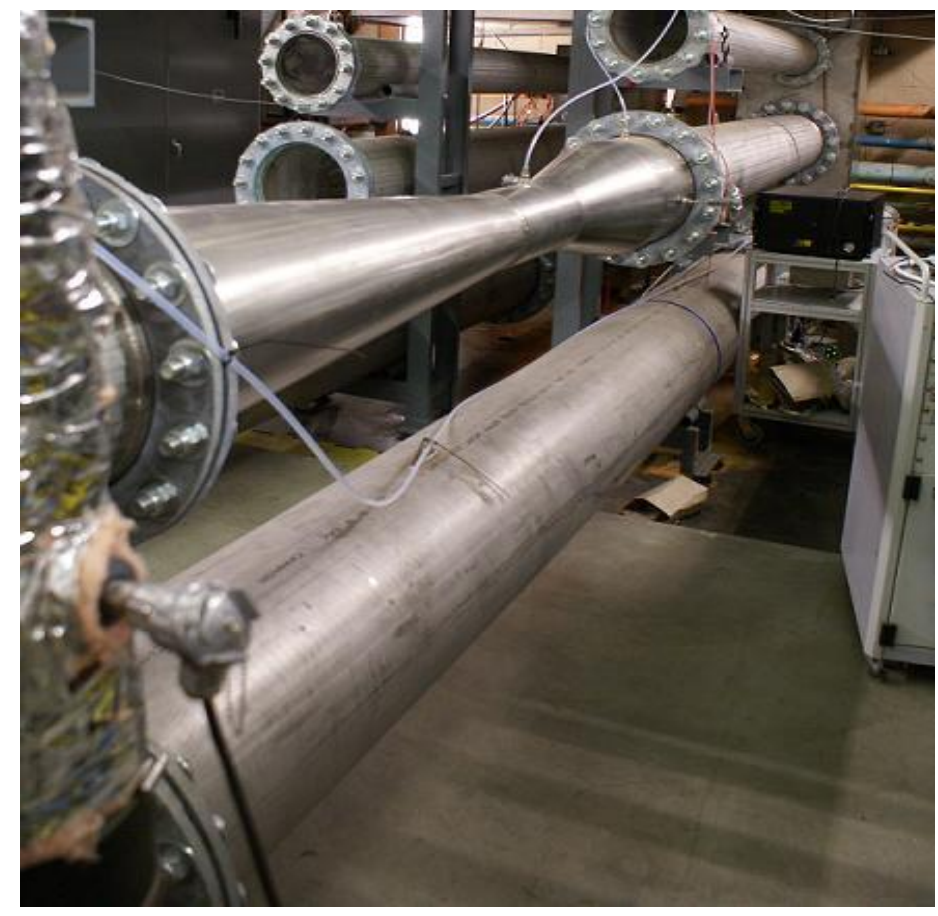

Figure 9: Primary dilution tunnel [3] 


\subsection{Secondary Dilution Tunnel}

The secondary dilution tunnel was used for mixing the sample exhaust from the primary tunnel and the secondary dilution air. The system was designed to maintain flow proportional to $\pm 5 \%$ of the main tunnel flow rate. The tunnel was maintained at a constant temperature of $47 \pm 5$ ${ }^{\circ} \mathrm{C}$.

\subsection{PM Box}

The PM Box is a temperature controlled, filter housing container in which sample flow was diverted to the sample filter holder or to a bypass leg. The flow rate was continuously monitored in order to provide accurate sample proportionality. The PM Box used at the West Virginia University EERL is shown in Figure 10.

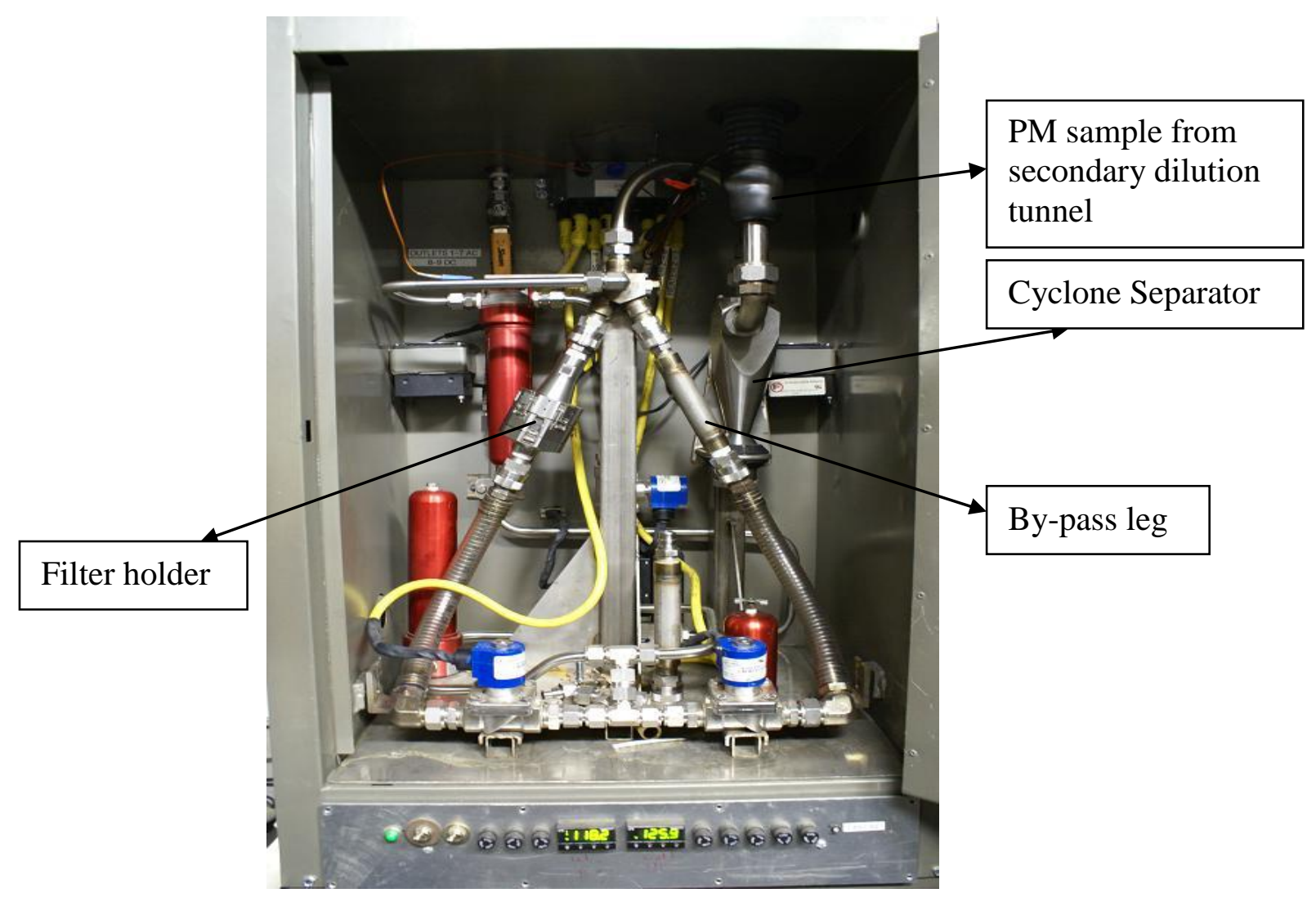

Figure 10: PM box [4] 


\subsection{Engine Dynamometer}

In order to simulate the real world vehicle load that an engine receives, a load must be applied to the engine while doing the experiments. The engine dynamometer serves this purpose. The dynamometer used for this study was a General Electric, Direct Current (DC), and air cooled dynamometer. It is capable of both absorbing and providing $800 \mathrm{hp}$. [Figure 11]. Torque was measured using a load cell, which was attached to an arm of known length to measure force. Engine speed was determined using a digital encoder mounted outside the dynamometer. A driveshaft and a coupling connect the dynamometer directly to the flywheel of the engine.

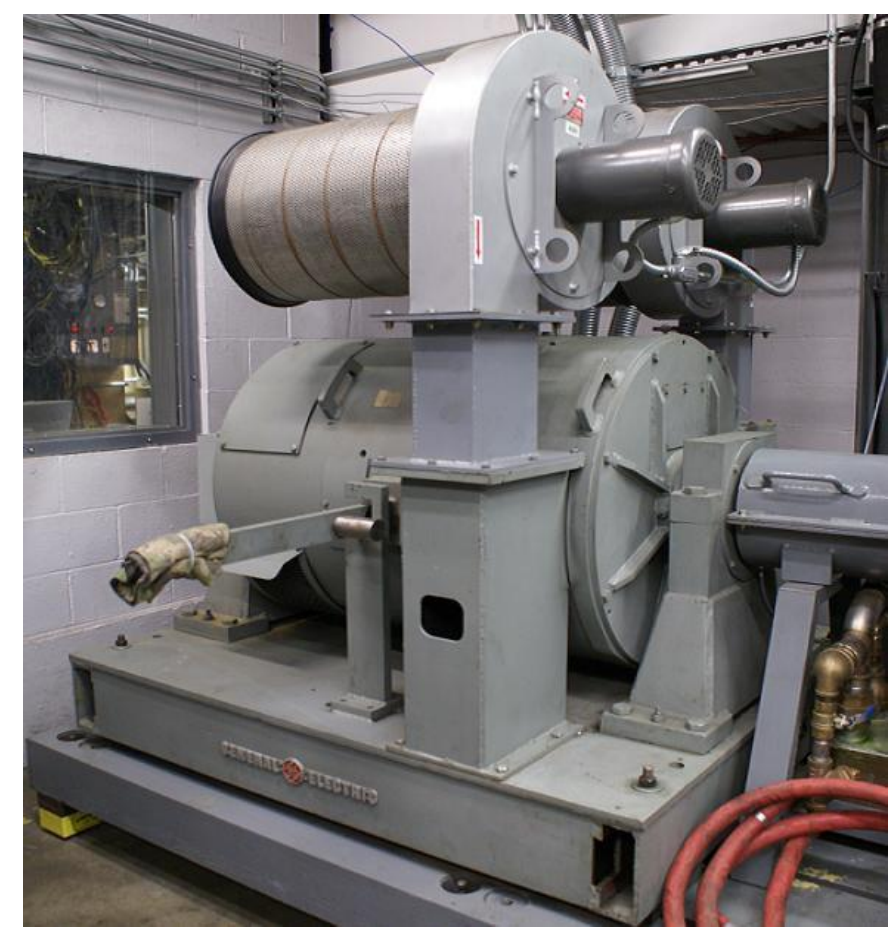

Figure 11: Engine dynamometer [3]

\subsection{Engine Configuration}

Experiments were conducted on the MY07 MD11 Volvo Engine shown in Figure 12, which was equipped with after-treatment devices like DPF and SCR. The DPF system connected to the engine was manufactured by Fleetgard. This DPF contains DOC in the upstream of the DPF. The SCR system used in this study was manufactured by Johnson Matthey. The amount of urea injected into the SCR can be controlled using an injection pump. 
Table 3: Engine specifications [3]

\begin{tabular}{|l|l|}
\hline Make & Volvo \\
\hline Model & MY07 MD11 \\
\hline Year of manufacture & 2007 \\
\hline Power & $339 \mathrm{bhp} \mathrm{@} \mathrm{1800} \mathrm{rpm}$ \\
\hline Rated speed & $1800 \mathrm{rpm}$ \\
\hline Maximum torque & $1298 \mathrm{ft}-\mathrm{lb} @ 1306 \mathrm{rpm}$ \\
\hline EGR & External, high pressure cooled EGR \\
\hline After-treatment system & Fleetgard DPF \& Johnson Matthey SCR \\
\hline Displacement, cu. in. (L) & $661(10.8)$ \\
\hline Compression Ratio & $16.0: 1$ \\
\hline Bore \& Stroke, in & 4.84 x 5.98 \\
\hline Base Configuration & 4 cycle, 6 in-line cylinders \\
\hline
\end{tabular}

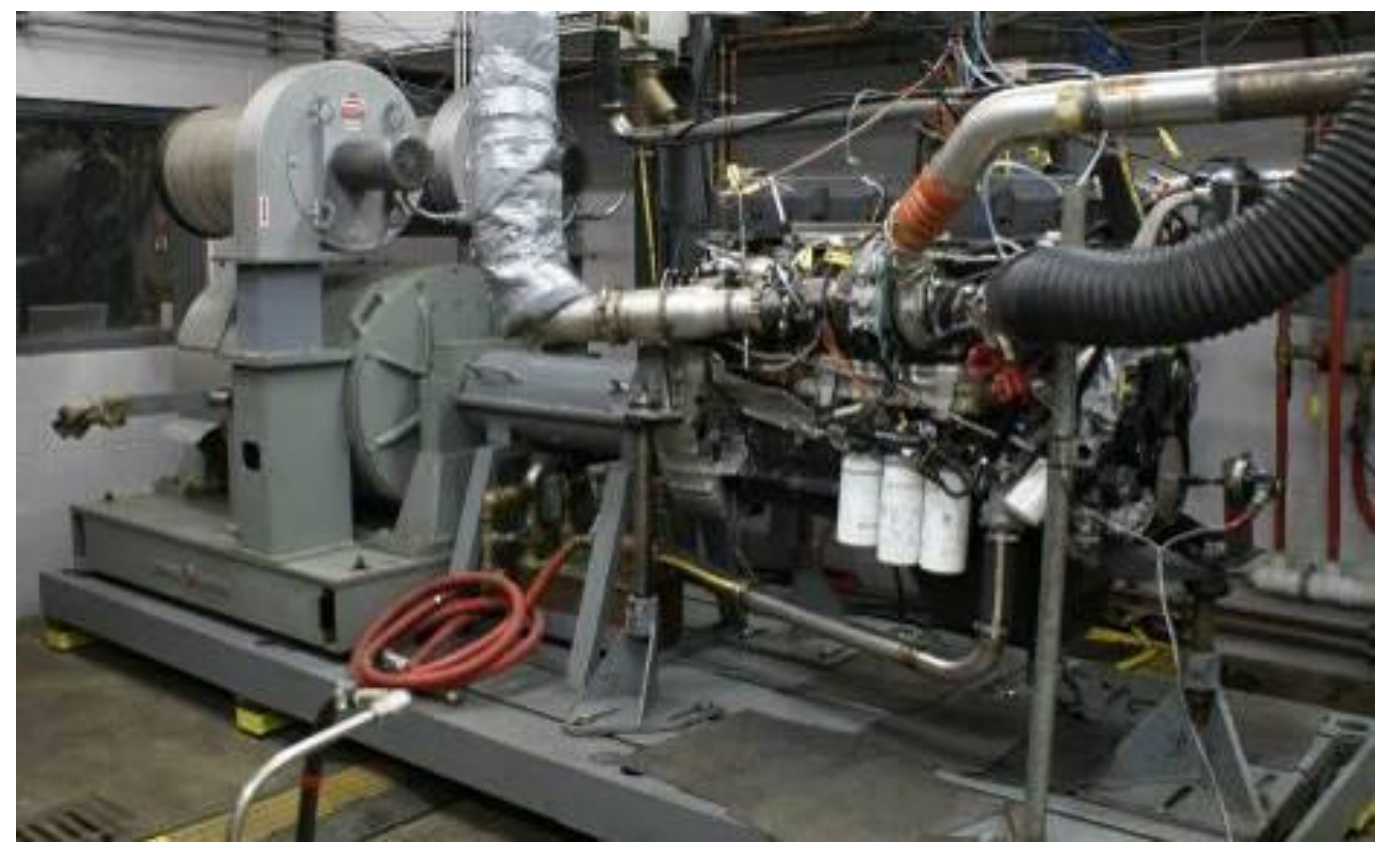

Figure 12: Test engine MY07 Volvo MD-11 [3]

\subsection{Gaseous Emission Sampling System}

This system consists of heated probes, heated transfer lines, temperature control units, and gas analyzers. This system was designed in accordance with 40 CFR Part 1065 regulations 
[28]. The flooded probe type heated probes are used to supply the zero and span gas to the analyzers. The probes were connected to the dilution tunnel at a distance of 10 diameters from the mixing region. The samples of the gases were taken separately with separate heated probes. A temperature controller was installed to control the temperature of the heated lines and probes. Teflon heated lines were used for $\mathrm{CO} / \mathrm{CO}_{2}$ and $\mathrm{NO}_{\mathrm{x}}$ analyzers and stainless steel heated lines were used for total hydrocarbons samples. The pressure regulators were used to control the flow through the heated lines.

\subsubsection{Flame Ionization Detector Analyzers}

Concentrations of various gases, including the hydrocarbons, were measured to measure the pollutants of the exhaust gas from the engine.. The analyzer used for total hydrocarbon measurement is based on the flame ionization detector (FID) principle. Hydrogen fuel and air are used to support the flame. The FID incorporated a direct current amplifier [29].

The FIDs are well accepted because they have several important features: low detection limits in concentration ranges, a broad linear range of levels, and a specific response to hydrocarbons.

For this study, a Rosemount model 402 [Figure 13] was used to measure the total hydrocarbons in the exhaust gas. This analyzer was based on the FID principle. The hydrocarbon sample was drawn from heated probes and stainless steel transfer lines maintained at $190^{\circ} \mathrm{C}$ $\left(375^{\circ} \mathrm{F}\right)$. Stainless steel transfer lines were maintained at higher temperatures in order to prevent the condensation of hydrocarbons in the transfer tubes.

The analyzer consists of a burner that is supplied with fuel (60\% hydrogen and $40 \%$ helium) and air. The sample gas passes through the burning flame and undergoes a complex ionization process, producing electrons and positive ions. These electrons are collected by an electrode, which causes a current to flow through the external circuit. The ionization current produced is proportional to the number of carbon atoms entering the burner, which is a measure of the hydrocarbon content of the sample. 


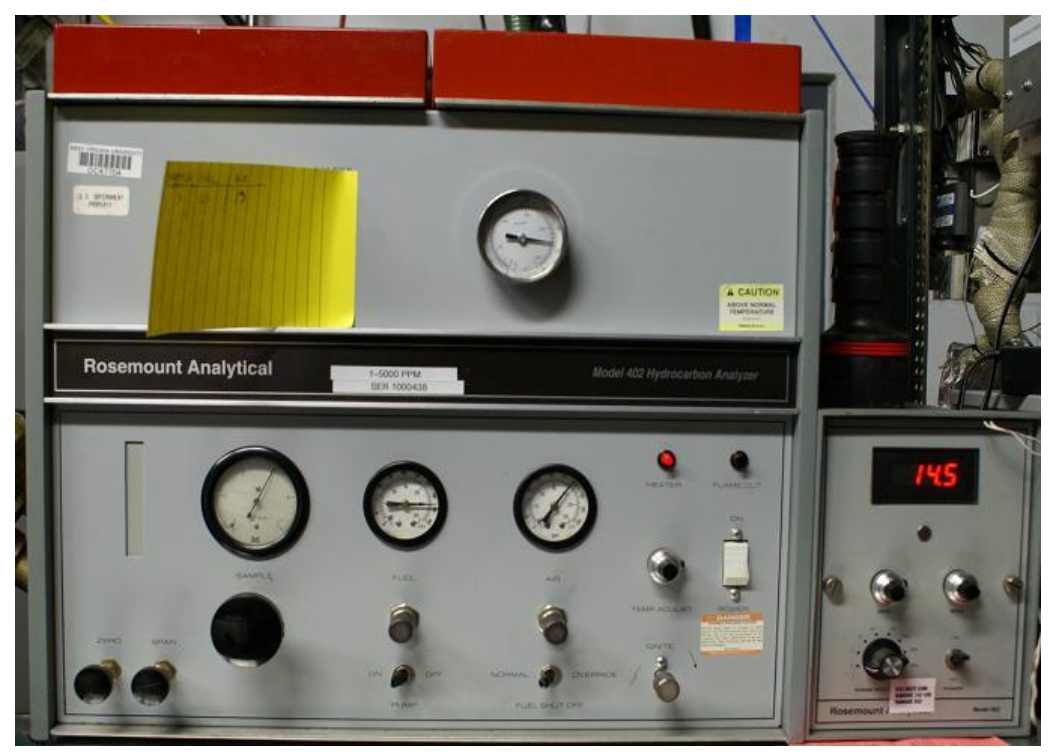

Figure 13: Rosemount analytical hydrocarbon analyzer model 402

\subsubsection{Non-Dispersive Infrared Analyzers}

Non-dispersive infrared analyzers (NDIR) are based on the absorption of infrared light. NDIR's incorporate features in their design, such as their simple construction, durability, high selectivity, and a capacity for continuous analysis. The infrared multilayer interference filter makes the NDIRs highly sensitive.

When gas molecules are irradiated by infrared light absorption will occur, resulting from stimulation by infrared light at a wavelength corresponding to the characteristic spectrum of vibration and rotation of the gas molecules. The WVU laboratory utilizes the Horiba $\mathrm{CO} / \mathrm{CO}_{2}$ analyzer, as shown in Figure 14. The infrared beams from the light source pass through both the comparison cell and sample cell [30]. The incident infrared light beams passing through the comparison cell and sample cell are adjusted by a light balancer so as to make them linearly equal in strength. At this point, if the concentration of gas in the sample cell changes, infrared absorption will occur due to the change. The comparison cell contains an inert gas that does not absorb the infrared beam, and a constant amount of light will continuously be transmitted to the detector. Therefore there will be a difference in the amount of infrared transmitted. These two different beams will pass through a light chopper, causing the condenser microphone in the sensor to vibrate [30]. 
The change in the electrostatic capacity resulting from this vibration can be processed as a signal for the concentration of the sample gas. The detector contains the same type of gas that is being measured in the sample cell, so normally there is no absorption by interference gas. However, should there be any overlapping of the absorption band of the sample gas and that of the interference gas, or should there remain minute amounts of interference gas in the detector, these will appear as influences of interference. The interference filter placed in front of the sensor plays an important role in reducing or eliminating these influences. The NDIR analyzer is shown in Figure 14.



Figure 14: Horiba $\mathrm{CO} / \mathrm{CO}_{2}$ analyzer

\subsubsection{Chemiluminescence Analyzers}

Chemiluminescence can be defined as production of light from a chemical reaction. The $\mathrm{NO}$ molecules are oxidized to $\mathrm{NO}_{2}$ in an excited state when they react with ozone. In the infrared portion of the spectrum, a small fraction of the molecules decay in this excited state. These decayed molecules emit a photon (i.e., giving off light). Therefore, the concentration of the gas can be determined by mixing the gas sample with ozone and measuring the amount of emitted light. Highly sensitive and linear measurement of $\mathrm{NO}_{\mathrm{x}}$ can be obtained by using the chemiluminescence technique [31]. 


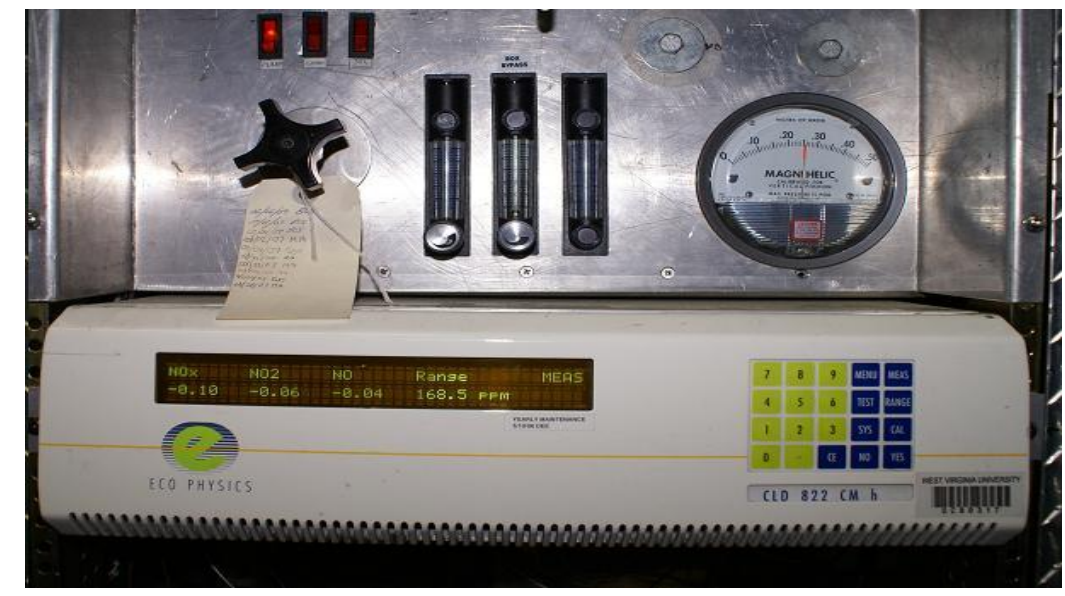

Figure 15: Eco physics $\mathrm{NO}_{\mathrm{x}}$ chemiluminescence analyzer

The principle of chemiluminescence is used in this analyzer to analyze concentration of $\mathrm{NO}$ or $\mathrm{NO}_{\mathrm{x}}$ in the exhaust sample. The chemiluminescent reaction between ozone and nitric oxide yields nitrogen dioxide $\left(\mathrm{NO}_{2}\right)$ and oxygen. A light beam which has intensity proportional to concentration of gas was produced in the reaction chamber. The intensity of the light was measured and concentration of gas was determined. The Eco Physics $\mathrm{NO}_{\mathrm{x}}$ analyzer is capable of making ppm (parts per million) measurements in research settings. Eco Physics CLD $822 \mathrm{NO}_{\mathrm{x}}$ analyzer was used in WVU EERC for sampling $\mathrm{NO}_{\mathrm{x}}$ emissions as shown in Figure 15.

\subsubsection{NDUV Analyzers}

Ultra-violet (UV) light is generally used to analyze $\mathrm{NO}, \mathrm{NO}_{2}$ and $\mathrm{SO}_{2}$. The gas is passed through a cuvette in which the UV light source and the filter were placed at one end and a cuvette and detector at the other end. The NDUV method uses the characteristics of the gas to be analyzed, which absorbs ultraviolet rays in an intrinsic wavelength region. Two solenoid valves were disposed in lines in order to feed the sample gas and reference gas. This mechanism consists of two solenoid valves, ultraviolet ray source, filter, and detector. The analysis of gas can be done by analyzing the ultraviolet absorption spectrum [32].

The NDUV gas analyzer was composed of ultraviolet ray source, sample cell, and detector. The sample gas and the reference gas were fed in to the analyzer alternately and the ultraviolet ray absorption was measured. The NDUV analyzer used in the WVU EERL for measuring $\mathrm{NO}, \mathrm{NO}_{2} \& \mathrm{NH}_{3}$ emissions is shown in Figure 16. 


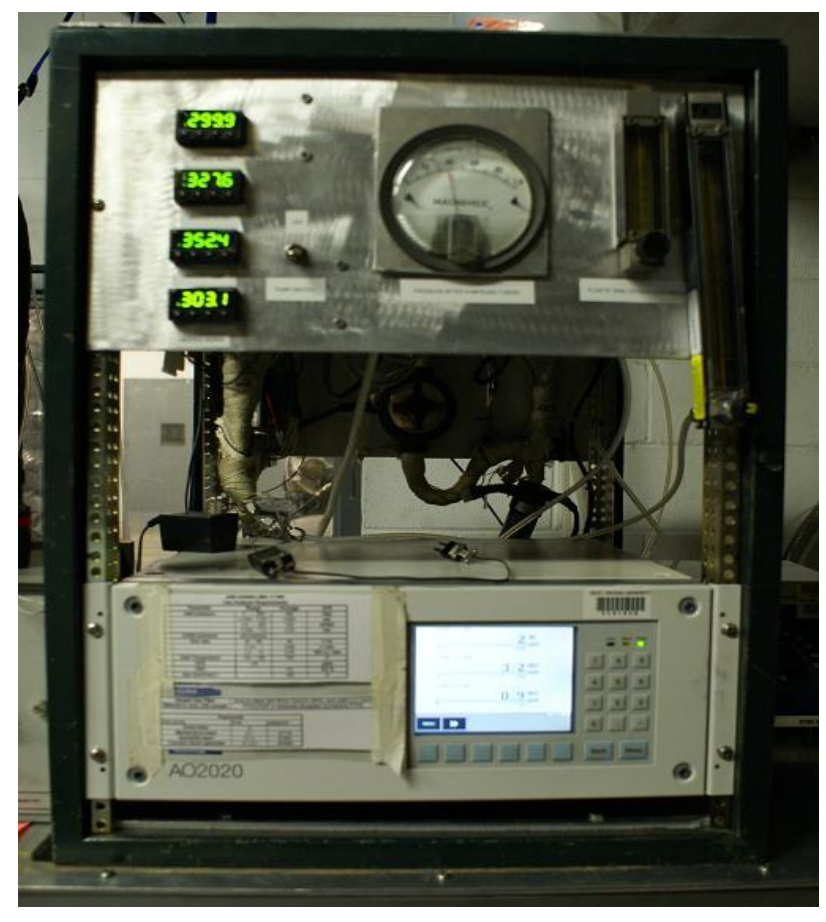

Figure 16: NDUV analyzer

\subsection{Exhaust After-treatment System}

Different wired meshes were tested by equipping the MY07 Volvo engine with exhaust after-treatment systems. This system consisted of DOC, DPF, and SCR systems. The DPF is manufactured by Fleetgard and consisted of DOC for continuous filtration of PM at low temperature conditions. Regeneration of the DPF was accomplished by increasing the temperature that needed for the oxidation of PM $\left(600^{\circ} \mathrm{C}\right)$ [3 and 4$]$. 


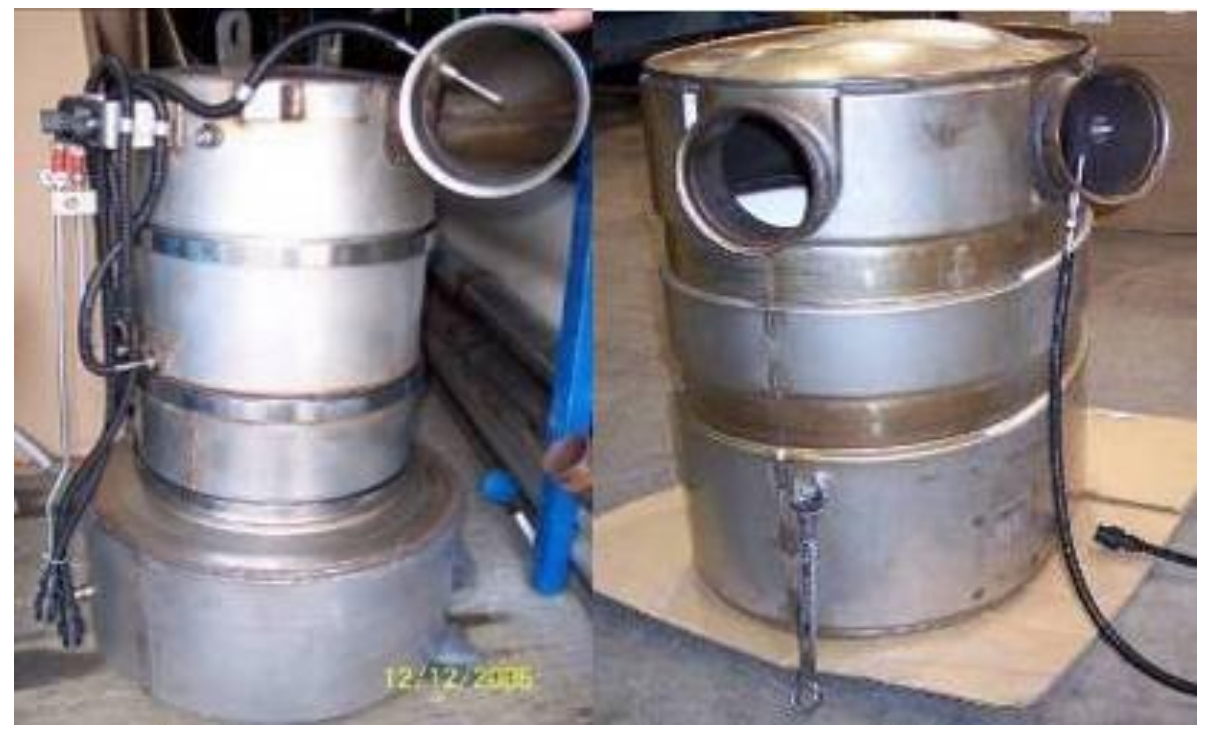

Figure 17 : Fleetgard compact DPF system and Johnson Matthey SCR system [4]

The SCR system was manufactured by Johnson Matthey. It consisted of a urea injection system, urea pump, urea tank, and an injection valve. For automotive applications the urea was used in a solution with water, called AdBlue. An oxidation catalyst is used in order to oxidize the ammonia slip along with the SCR catalyst [34].

The exhaust after-treatment system containing DPF, SCR, the urea tank and the injector assembly were shown in the Figure 17 and Figure 18.



Figure 18 : Urea tank and urea injector connected to the exhaust after-treatment system [4] 


\subsection{WVU's EERL}

The tests for this research were conducted with the engine dynamometer installed in West Virginia University's Engine Emission Laboratory (WVU EERL). The laboratory was built to meet the specifications given in 40 CFR, Part 1065 [7]. Figure 19 shows a schematic diagram of the WVU EERL emission measurement system.

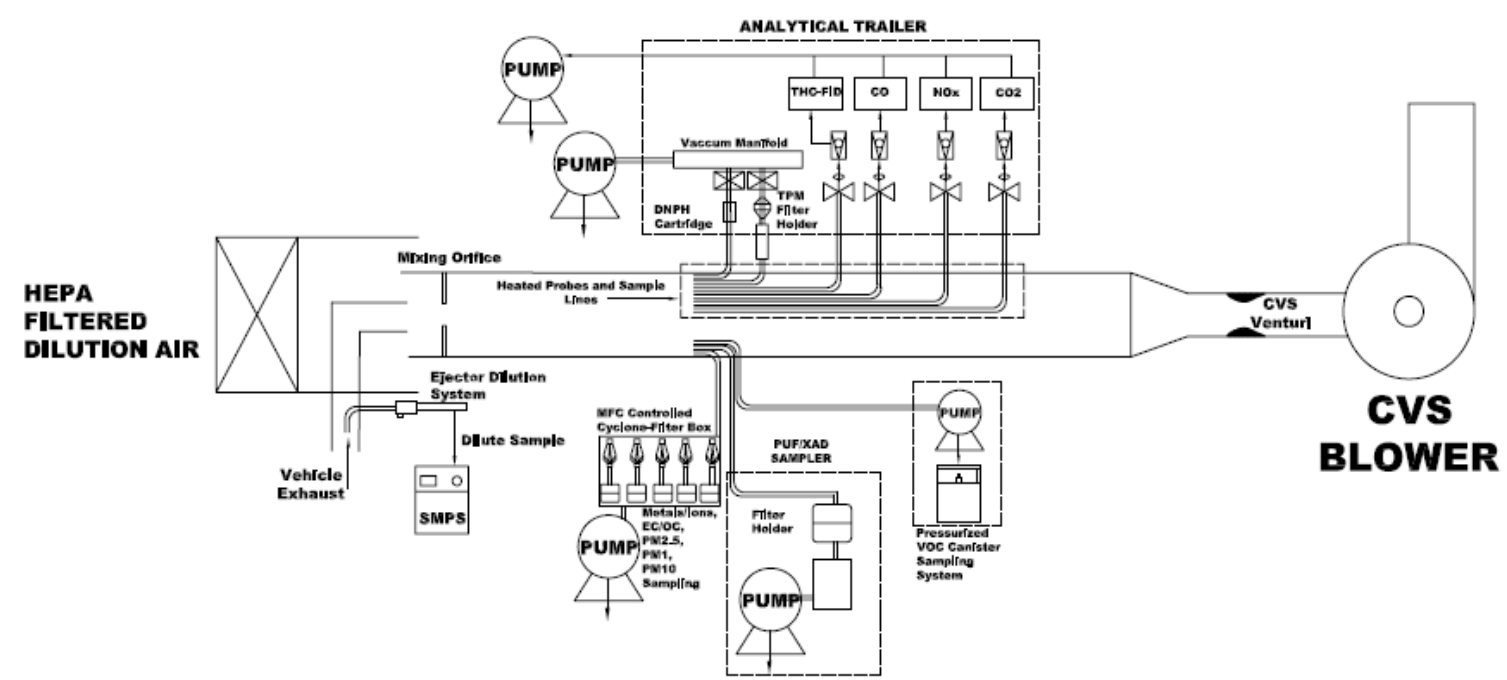

Figure 19: Schematic diagram of clean tunnel sampling setup [35] 


\section{Chapter 4: Emission Testing Procedure}

This section discusses the preliminary goals for this project as well as the expected outcomes. The procedures used to derive the results are also explained in this chapter. The steps involved in preparing the laboratory for emissions testing, which include calibration of instruments, system checks, engine loading, etc., are discussed in this chapter.

\subsection{Project Scope}

The most important aspect of this research was to determine optimal wired mesh substrate among non-coated and $\mathrm{TiO}_{2}$ coated wired mesh substrates of different lengths to achieve further reduction in $\mathrm{NO}_{\mathrm{x}}$ emissions than the previous results from ADECS Program. The test data was collected and compared with the previous data collected from SCR out tests conducted in the laboratory.

It was important to determine the optimized mesh which gives the maximum reduction. The meshes used for this study were 2 non-coated meshes with $1 \frac{1}{2}$ " and 2 " lengths and three meshes with 1", 11/2" and 2" lengths coated with titanium dioxide.

\subsection{Laboratory Setup}

The MY07 MD-11 Volvo engine was mounted on the 2007 testing bench in the WVU EERL as shown in Figure 20. In order to avoid variations in engine loading due to inclination, the surface was checked for flatness. The exhaust transfer tube was connected to the tunnel and checked for leaks. Back pressure valve was adjusted and locked in a fixed position to maintain the backpressure constant (back pressure increase due to the introduction of wired mesh substrate is discussed in Section 5.9). The heated probes used for sampling the various gas species were connected to the sampling plane of the tunnel through the available ports. The probes were fitted facing upstream of the clean tunnel. The heated transfer lines were routed to the analyzer bench and connected to their respective ports. The analyzers, heated lines and probes were all powered up for warm-up and stabilization before further setup procedures were carried out. The thermocouples and the pressure transducers were connected to the engine and calibrated. The water and fuel supply to the engine were connected. The intake air hose was connected to the engine. The coolant supply tube was connected, and the tank was filled with coolant. The power to the engine was connected, and the electronic control unit (ECU) was placed in its respective 
position. The DPF and SCR were hooked up to the engine, and the exhaust pipe was connected to the dilution tunnel.

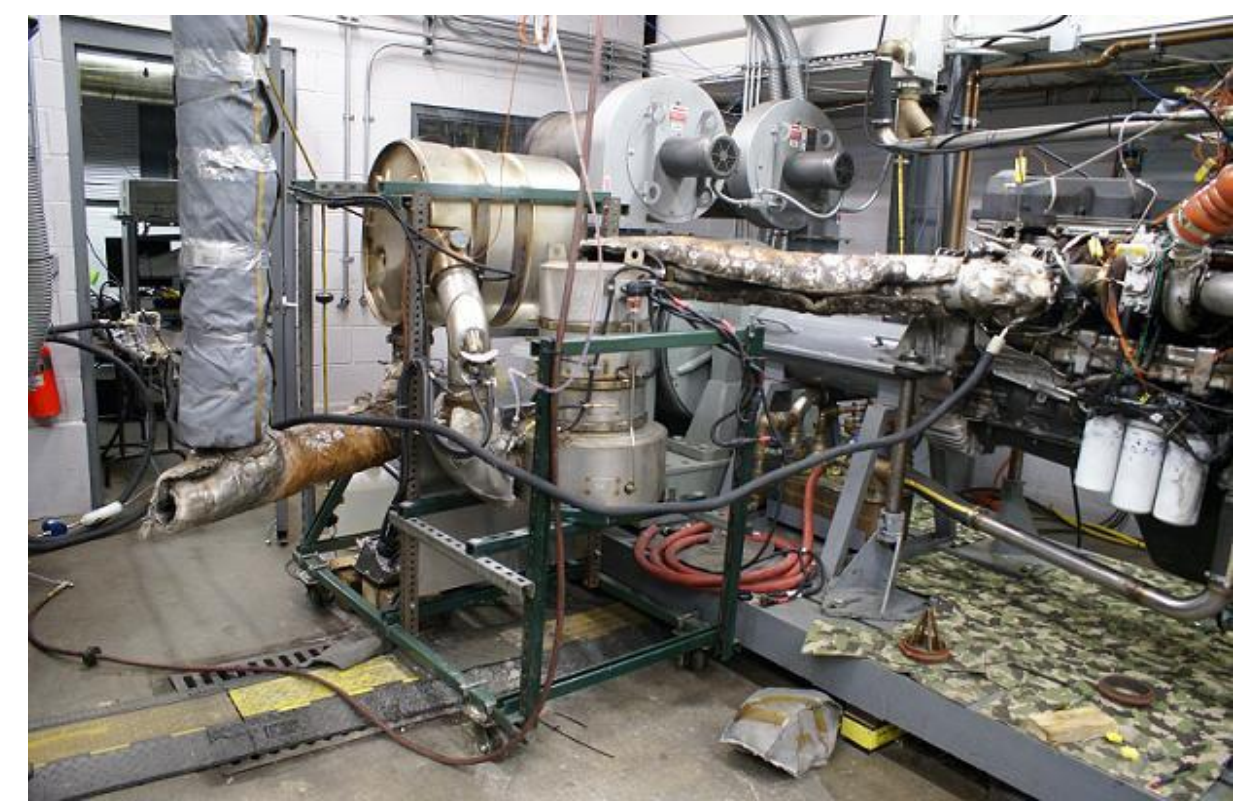

Figure 20: Connections of DPF and SCR to the engine [4]

\subsection{Analyzer Setup}

Prior to the start of calibration procedures of the analyzers, various analyzer check procedures were carried out as stated in 40 CFR Part 1065 [36]. These checks were performed in order to assess the efficiency, interferences, and response of the gas analyzers. NDIR analyzers experience interference from water vapor as it exhibits the same property towards infrared light as $\mathrm{CO}$ and $\mathrm{CO}_{2}$. This test was performed by admitting span gases into the analyzer through a bubbling chamber and bypassing the bubbling chamber so as to assess the water vapor interference level. The water interference check denoted the efficiency of the chiller and dryer unit in removing water content from the gas sample.

In a $\mathrm{CO}$ analyzer, a $\mathrm{CO}_{2}$ interference check was performed to assess the efficiency of the analyzer to read $\mathrm{CO}$ concentrations during $\mathrm{CO}_{2}$ interference. Similarly $\mathrm{CO}_{2}$ and water vapor interference check for the $\mathrm{NO}_{\mathrm{x}}$ analyzer was performed. Analyzer optimization tests, such as an oxygen interference check for FID flame optimization and $\mathrm{NO}_{\mathrm{x}}$ converter efficiency for optimum working of the $\mathrm{NO}_{\mathrm{x}}$ analyzer in the $\mathrm{NO}_{\mathrm{x}}$ mode were performed. The procedures for performing 
these steps were given in 40 CFR Part 1065 [36] and are carried out periodically to ensure proper working of the analyzers. Figure 21 shows the analyzer bench used for this study.

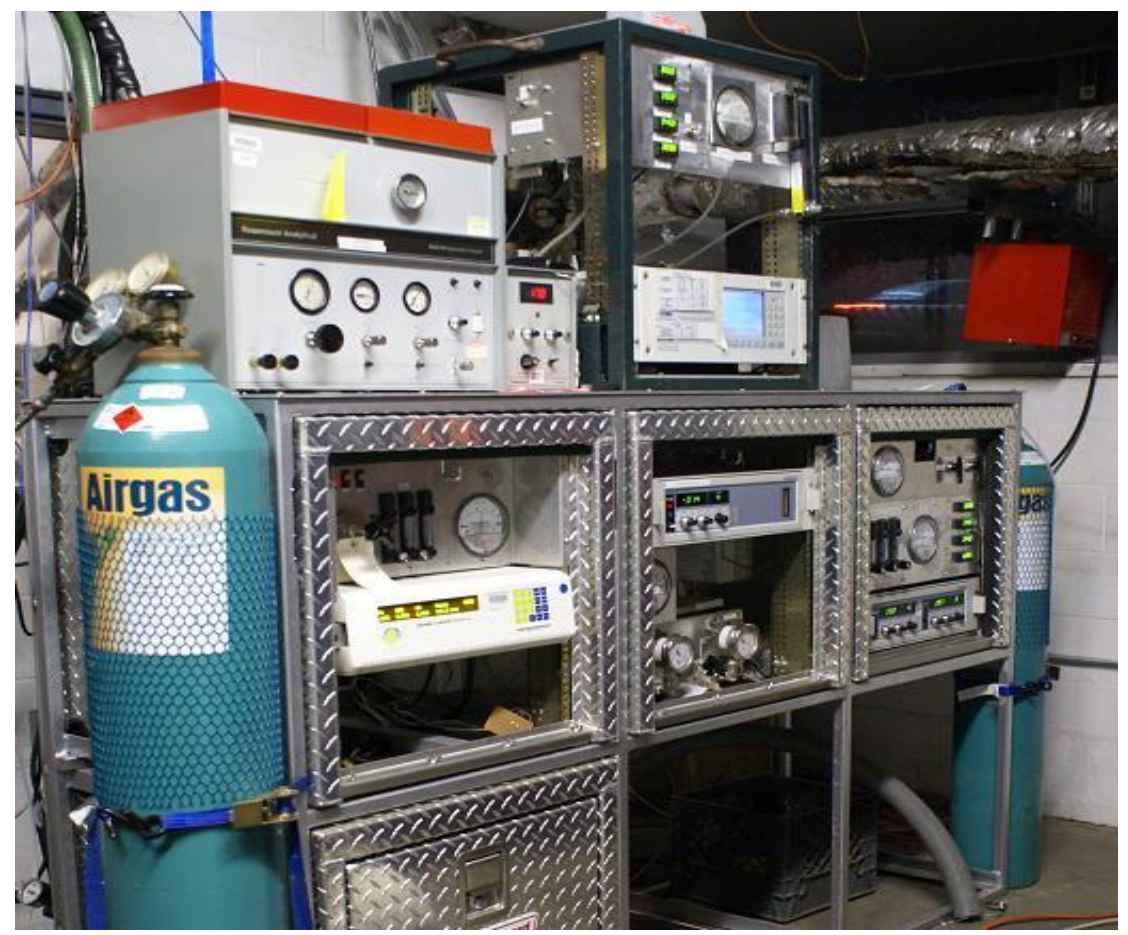

Figure 21: Analyzer bench used for 2007 tunnel [3]

Analyzer calibrations were performed as prescribed in 40 CFR Part 1065. The analyzers were calibrated between zero and full-scale gas concentration readings expected during the tests. The span gas concentrations had an accuracy of 1\%, and zero air was used as a zero gas for hydro carbon analyzers which was generated using a zero air generator. Nitrogen was used as a zero gas for $\mathrm{NO}_{\mathrm{x}}$ and $\mathrm{NO}$ analyzers. An 11 point calibration was performed on each analyzer using a gas divider which mixes a measured amount of span and zero gas to give sample concentrations varying in percentages of 10 between $0 \%$ and $100 \%$. The analyzers were given a stabilization period at each calibration point before the data acquisition was initiated. The computer averages a 10 second reading at each point when data acquisition was initiated. A polynomial fit of the 11 point calibration was performed to check the linearity of the analyzers. The span gases were chosen according to the level of emissions expected from an engine and also for the greatest accuracy range. The decision was made from previous test experiences and engine configurations.

If emission concentrations exceed the span gas value more than the allowable limit, as stated in 40 CFR Part 1065, the analyzers were recalibrated with a higher span gas concentration, and the tests repeated. The calibration files were always overwritten in order to avoid use of 
wrong calibration files. At the end of each test, zero and span values of the analyzer were checked to estimate the analyzer drift. If the drift for zero and span values of the analyzers were more than $3 \%$, then the analyzers were recalibrated. The $\mathrm{NO}_{\mathrm{x}}$ converter efficiency was checked for $95 \%$ or more efficiency in conversion or else maintenance was performed on the analyzer.

\subsection{Previous Mixing Devices and Selection of Wired Meshes}

Different exhaust mixing devices were evaluated in WVU EERL as a part of ADECS program to provide enhanced mixing of the exhaust with the urea injected up stream of the SCR catalyst. The main objective was to create turbulence in the exhaust stream and allow it to mix with the injected urea effectively. Different patterns were made in the laboratory and tested for mixing effect by monitoring the urea slip and $\mathrm{NO}_{\mathrm{x}}$ reduction.

\subsubsection{Mixing Device 1}

Iron pieces were welded in a conical shape as shown in the Figure 22, and placed in the exhaust stream, upstream of the SCR catalyst before point of urea injection. It was expected that the mixing device could cause turbulence in the exhaust flow and can lead to further $\mathrm{NO}_{\mathrm{x}}$ reduction. Experimental data showed that the mixing device could not provide any further reduction in $\mathrm{NO}_{\mathrm{x}}$. The $\mathrm{NO}_{\mathrm{x}}$ emissions numbers were similar to previous data from ADECS program for the tests ran placing the mixing device in the exhaust stream. 


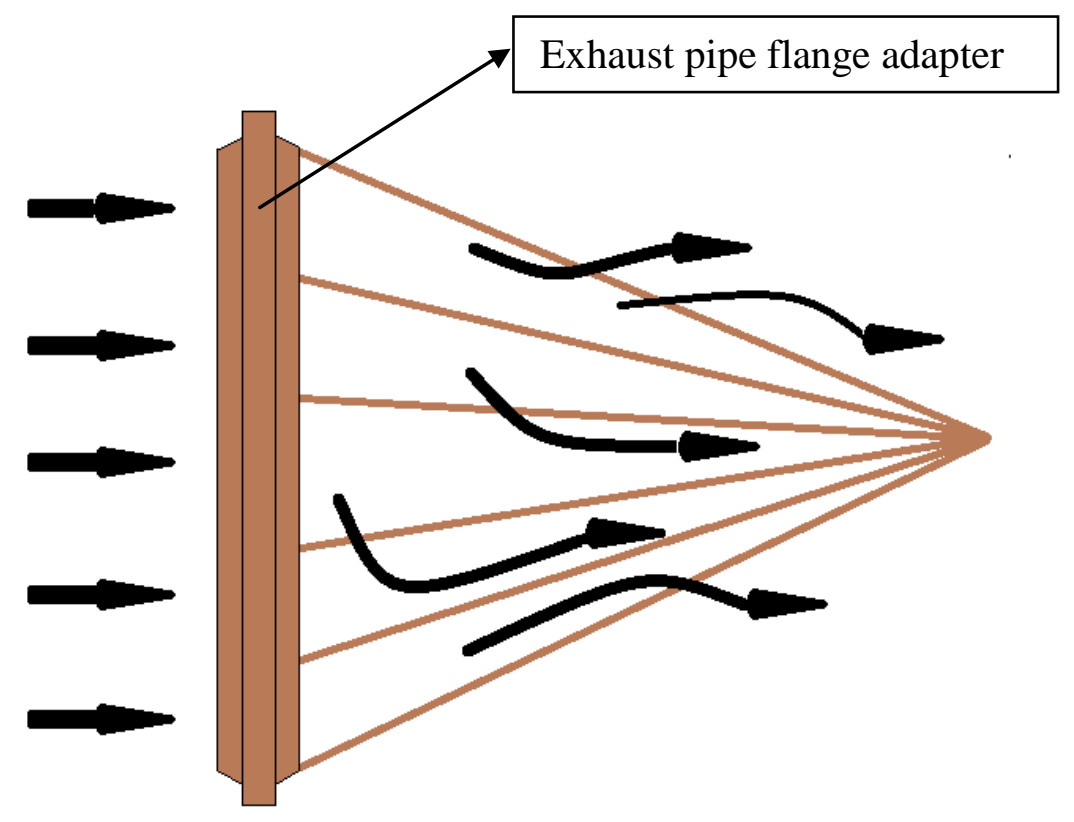

Figure 22: Mixing device 1 (Conical Turbulator)

Turbulence caused by the conical shaped mixing device was not sufficient to provide improved mixing with the urea, which led to developing other designs for the mixing device.

\subsubsection{Mixing Device 2}

The design of the mixing device was modified by changing the pattern as shown in the Figure 23. Small pieces of iron plates were bent and welded randomly as shown in the figure. It was expected that this design could provide increased turbulence than the previous mixing device.

Experimental data showed that the mixing device 2 was able to provide good mixing effect and resulted in further reduction of $\mathrm{NO}_{\mathrm{x}}$. Placing the mixing device 2 in the exhaust stream before the point of urea injection provided $4 \%$ further $\mathrm{NO}_{\mathrm{x}}$ reduction compared to the previous data. 


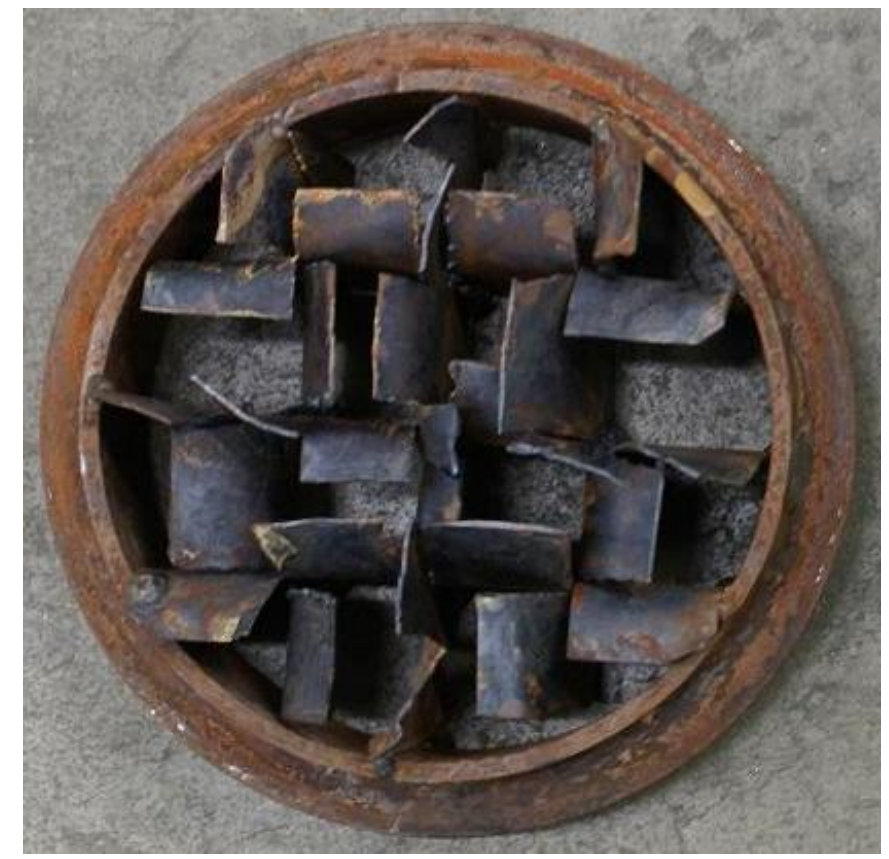

Figure 23: Mixing device 2 (WVU Turbulator)

Wired mesh substrate coated with oxidation catalyst, placed in the exhaust stream after the point of urea injection could provide very good mixing of the exhaust with the urea and could provide good $\mathrm{NO}_{\mathrm{x}}$ reduction by reducing the $\mathrm{NH}_{3}$ slip within short mixing distances [1]. This led to the selection of wired mesh substrates for this study to evaluate the mixing effect and $\mathrm{NO}_{\mathrm{x}}$ reduction efficiencies of different lengths of substrates. Mesh substrates coated with $\mathrm{TiO}_{2}$ were used in this study as $\mathrm{TiO}_{2}$ is a oxidation catalyst.

\subsection{Different Kinds of Mesh Substrates Used}

Five wired mesh substrates of different sizes are used in this study. Of which, three meshes were coated with Titanium dioxide and the remaining two were non-coated. The mesh substrates were shown to provide a uniform flow throughout the exhaust pipe so that proper mixing of the exhaust with urea was attained [1]. The non-coated mesh substrates of 11/2" and 2" lengths are shown in Figure $24 \&$ Figure 25. The coated mesh substrates of 1", 11/2", and 2" lengths are shown in Figure 26, Figure 27 and Figure 28, respectively. 


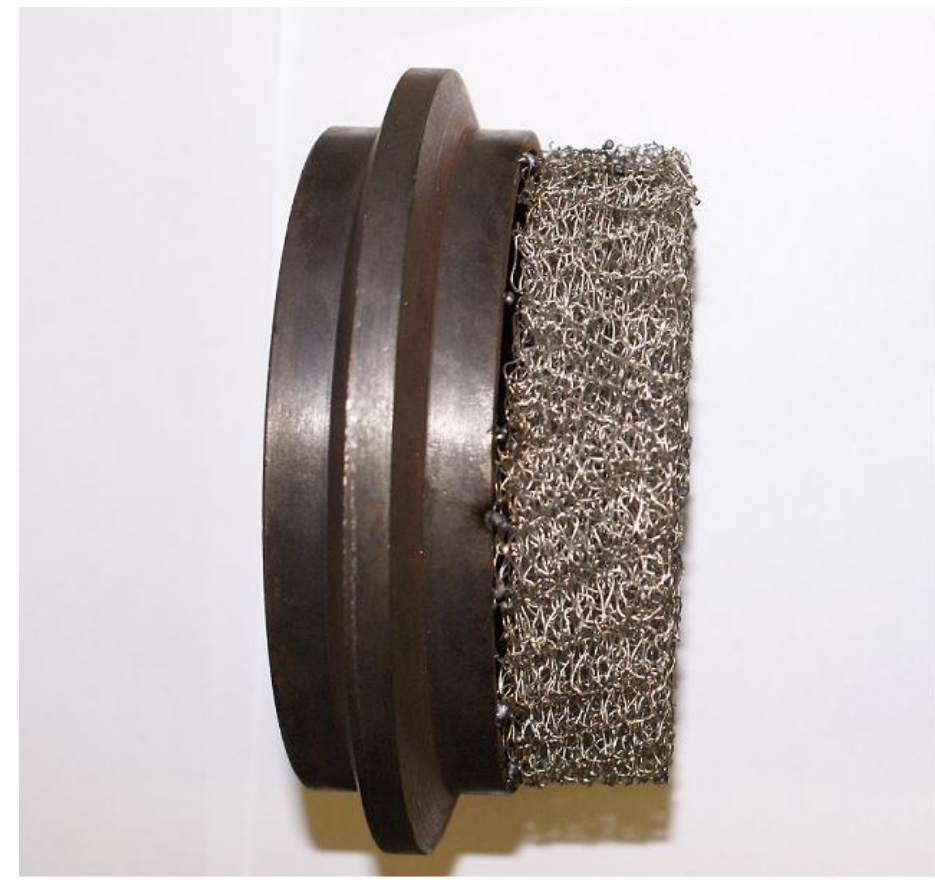

Figure 24: 11/2" Non-coated wired mesh substrate

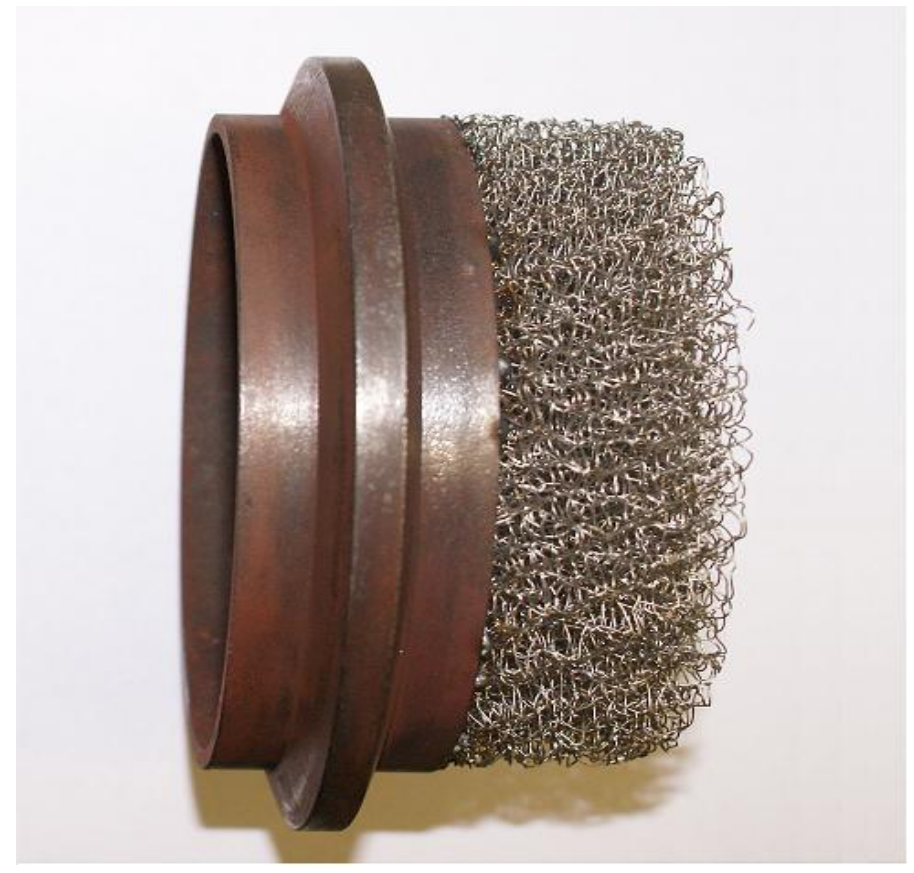

Figure 25: 2" Non-coated wired mesh substrate 


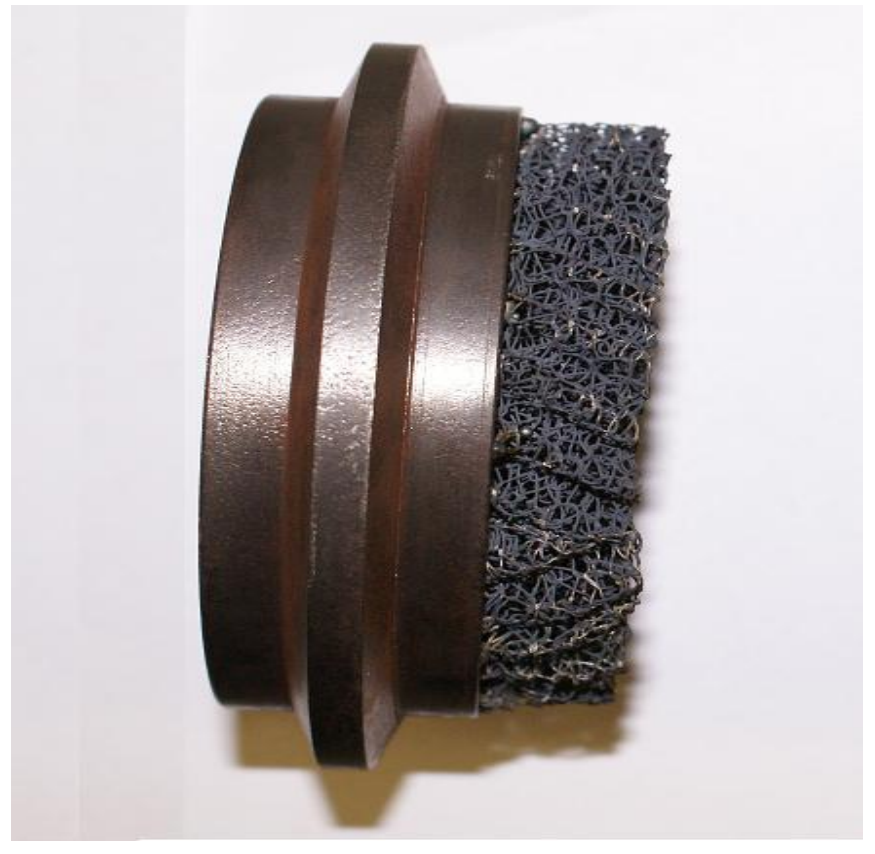

Figure 26: 1" Coated wired mesh substrate

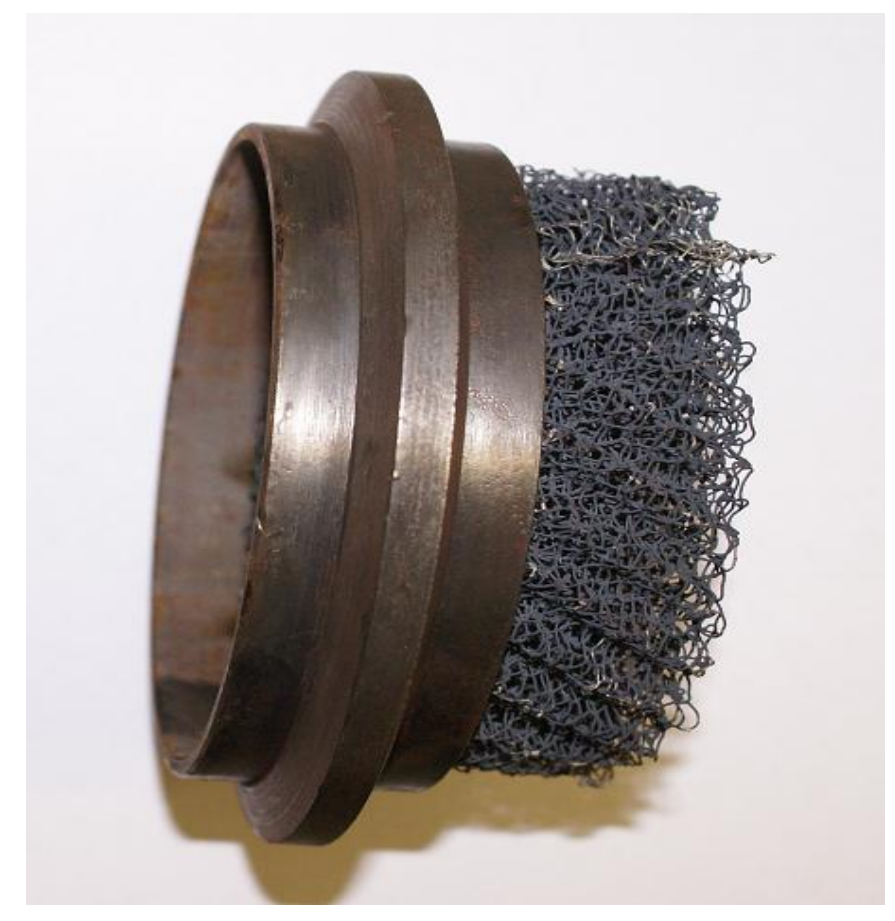

Figure 27: 11/2" Coated wired mesh substrate 


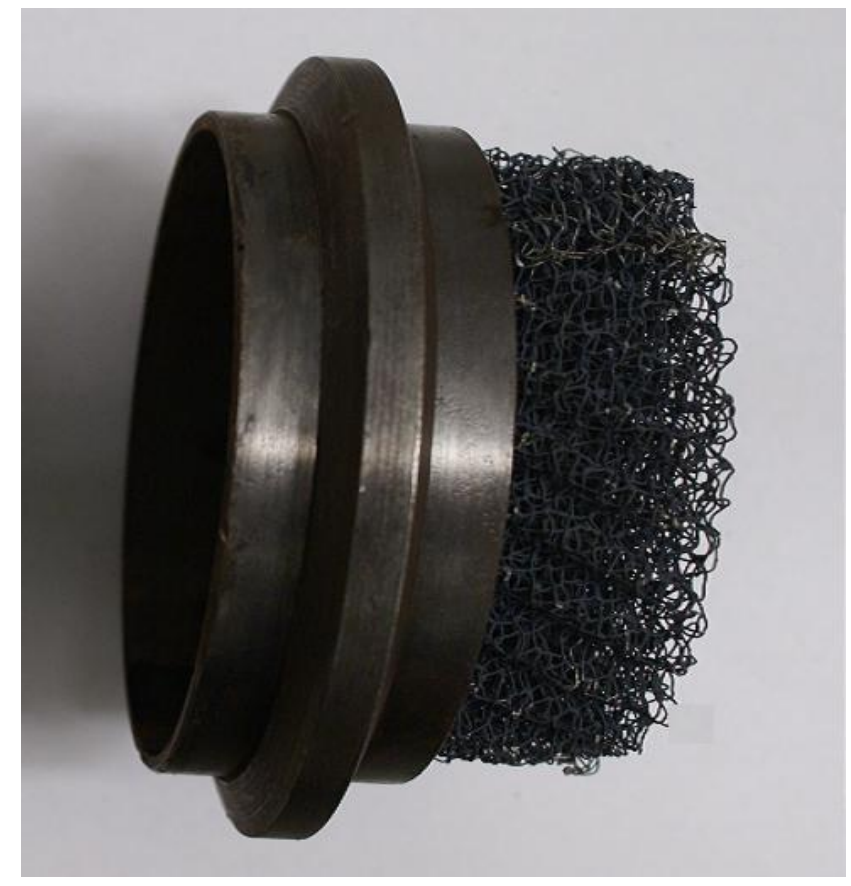

Figure 28: 2" Coated wired mesh substrate

These mesh substrates were welded to flanges and placed near the exhaust pipe joint inside the clamps as shown in Figure 29. The back pressure changes with different mesh substrates were monitored and recorded during the testing.

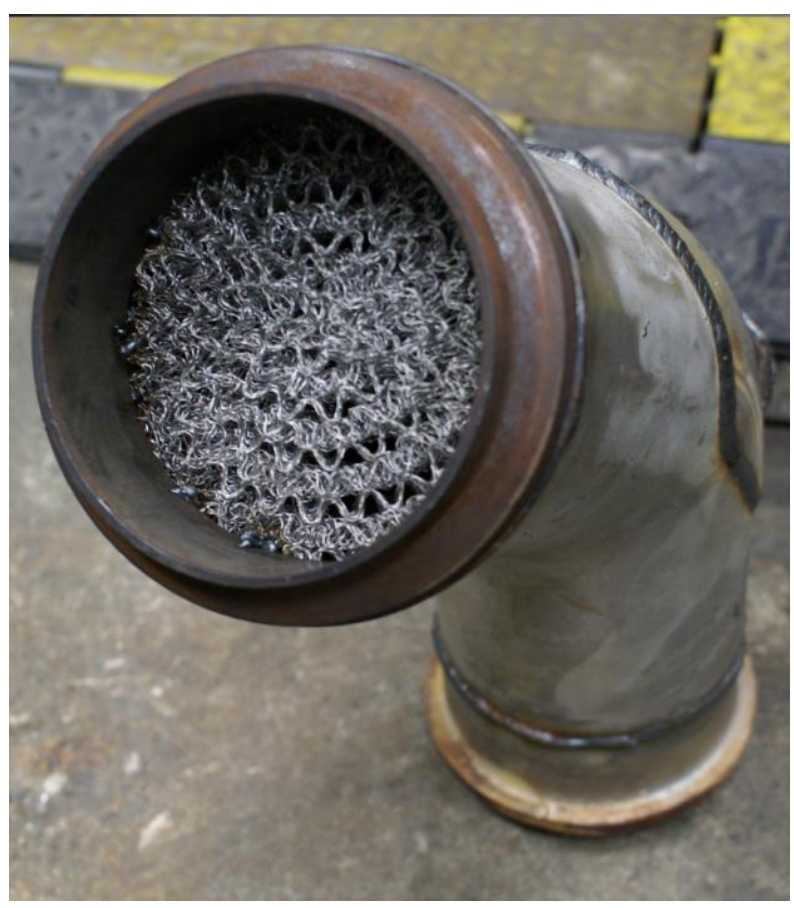

Figure 29 : Installation of wired mesh substrate in exhaust pipe 


\subsection{Test Procedure}

To test the effect of the location of wired mesh substrates on $\mathrm{NO}_{\mathrm{x}}$ emissions and $\mathrm{NH}_{3}$ slip with respect to the point of urea injection, the length of the connecting pipe between DPF and SCR is increased by introducing a 7-inch pipe in between, as shown in Figure 30. Three locations (locations 1, 2 and 3 as indicated in Figure 30) are selected to test the effect of wired mesh substrates Using one mesh substrate at a time, data is collected at each of these locations separately.

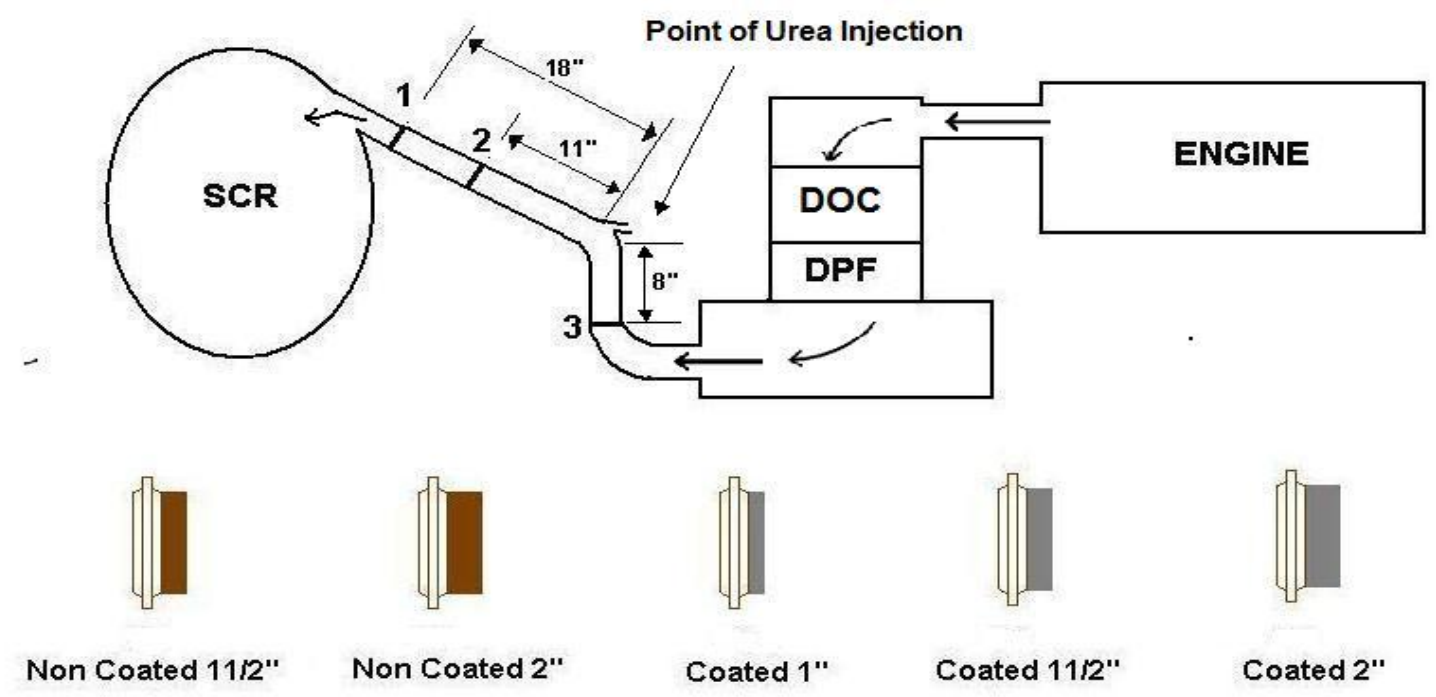

Figure 30: Experimental set up

\subsection{Test Matrix}

Testing all five mesh substrates at three locations resulted in a total of 15 test series. In order to reduce the number of tests, all the substrates are tested at location 1. Based on the results, a wired mesh substrate with greater $\mathrm{NO}_{\mathrm{x}}$ reduction is selected to test it at locations $2 \& 3$. Then, the number of tests is reduced to 8 test series.

A special test cycle is created by selecting specific modes from 13 mode ESC cycle. This test cycle is used to determine the best wired mesh substrate and the location which yielded increased $\mathrm{NO}_{\mathrm{x}}$ reduction. FTP and ESC cycles were performed using the selected wired mesh substrate in the exhaust upstream of the SCR and the results are collected. These results are compared with the previous SCR out cycles performed in WVU EERL as a part of ADECS program [3, 4, and 5]. 


\subsection{Test Cycle}

The test cycle is created by selecting specific modes which yielded high $\mathrm{NO}_{\mathrm{x}}$ emissions. Detailed analysis of the results from ADECS program showed that modes 2, 8, 10, and 12 during an ESC cycle yielded high $\mathrm{NO}_{\mathrm{x}}$ emissions compared to other modes. A test cycle "The Urea Mixing Test Cycle" is created by selecting these modes. This test cycle starts with an idle mode, and then goes through a series of selected modes from the ESC Cycle.

Table 4: Test cycle

\begin{tabular}{|c|c|c|c|}
\hline Mode & Set Speed (rpm) & Set Torque (ft. lb) & Time (mins) \\
\hline Idle & 652 & 0 & 4 \\
\hline Mode 2 & 1263 & 1258 & 2 \\
\hline Mode 8 & 1527 & 1152 & 2 \\
\hline Mode 10 & 1790 & 983 & 2 \\
\hline Mode 12 & 1790 & 730 & 2 \\
\hline Motoring Mode & 1000 & $-150($ approx) & 1 \\
\hline Mode 2 & 1263 & 1258 & 2 \\
\hline Mode 8 & 1527 & 1152 & 2 \\
\hline Mode 10 & 1790 & 983 & 2 \\
\hline Mode 12 & 1790 & 730 & 2 \\
\hline Motoring Mode & 1000 & $-150($ approx) & 1 \\
\hline Mode 2 & 1263 & 1258 & 2 \\
\hline Mode 8 & 1527 & 1152 & 2 \\
\hline Mode 10 & 1790 & 983 & 2 \\
\hline Mode 12 & 1790 & 730 & 2 \\
\hline
\end{tabular}

The selected modes were combined to a new cycle and all five mesh substrates were tested at location 1 (18" downstream of urea injector). The "Optimized Urea Map" created in WVU EERL during the ADECS program was used for all the tests conducted during this study [8 and 9].

\subsection{Emission Calculation}

The data acquisition system used in the EERL consists of different channels for reading signals from all the sensors. The data from these channels were used in respective equations to calculate the mass specific emissions. For the calculation of the mass specific emissions of different exhaust constituents, it is necessary to calculate the flow through the tunnel $(\dot{n})$. The total volume of dilute exhaust drawn through the tunnel for a test period is calculated. All these calculations carried out by the data acquisition system are according to 40 CFR Part 1065 Subpart G [7]. Calculations are discussed in detail in Appendix 


\section{Chapter 5: Results and Discussion}

In this section the effect of wired mesh on the temperature, back pressure and different emissions of the exhaust gas are discussed along with the experimental procedures and results. The data measured includes $\mathrm{NO}_{\mathrm{x}}$ concentrations, back pressure and exhaust temperatures obtained from conducting ESC and FTP cycles for ADECS program at WVU EERL. These data are used for comparison. A series of tests were performed using the modified ESC cycle by placing wired mesh substrates of different lengths at three locations. These tests conducted by placing wired mesh substrate upstream of SCR resulted in increased reduction of $\mathrm{NO}_{\mathrm{x}}$ compared to previous test data from ADECS program. By introducing a wired mesh substrate, an enhanced performance was obtained by making the exhaust flow uniform in both radial and longitudinal directions which resulted in proper mixing of the exhaust gas with urea injected. This also helped in increasing the thermolysys of $\mathrm{HNCO}$ and Ammonia $\left(\mathrm{NH}_{3}\right)$ [1]. The tests conducted on the modified ESC cycle using all five mesh substrates at different locations showed a further reduction in $\mathrm{NO}_{\mathrm{x}}$ with $1 \frac{1}{2}$ " long, $\mathrm{TiO}_{2}$ coated wired mesh at location 1 (explained in section 4.5). Using this particular mesh substrate, regular ESC cycles were conducted which showed 23\% reduction in $\mathrm{NO}_{\mathrm{x}}$ emissions.

All the experiments were conducted on MY 07 MD 11 Volvo engine on the 2007 testing bench in WVU EERL. The following procedure was carried out step-by-step before every test cycle.

1. Warm up for 5 minutes before the actual cycle was started.

2. Stabilization time of 45 seconds was allowed for every mode (explained in section 2.5.2) before starting the data acquisition.

3. The data was collected for 75 seconds for each mode and averaged values were tabulated in the forthcoming sections. 


\subsection{Results for MODE $2(1263 \mathrm{rpm}, 1258 \mathrm{ft}-\mathrm{lb})$}

The speed and load conditions of mode 2 of the ESC cycle are $1263 \mathrm{rpm}$ and $1258 \mathrm{ft}-\mathrm{lb}$ respectively. Analysis of the results from the ADECS program showed that mode 2 was yielding higher concentrations of $\mathrm{NO}_{\mathrm{x}}$. A comparison of $\mathrm{NO}_{\mathrm{x}}$ emissions using different wired mesh substrates is shown Figure 31 It shows there was a reduction of $\mathrm{NO}_{\mathrm{x}}$ emissions for all substrates and the concentrations ranges between $5.9 \mathrm{ppm}$ and $12 \mathrm{ppm}$ for all the mesh substrates. Among all the five mesh substrates, 11/2" thick non-coated wired mesh placed at 18 inches from the urea injector yielded further reduction of about $6 \mathrm{ppm}$. Averages of $\mathrm{NO}_{\mathrm{x}}$ concentrations and exhaust temperatures from Run 1 to Run 3 of mode 2 are shown in Table 5.

Table 5: Average concentrations and temperatures - Mode 2

\begin{tabular}{|c|c|c|c|c|c|}
\hline \multicolumn{2}{|l|}{ Test Description } & $\mathrm{NO}_{\mathrm{x}}(\mathrm{ppm})$ & $\mathrm{NO}(\mathrm{ppm})$ & $\mathrm{NH}_{3}$ Slip(ppm) & Temp $\left({ }^{\circ} \mathrm{C}\right)$ \\
\hline Mesh & Width & Average & Average & Average & Average \\
\hline ESC without Mesh & -- & 12.6 & 5.7 & 0.65 & 420 \\
\hline Non Coated Location 1 & $11 / 2 "$ & 12 & 11.3 & 0.67 & 462 \\
\hline Non Coated Location 1 & $2 "$ & 7.7 & 6.4 & 0.30 & 449 \\
\hline Coated Location 1 & $1 "$ & 9 & 7.9 & 0.34 & 450 \\
\hline Coated Location 1 & $11 / 2 "$ & 5.9 & 4.7 & 0.26 & 443 \\
\hline Coated Location 1 & $2 "$ & 7.1 & 5.9 & 0.30 & 446 \\
\hline Coated Location 2 & $11 / 2 "$ & 11.3 & 10.1 & 0.72 & 447 \\
\hline Non Coated Location 2 & $11 / 2 "$ & 11.9 & 10.1 & 0.74 & 449 \\
\hline Non Coated Location 3 & $11 / 2 "$ & 10.7 & 8.9 & 0.55 & 450 \\
\hline
\end{tabular}

These cycles were run to investigate the length of the mesh substrate and coating necessary for a further reduction. The increased reduction caused by using different wired mesh substrates and the temperature trends were shown in Figure 31 and Figure 32. The exhaust temperatures of the tests run with mesh substrates showed higher values compared to the ADECS program results. Increase in temperatures will reduce the $\mathrm{NO}_{\mathrm{x}}$ conversions [Figure 8]. This gives an allowance to inject more urea in the exhaust with minimal ammonia slip. 


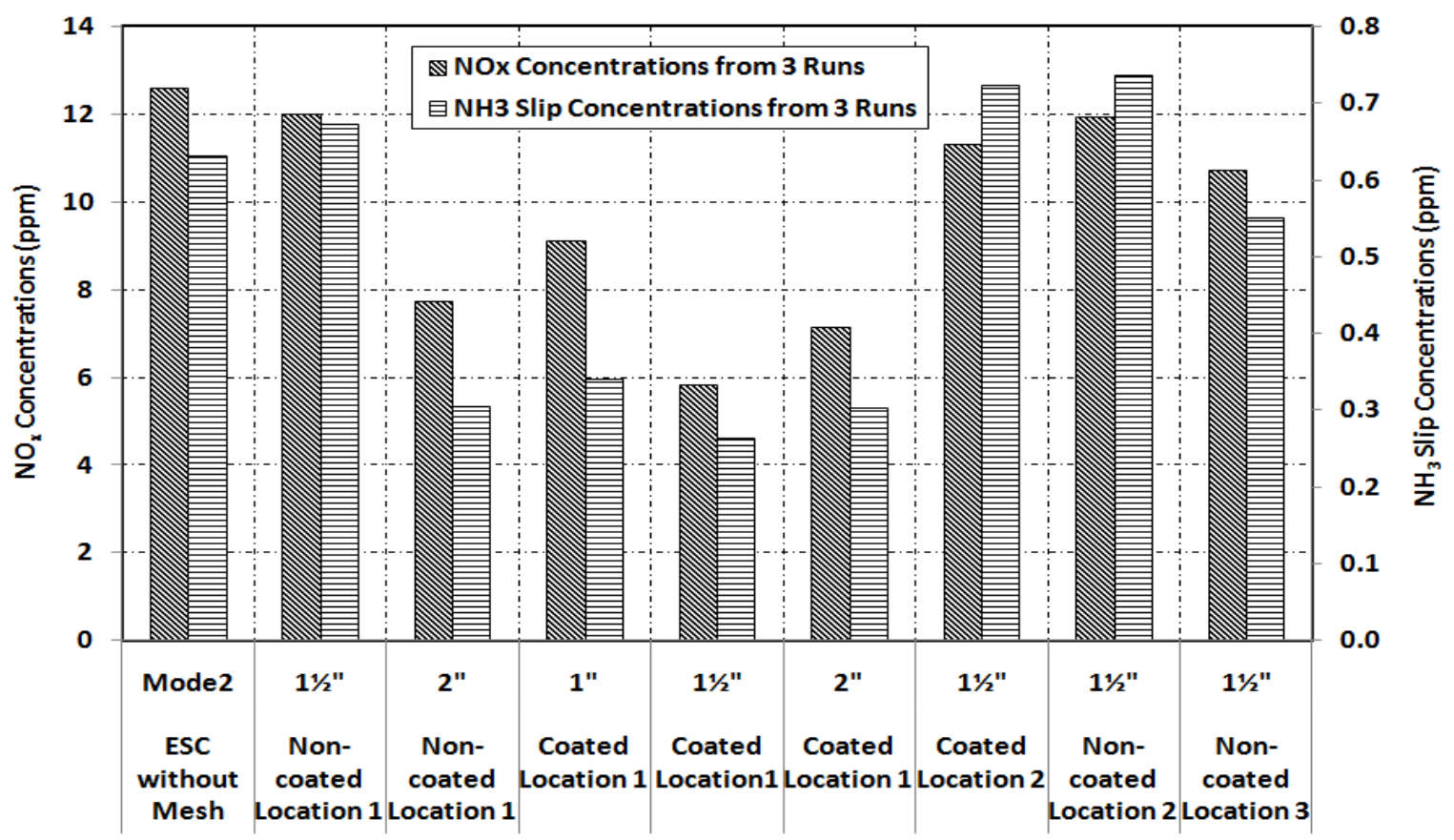

Figure 31: Comparison of $\mathrm{NO}_{\mathrm{x}}$ for mode 2

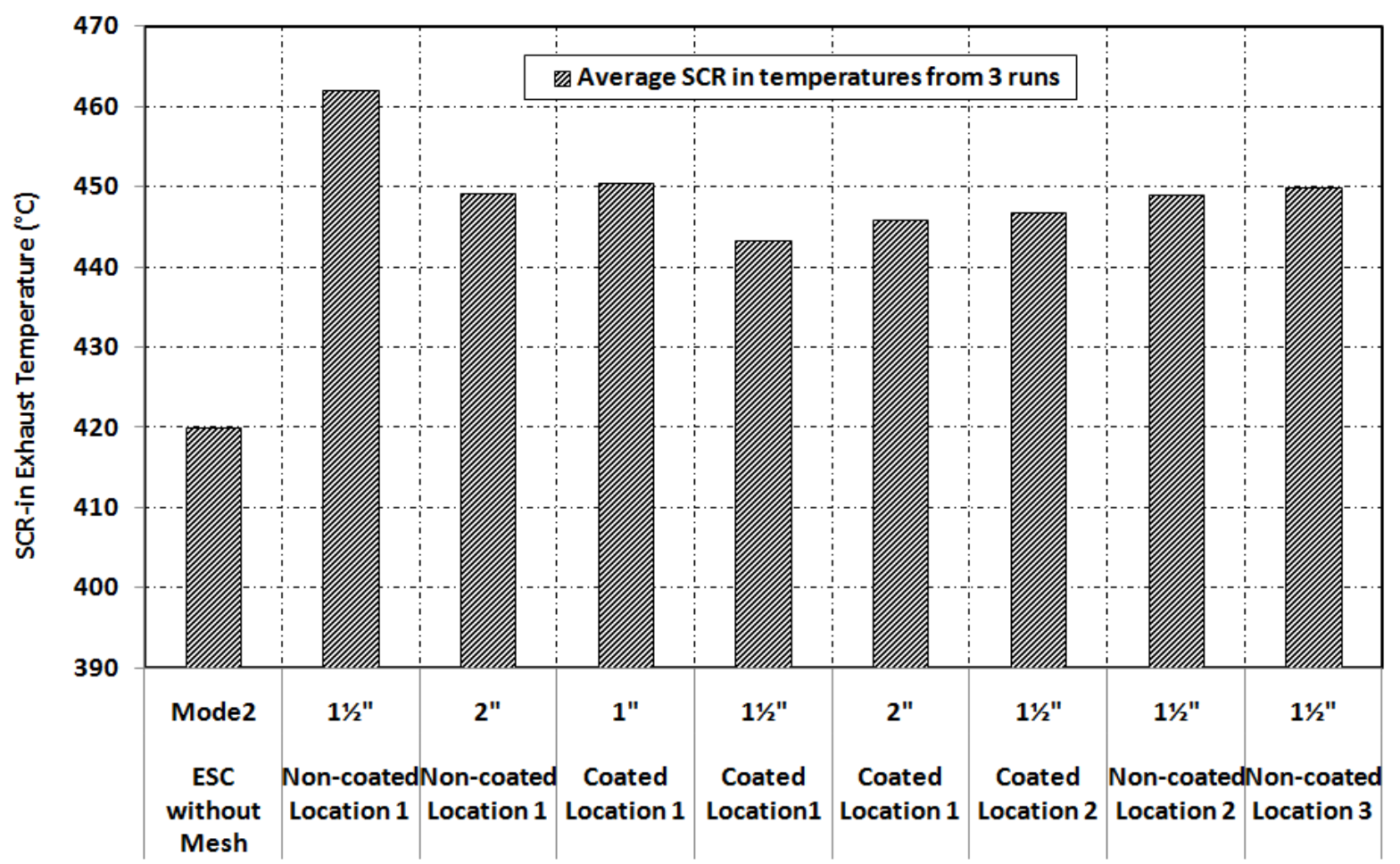

Figure 32: Comparison of SCR-in exhaust temperature measured at mode 2 
Non-coated wired mesh substrate of $1 \frac{1}{2}$ " length gave an increased reduction of $7 \mathrm{ppm}$ compared to the other substrates. Wired mesh substrates also helped in minimizing the urea crystallization because of the high heat capacity of the mesh and thus the $\mathrm{NH}_{3}$ slip occurred during this study is minimized [1].

\subsection{Results for MODE $8(1527$ rpm, 1152 ft-lb)}

Mode 8 was run at $1527 \mathrm{rpm}$ and $1152 \mathrm{ft}-\mathrm{lb}$. Trend similar to mode 2 was observed in mode $8 . \mathrm{NO}_{\mathrm{x}}$ concentrations were found to be reduced with all mesh substrates and ranges between $30 \mathrm{ppm}$ and $41 \mathrm{ppm}$. Of all the five wired mesh substrates, $\mathrm{TiO}_{2}$ coated, 11/2" length gave improved reduction of $11 \mathrm{ppm}$ at location 1 (i.e. 18" from point of injection) than tests ran without mesh. Ammonia slip of less than $0.8 \mathrm{ppm}$ was observed in all the tests. Table 6 shows the average concentrations of $\mathrm{NO}_{\mathrm{x}}$ and temperatures_recorded during the tests.

Table 6: Average concentrations and temperatures - Mode 8

\begin{tabular}{|c|c|c|c|c|c|}
\hline \multicolumn{2}{|c|}{ Test Description } & $\mathrm{NO}_{\mathrm{x}}(\mathrm{ppm})$ & $\mathrm{NO}(\mathrm{ppm})$ & $\mathrm{NH}_{3}$ Slip $(\mathrm{ppm})$ & Temp $\left({ }^{\circ} \mathrm{C}\right)$ \\
\hline Mesh & Width & Average & Average & Average & Average \\
\hline ESC without Mesh & -- & 41.8 & 29.3 & 0.64 & 411 \\
\hline Non Coated Location 1 & $11 / 2^{\prime \prime}$ & 38.5 & 35.5 & 0.54 & 432 \\
\hline Non Coated Location 1 & $2^{\prime \prime}$ & 37.9 & 33.3 & 0.19 & 418 \\
\hline Coated Location 1 & $1 "$ & 41.1 & 29 & 0.40 & 419 \\
\hline Coated Location1 & $11 / 2 "$ & 30.9 & 21.7 & 0.37 & 413 \\
\hline Coated Location 1 & $2^{\prime \prime}$ & 34.5 & 24 & 0.40 & 415 \\
\hline Coated Location 2 & $11 / 2 "$ & 40.8 & 31.9 & 0.74 & 417 \\
\hline Non Coated Location 2 & $11 / 2 "$ & 41.2 & 33.1 & 0.71 & 418 \\
\hline Non Coated Location 3 & $11 / 2 "$ & 41.4 & 30.4 & 0.53 & 418 \\
\hline
\end{tabular}

Comparison of the $\mathrm{NO}_{\mathrm{x}}$ concentrations for mode 8 is shown below in Figure 33. The ammonia slip is minimal $(<1 \mathrm{ppm})$ during these stages [Table 6]. Also, the exhaust temperatures for mode 8 are observed to be higher with the tests run using wired mesh. [Figure 34] 


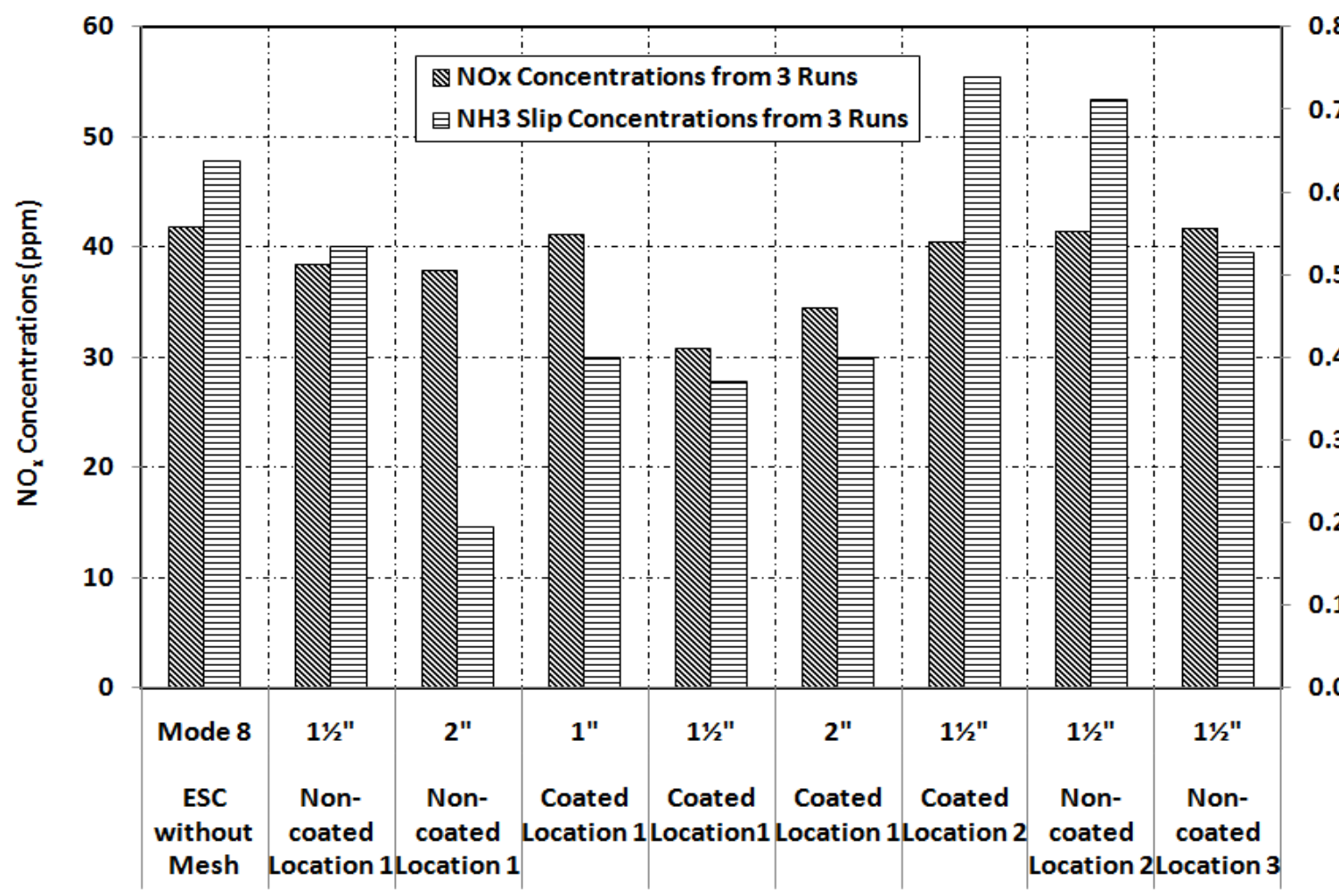

Figure 33: Comparison of $\mathrm{NO}_{\mathrm{x}}$ for mode 8

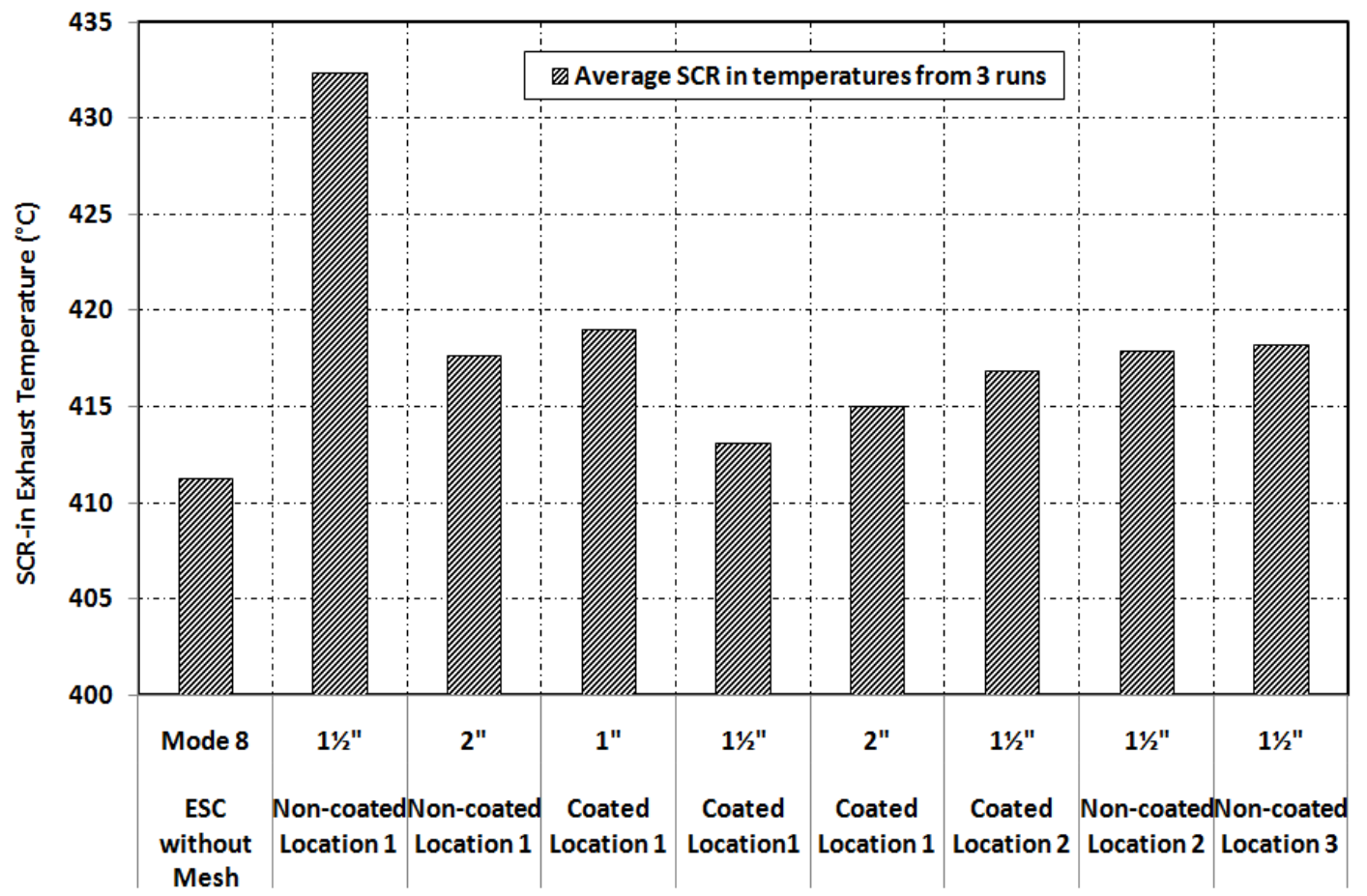

Figure 34: Comparison of SCR-in exhaust temperature measured at mode 8 


\subsection{Results for MODE 10 (1790 rpm, 983 ft-lb)}

Average concentrations for mode 10 are shown in Table 7. Results show that the tests run with wired mesh substrates produced mixed results. Tests run with 2" non-coated mesh at location 1, and the tests run with wired mesh substrates at locations 2 and 3 yielded higher $\mathrm{NO}_{\mathrm{x}}$ emissions than the previous data from the ADECS project. The engine-out temperatures in this mode were very high (about $400{ }^{\circ} \mathrm{C}$ ). Of all the mesh substrates, non-coated mesh substrate of $11 / 2$ " length at location 1 provided satisfying results. The $\mathrm{NO}_{\mathrm{x}}$ concentrations were plotted in Figure 35. The mixing effect was reduced in this mode because of high exhaust flow and the mode of engine operation.

Table 7: Average concentrations and temperatures - Mode 10

\begin{tabular}{|c|c|c|c|c|c|}
\hline \multicolumn{2}{|c|}{ Test Description } & $\mathrm{NO}_{\mathrm{x}}(\mathrm{ppm})$ & $\mathrm{NO}(\mathrm{ppm})$ & $\mathrm{NH}_{3}$ Slip(ppm) & Temp $\left({ }^{\circ} \mathrm{C}\right)$ \\
\hline Mesh & Width & Average & Average & Average & Average \\
\hline ESC without Mesh & -- & 20.3 & 7.8 & 0.17 & 378 \\
\hline Non Coated Location 1 & $1 \frac{1}{2} 2^{\prime \prime}$ & 16.5 & 10 & 1.31 & 411 \\
\hline Non Coated Location 1 & $2 "$ & 25.4 & 17 & 0.29 & 393 \\
\hline Coated Location 1 & $1 "$ & 19.8 & 12.2 & 0.46 & 395 \\
\hline Coated Location1 & $1 \frac{1}{2} "$ & 17.9 & 10 & 0.40 & 386 \\
\hline Coated Location 1 & $2 "$ & 17.7 & 10 & 0.43 & 390 \\
\hline Coated Location 2 & $1 \frac{1}{2 "}$ & 21.9 & 13.5 & 0.81 & 394 \\
\hline Non Coated Location 2 & $1 \frac{1}{2 "}$ & 25 & 15 & 0.88 & 395 \\
\hline Non Coated Location 3 & $1 \frac{1}{2 "}$ & 23.6 & 13.8 & 0.70 & 394 \\
\hline
\end{tabular}




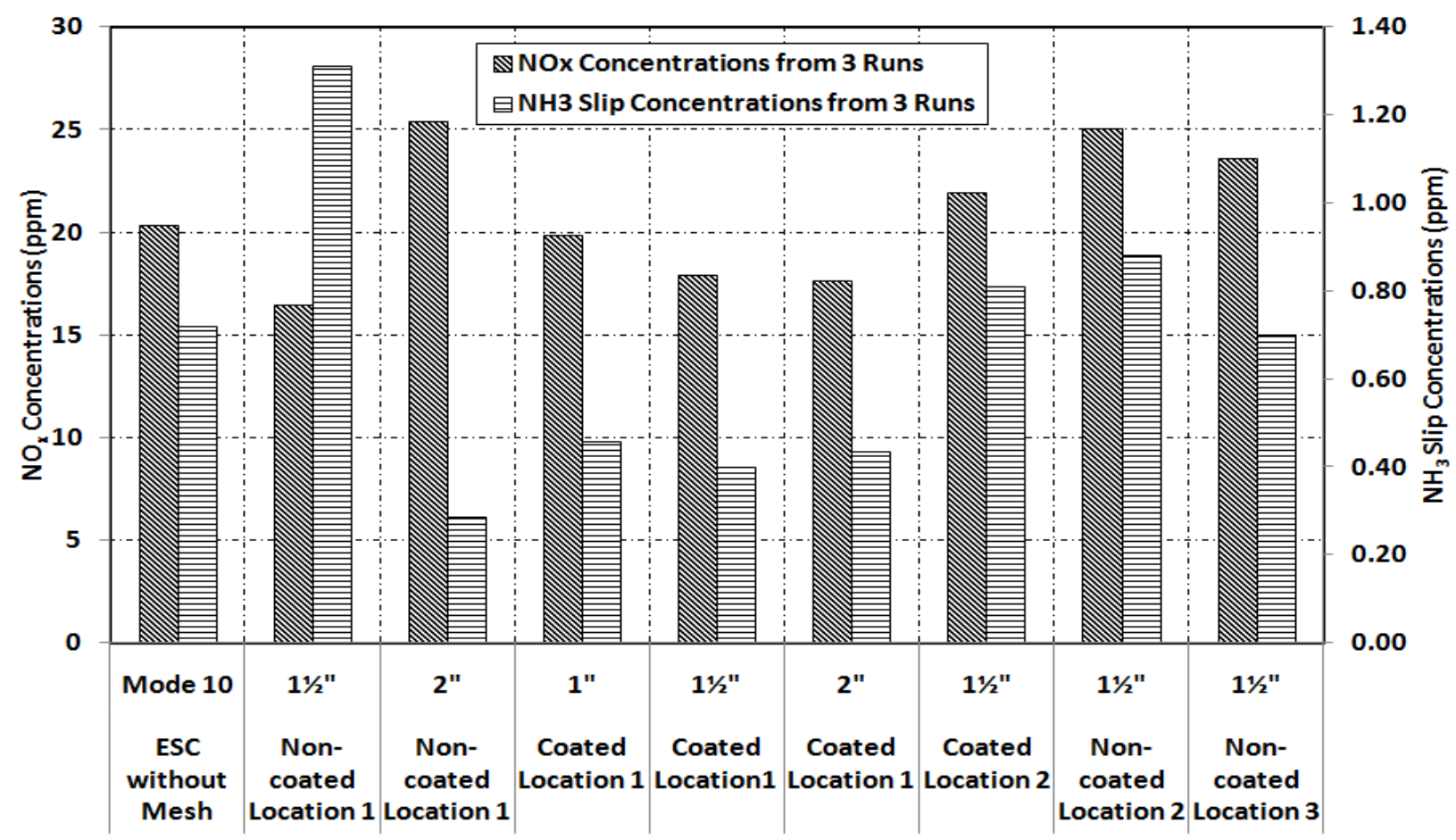

Figure 35: Comparison of $\mathrm{NO}_{\mathrm{x}}$ for mode 10

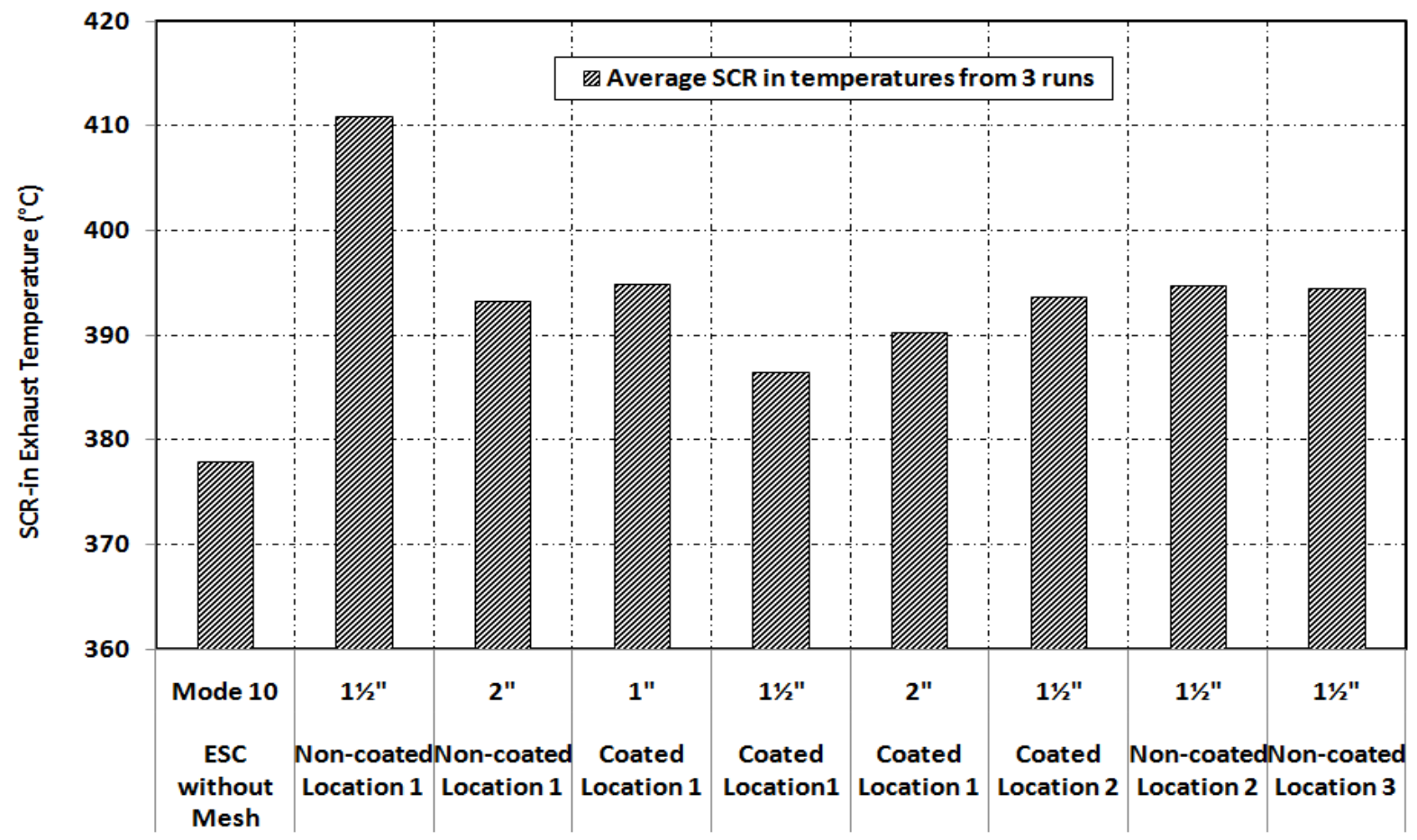

Figure 36: Comparison of exhaust temperature for mode 10 
The wired mesh substrate in this mode also showed increase in exhaust temperatures like mode $2 \&$ mode 8 . This resulted in reduced $\mathrm{NO}_{\mathrm{x}}$ reduction efficiencies and $\mathrm{NH}_{3}$ slip of less than $1 \mathrm{ppm}$ was observed. The temperature variations during the tests were shown in the Figure 36.

\subsection{Results for MODE $12(1790 \mathrm{rpm}, 730 \mathrm{ft}-\mathrm{lb})$}

$\mathrm{NO}_{\mathrm{x}}$ concentrations are found to be very high in mode 12 during the ESC cycle. Introducing a mesh substrate enhanced the mixing of urea with exhaust, and in turn reduced the $\mathrm{NO}_{\mathrm{x}}$ concentrations. Table 8 shows the exhaust temperatures and the average $\mathrm{NO}_{\mathrm{x}}$ concentrations which are found to be in the range of $4.8 \mathrm{ppm}$ to $9.7 \mathrm{ppm}$. All the mesh substrates gave good reduction from ESC without wired mesh as shown in the Figure 37. $\mathrm{TiO}_{2}$ coated mesh substrate of $1 \frac{1}{2} "$ length gave more than $50 \%$ reduction in concentration, compared to all the five mesh substrates.

Table 8: Average concentrations and temperatures - Mode 12

\begin{tabular}{|c|c|c|c|c|c|}
\hline \multicolumn{2}{|c|}{ Test Description } & $\mathrm{NO}_{\mathrm{x}}(\mathrm{ppm})$ & $\mathrm{NO}(\mathrm{ppm})$ & $\mathrm{NH}_{3}$ Slip $(\mathrm{ppm})$ & Temp $\left({ }^{\circ} \mathrm{C}\right)$ \\
\hline Mesh & Width & Average & Average & Average & Average \\
\hline ESC without Mesh & -- & 10.03 & 5.35 & 0.11 & 367 \\
\hline Non Coated Location 1 & $1 \frac{1 / 2 "}{2}$ & 7.65 & 5.24 & 1.00 & 401 \\
\hline Non Coated Location 1 & $2 "$ & 5.71 & 2.82 & 0.26 & 381 \\
\hline Coated Location 1 & $1 "$ & 6.13 & 2.87 & 0.35 & 381 \\
\hline Coated Location1 & $11 / 2 "$ & 4.81 & 2.49 & 0.36 & 375 \\
\hline Coated Location 1 & $2 "$ & 5.16 & 2.51 & 0.40 & 376 \\
\hline Coated Location 2 & $11 / 2 "$ & 8.34 & 3.72 & 0.68 & 378 \\
\hline Non Coated Location 2 & $11 / 2 "$ & 9.71 & 4.40 & 0.76 & 380 \\
\hline Non Coated Location 3 & $11 / 2 "$ & 9.36 & 4.02 & 0.57 & 380 \\
\hline
\end{tabular}




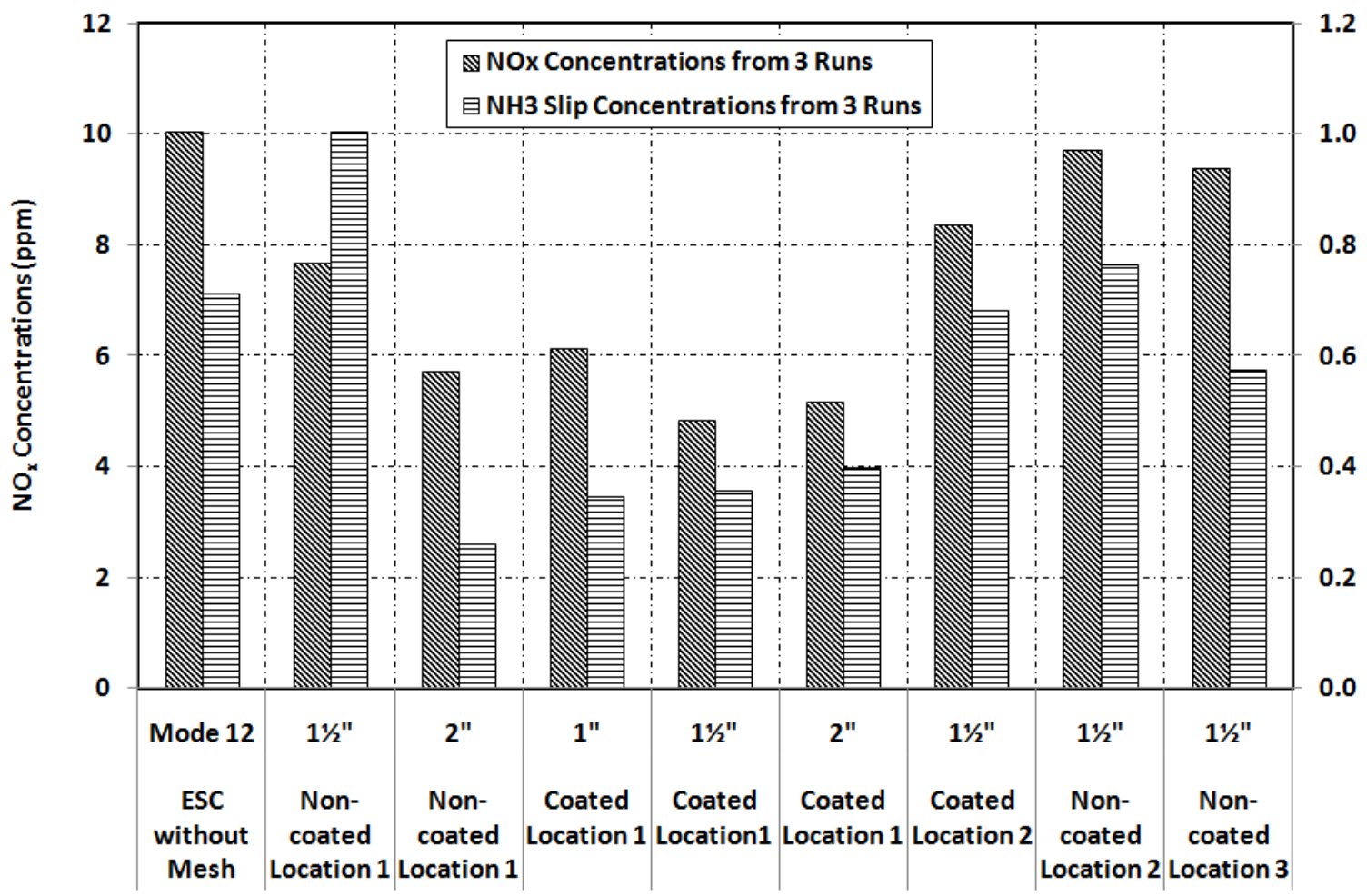

Figure 37: Comparison of NOx for mode 12

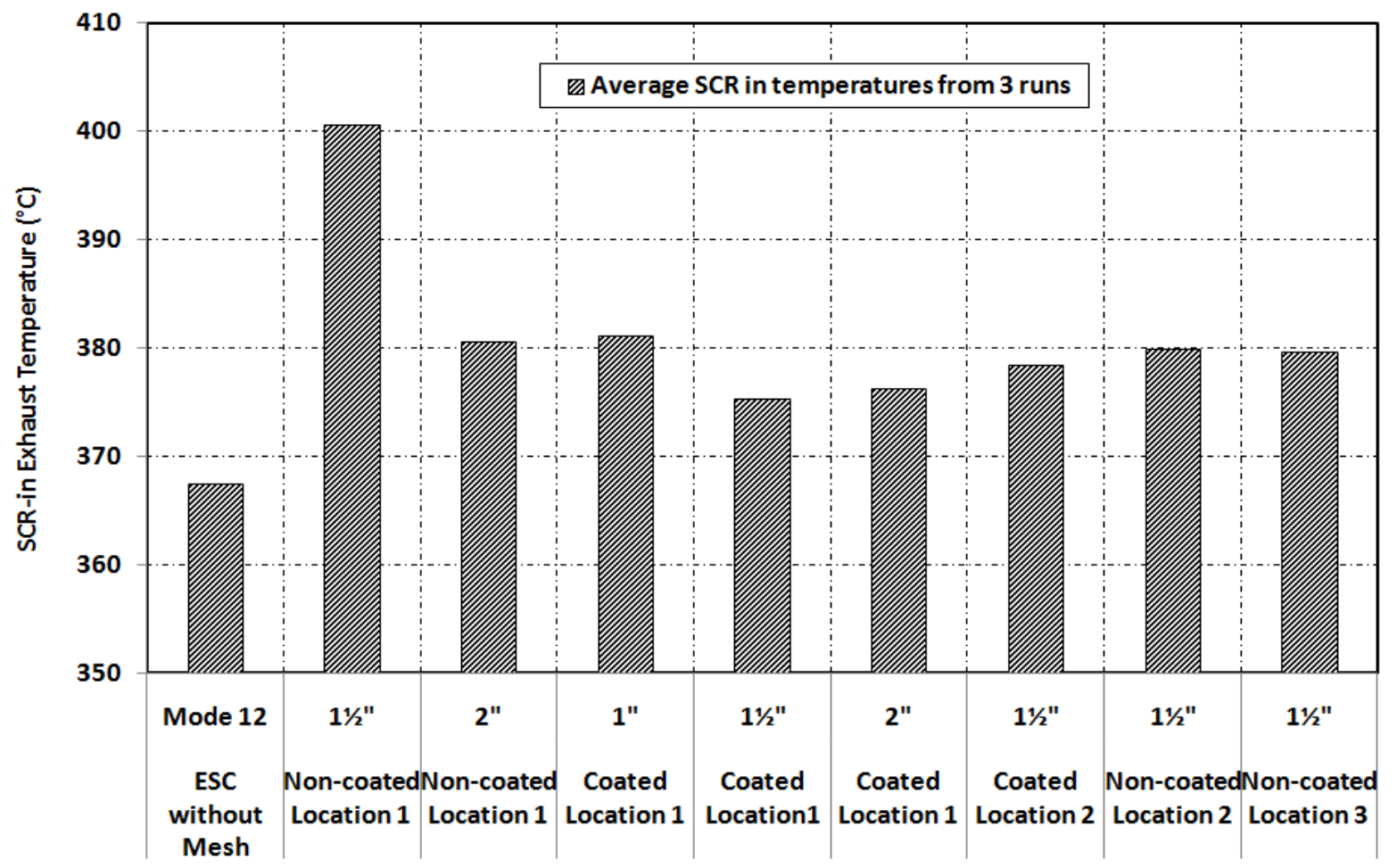

Figure 38: Comparison of exhaust temperature for mode 12 
The exhaust temperatures in this mode are slightly increased compared to ESC cycle without mesh substrate. As in previous cases, the mesh substrates provided good mixing of the urea with the exhaust which resulted in further $\mathrm{NO}_{\mathrm{x}}$ reductions. The temperature profiles of each test in this mode are as shown in Figure 38.

All the experiments showed that the wired mesh substrates are capable of providing the mixing effect and increased reduction in $\mathrm{NO}_{\mathrm{x}}$ emissions. Considering all the tests on a whole, mesh substrate of $1 \frac{1}{2}$ " long coated with titanium dioxide $\left(\mathrm{TiO}_{2}\right)$ gave more than $50 \%$ further $\mathrm{NO}_{\mathrm{x}}$ reduction compared to mode 12 data of ADECS program. The wired mesh substrate made the exhaust flow to spread in both radial and axial directions, thus making the flow uniformly distributed along the exhaust pipe. The mixing effect provided by wired mesh enhanced mixing of exhaust with injected urea, and hence the performance of SCR. To confirm the results, conventional FTP and ESC cycles were run using the 11/2" thick $\mathrm{TiO}_{2}$ coated mesh at location 1 and the results were compared with the previous data collected during the ADECS program in the upcoming sections [Sections 5.6, 5.7, 5.8, and 5.9].

\subsection{Correlation between $\mathrm{NO}_{\mathrm{x}}$ and Exhaust Temperatures}

The $\mathrm{NO}_{\mathrm{x}}$ reduction efficiencies will decrease with the increase in exhaust temperature [Figure 8]. Therefore urea dosage should be increased to reduce the $\mathrm{NO}_{\mathrm{x}}$ emissions [24]. Figure 39 shows increase in NOx concentrations with the SCR-in exhaust temperatures. Average concentrations of $\mathrm{NO}_{\mathrm{x}}$ and the exhaust temperatures for the tests run with the mesh substrate in $1^{\text {st }}$ Run to $3^{\text {rd }}$ Run were plotted and is shown below in Figure 39. The $\mathrm{NO}_{\mathrm{x}}$ concentration is observed to be increased from Run 1 to Run 3 with the same amount of urea being injected in all the runs. A cool down phase of 60 seconds is allowed between each run to lower the temperature of the exhaust. Data shows that the cool down phase of 60 seconds is not enough to attain the similar thermal boundary conditions in all the runs. The cool down phase might have extended to attain the similar boundary conditions in all runs. 


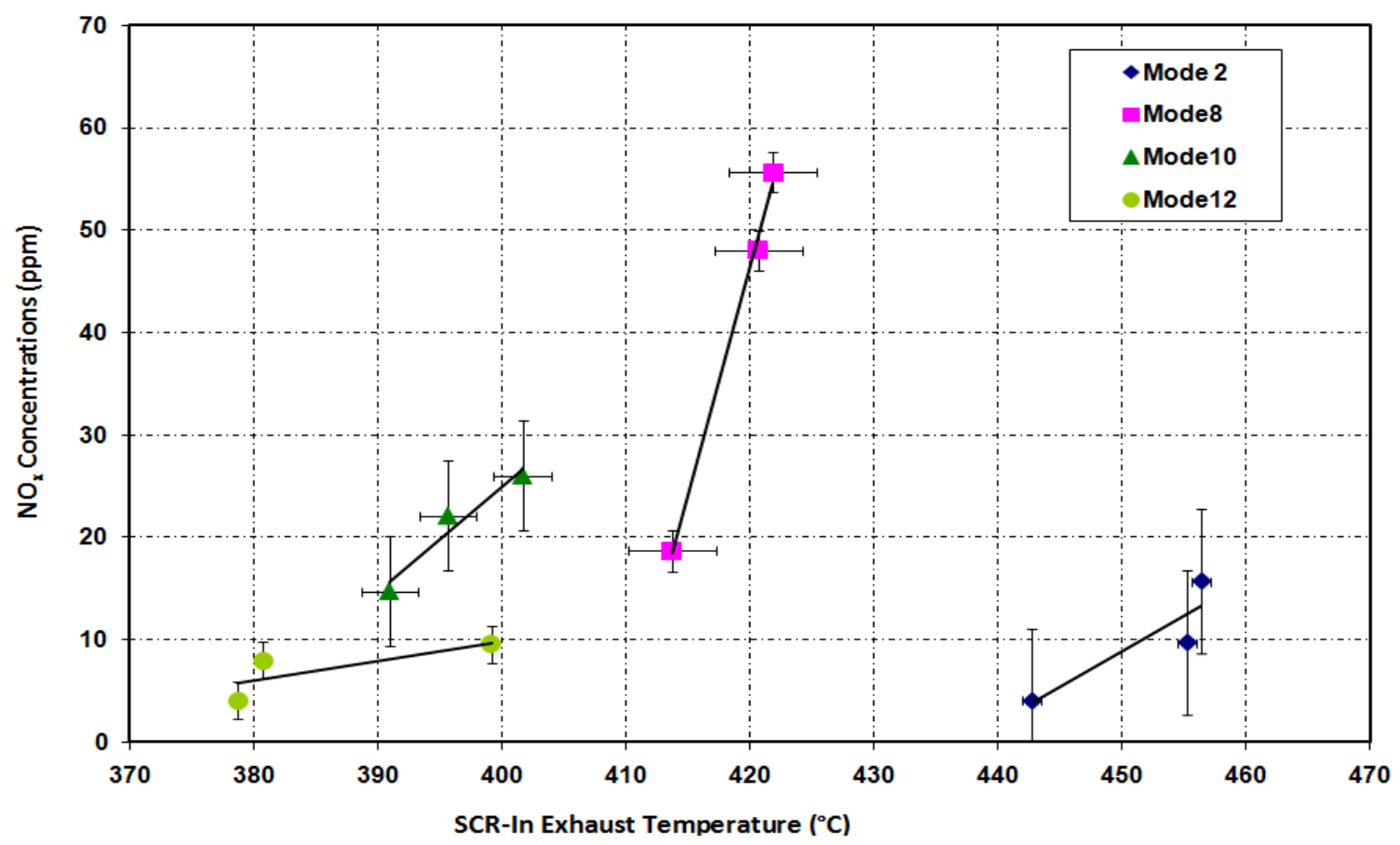

Figure 39: Correlation between $\mathrm{NO}_{\mathrm{x}}$ and exhaust temperatures

\subsection{Comparison of $\mathrm{NO}_{\mathrm{x}} \& \mathrm{NO}_{2} / \mathrm{NO}$ Ratio}

Experimental study conducted on the new developed cycle showed that $1 \frac{1 / 2}{2}$ thick, $\mathrm{TiO}_{2}$ coated wired mesh substrate gave an improved reduction in $\mathrm{NO}_{\mathrm{x}}$ compared to the other substrates. Three ESC cycles and three FTP cycles are run using the selected mesh and the results are compared with the previous SCR out tests performed. Because of the effect caused by the wired mesh substrate the concentration of $\mathrm{NO}_{\mathrm{x}}$ is reduced by $23 \%$ during ESC cycles.

\subsubsection{Comparison of Brake Specific Emissions of $\mathrm{NO}_{\mathrm{x}}$}

The results from the FTP and ESC cycles run using the wired mesh substrate are plotted and as shown in Figure 40 and Figure 41. These plots show the reductions in brake specific $\mathrm{NO}_{\mathrm{x}}$ emissions when 1 1/2" length coated wired mesh substrate is used in the exhaust stream, upstream of the SCR. Three consecutive ESC cycles showed a reduction of $23 \%$ when compared with the tests run without using the mesh substrate in the exhaust stream. No further reduction is observed in case of FTP cycles. This shows that the mesh had no effect on $\mathrm{NO}_{\mathrm{x}}$ emissions during an FTP cycle. 


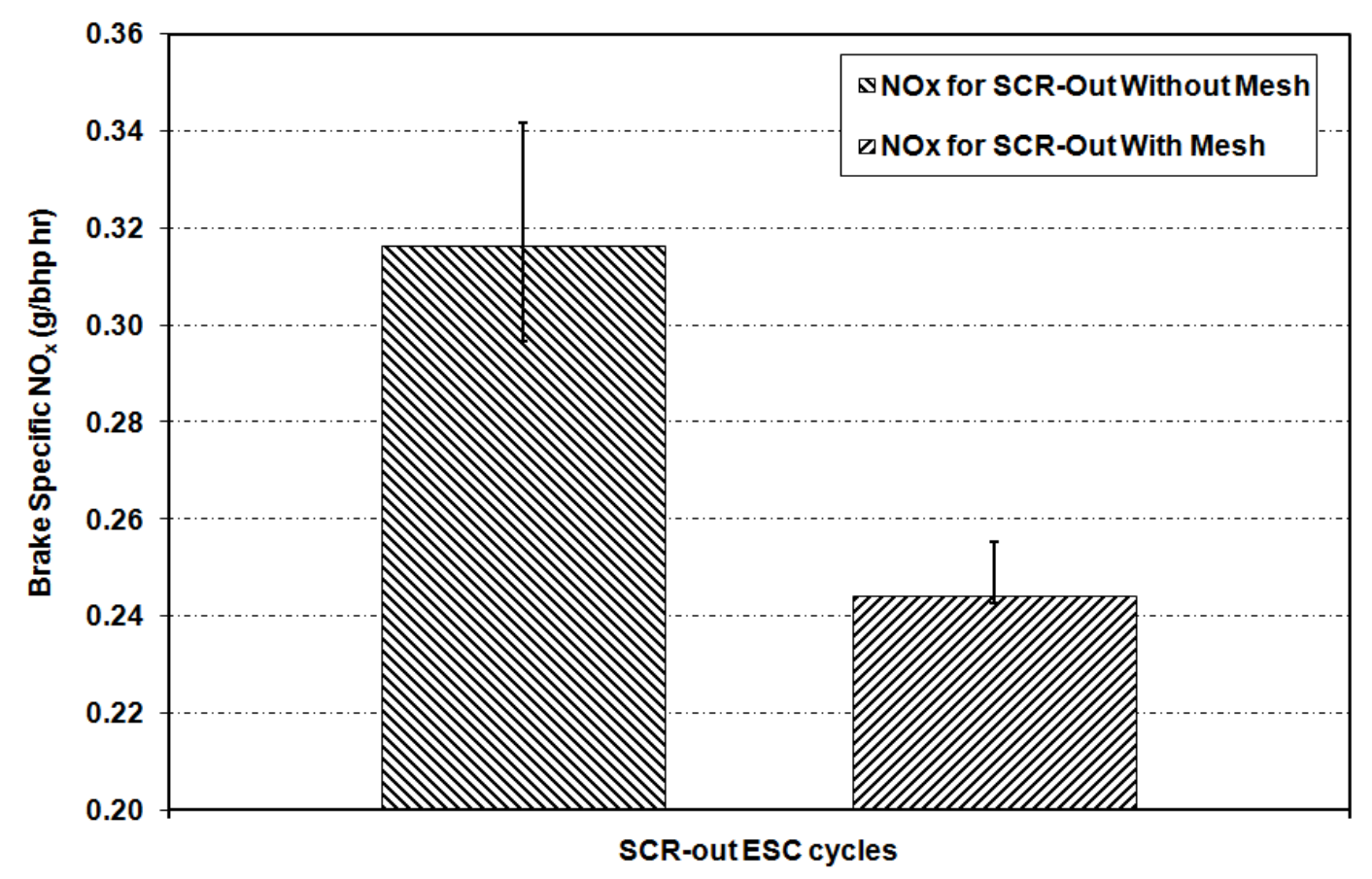

Figure 40: Comparison of SCR-out $\mathrm{NO}_{\mathrm{x}}$ in $\mathrm{g} / \mathrm{bhp}-\mathrm{hr}$ measured using ESC cycles



Figure 41: Comparison of SCR-out $\mathrm{NO}_{\mathrm{x}}$ in $\mathrm{g} / \mathrm{bhp}-\mathrm{hr}$ measured using FTP cycles 
There is a slight increase in the $\mathrm{NO}_{\mathrm{x}}$ emissions measured using FTP cycle, but this increase was very insignificant which might be due to day-to-day variations. These are the average values of the $\mathrm{NO}_{\mathrm{x}}$ from three consecutive ESC and FTP Cycles conducted without and with mesh in the exhaust stream with the optimized urea map created during the ADECS program.

\subsubsection{Comparison of $\mathrm{NO}_{\mathrm{x}}$ Concentrations}

Averaged values of $\mathrm{NO}_{\mathrm{x}}$ concentrations from three consecutive ESC cycles showed reduced levels in almost every mode. The overall performance of the wired mesh substrate on the ESC cycle is about $23 \%$ reduction in brake specific $\mathrm{NO}_{\mathrm{x}}$ emissions during the ESC cycle. Figure 42 shows a clear indication of the mixing effect caused by wired mesh substrate on $\mathrm{NO}_{\mathrm{x}}$ emissions.

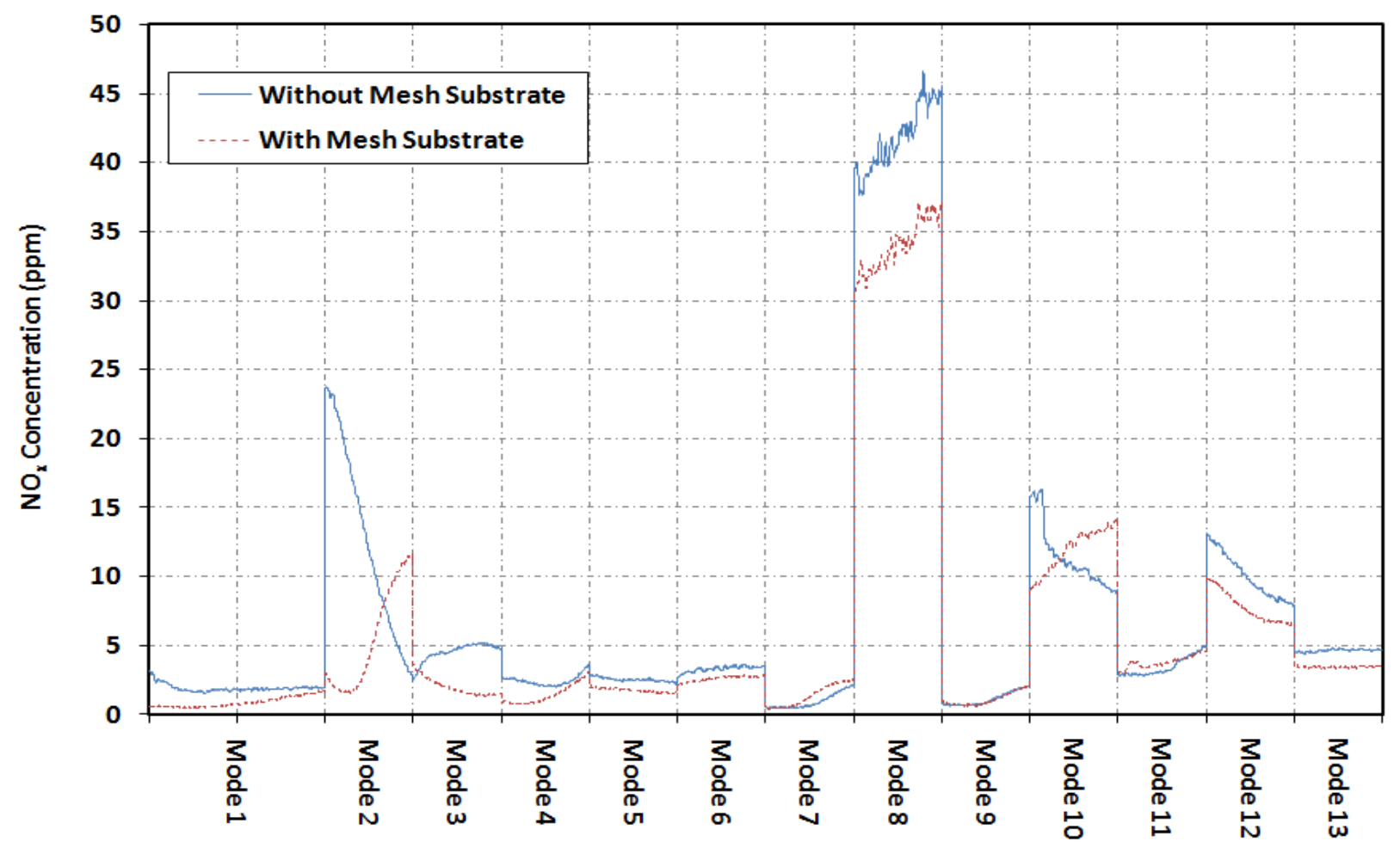

Figure 42: Comparison of SCR-Out $\mathrm{NO}_{\mathrm{x}}$ in ppm measured using ESC cycles

The comparison shown in Figure 42 indicates a good reduction of $\mathrm{NO}_{\mathrm{x}}$ concentration in all the modes of an ESC cycle. $\mathrm{NO}_{\mathrm{x}}$ concentrations are unstable during mode 2, but shows good reduction with the mixing effect of wired mesh substrate. Because the engine was in a transition 
from idle to high speed and high torque (1263 rpm and $1258 \mathrm{lb}-\mathrm{ft}$ ), it need more time for stabilization than allowed. The duration of the mode 2 could be extended to achieve stable emissions. Similarly, the concentrations were reduced considerably during the modes 8, 10, and 12. Significant reduction of $\mathrm{NO}_{\mathrm{x}}$ was shown by the mixing effect of wired mesh substrate during the ESC cycle. The effect of wired mesh substrate during the FTP cycle is insignificant when compared with tests run without wired mesh substrate during the ADECS program. The exhaust temperatures are found to be low during the FTP cycle which is the primary reason for low SCR efficiencies.

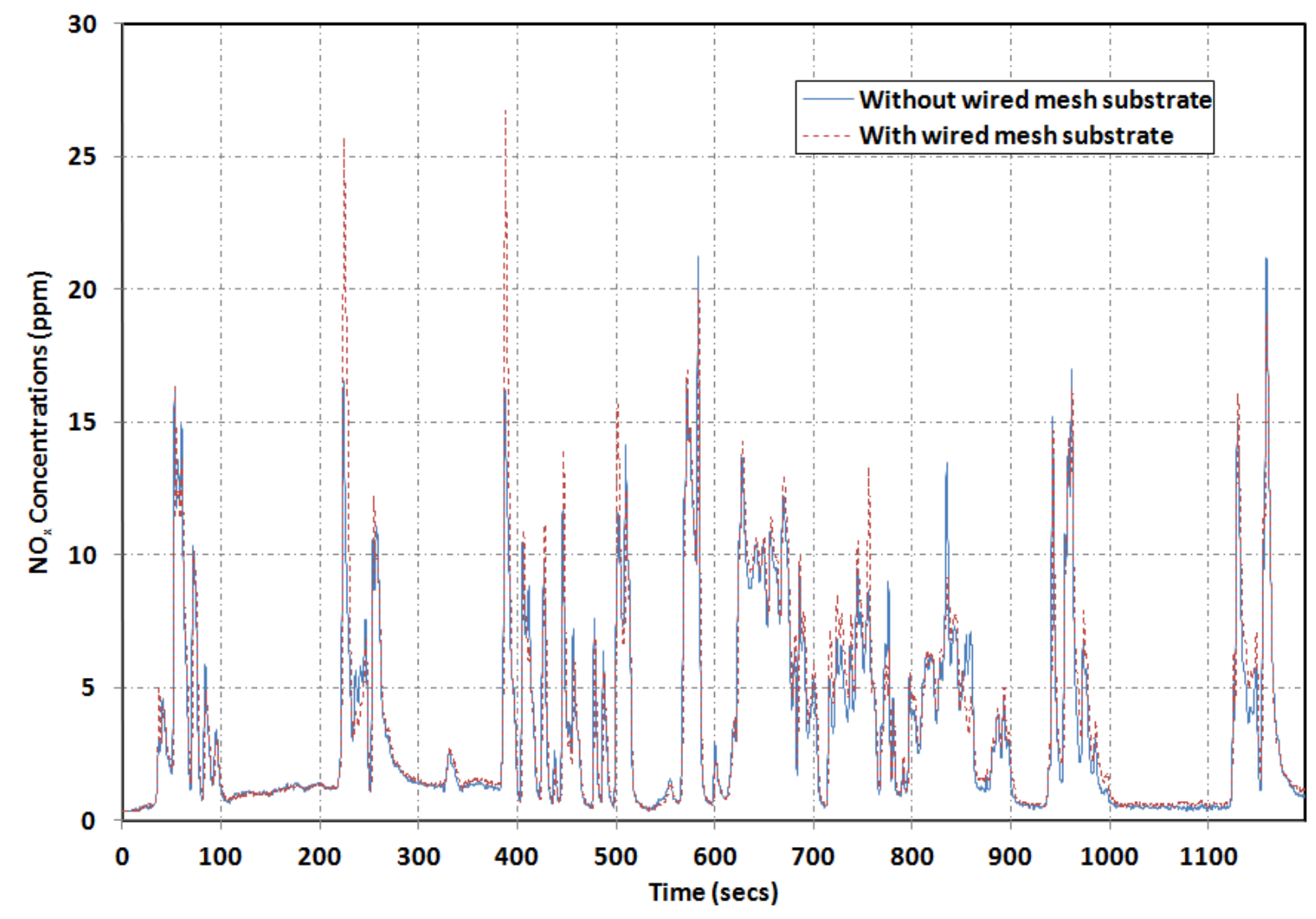

Figure 43: Comparison of SCR-Out $\mathrm{NO}_{\mathrm{x}}$ in ppm measured using FTP cycles

Plot shown in the Figure 43 indicates that no reductions were achieved using the wired mesh.

\subsubsection{Comparison of $\mathrm{NO}_{2} / \mathrm{NO}$ Ratio}

The $\mathrm{NO}_{2}$ concentrations were calculated by subtracting $\mathrm{NO}$ from $\mathrm{NO}_{\mathrm{x}}$ concentrations. The analysis of the $\mathrm{NO}_{2} / \mathrm{NO}$ ratio indicates that the wired mesh led to considerable increase in 
the concentration of $\mathrm{NO}_{2}$, and a reduction in the concentration levels of $\mathrm{NO}$. The $\mathrm{NO}_{2} / \mathrm{NO}$ ratio was increased with the use of the mesh in comparison to tests without the mesh substrate. $\mathrm{NO}_{2}$ concentrations were increased due to the catalytic oxidation of the wired mesh substrate. NO content in the exhaust reacted with the urea injected and converted it into $\mathrm{N}_{2}$ as a result of SCR performance. Figure 44 and Figure 45 compare the $\mathrm{NO}_{2} / \mathrm{NO}$ ratio comparison during the three ESC and FTP cycles ran with and without using the wired mesh substrate, respectively.

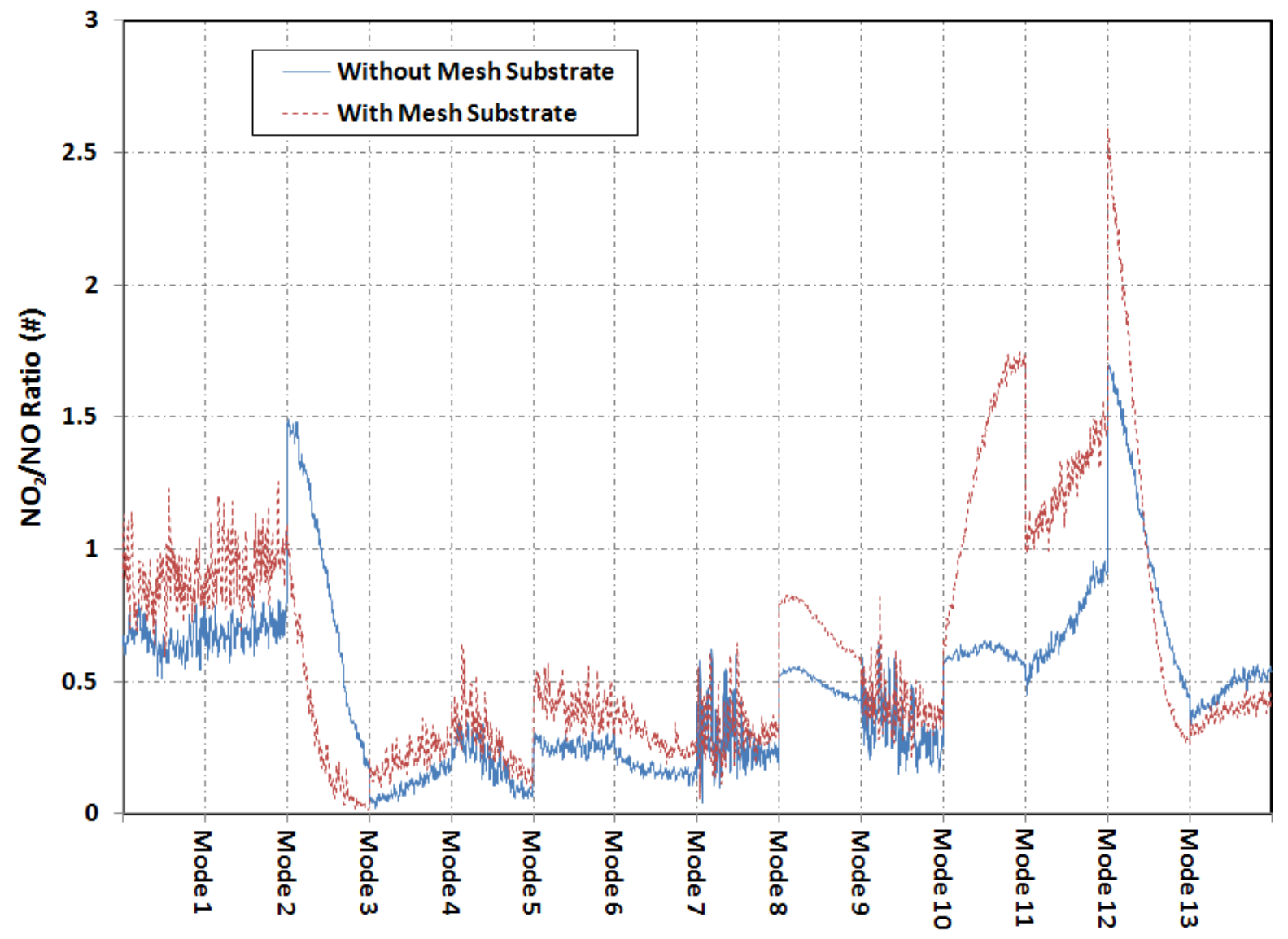

Figure 44: Comparison of $\mathrm{NO}_{2} / \mathrm{NO}$ ratio for $\mathrm{ESC}$ cycles

The $\mathrm{NO}_{2} / \mathrm{NO}$ ratios during the ESC and FTP cycles ran with the $1 \frac{1}{2} " \mathrm{TiO}_{2}$ coated wired mesh substrate shows that the ratio was increased from the tests, which were run during the ADECS program. This indicates that the catalytic coating on the wired mesh was increasing the $\mathrm{NO}_{2}$ and the $\mathrm{NO}$ concentrations were reduced. Figure 45 shows that the $\mathrm{NO}_{2} / \mathrm{NO}$ ratio was increased from the ESC without mesh substrate. This is also a reason for having higher $\mathrm{NO}_{\mathrm{x}}$ concentrations during the FTP cycle. 


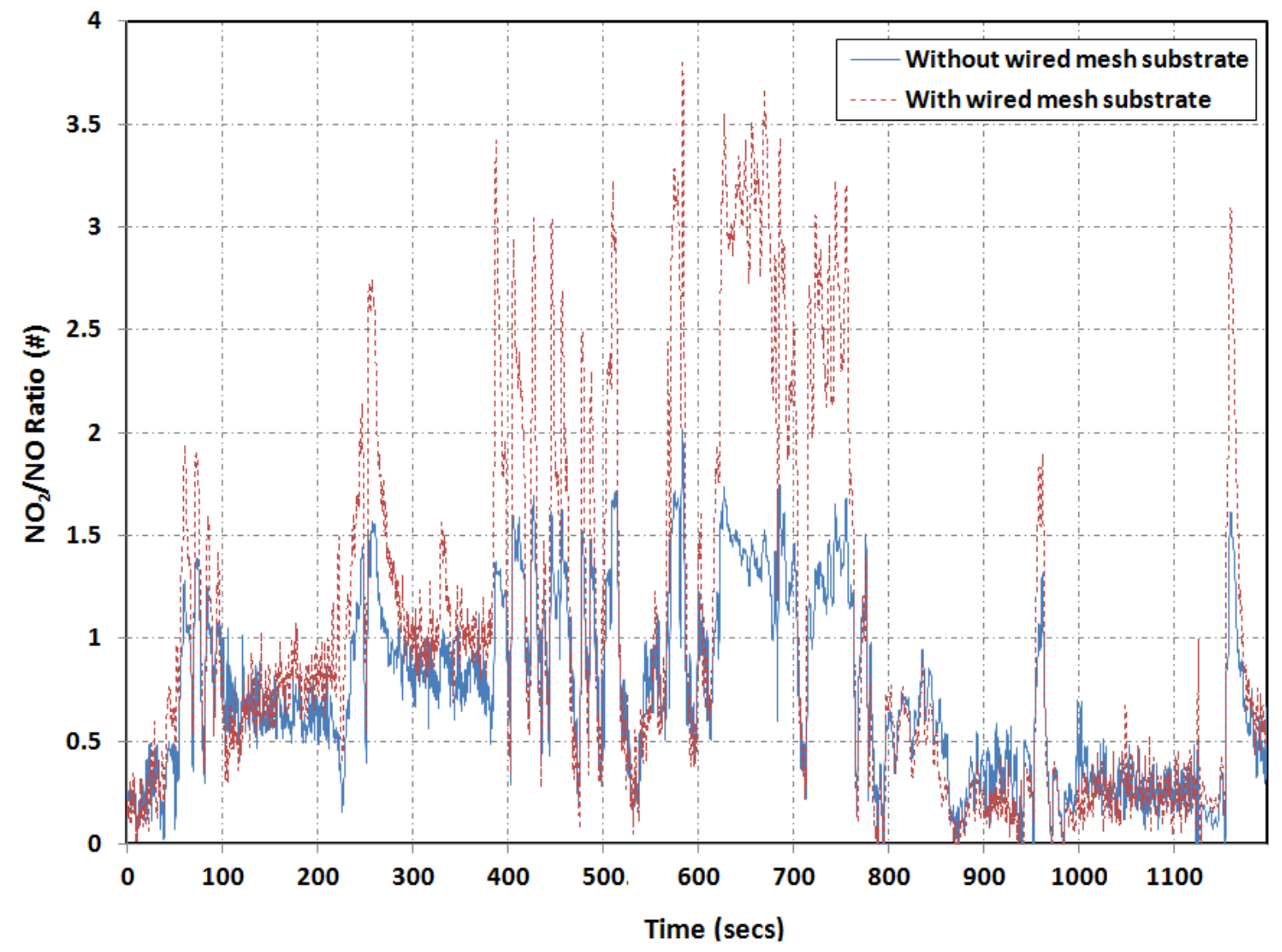

Figure 45: Comparison of $\mathrm{NO}_{2} / \mathrm{NO}$ ratio for FTP cycles

\subsection{Comparison of Exhaust Temperature, $\mathrm{NO}_{\mathrm{x}}$, and $\mathrm{NH}_{3}$ Slip Concentrations}

Exhaust gas temperatures more than $250{ }^{\circ} \mathrm{C}$ are required for the SCR to perform the $\mathrm{NO}_{\mathrm{x}}$ reduction process efficiently. Temperature above $250{ }^{\circ} \mathrm{C}$ is the minimum limit for the urea injection system to inject urea. These temperatures are ideal for the SCR operation.

Exhaust temperature was above $350{ }^{\circ} \mathrm{C}$ throughout the ESC cycle. These temperature levels make the SCR to perform optimal and generate increased $\mathrm{NO}_{\mathrm{x}}$ reduction efficiencies. Figure 46 shows the exhaust temperature profile compared with the $\mathrm{NO}_{\mathrm{x}}$ and $\mathrm{NH}_{3}$ slip concentrations. Introducing the wired mesh substrates in the exhaust stream provide good mixing of the exhaust with the urea injected; thereby, providing increased SCR performance. 


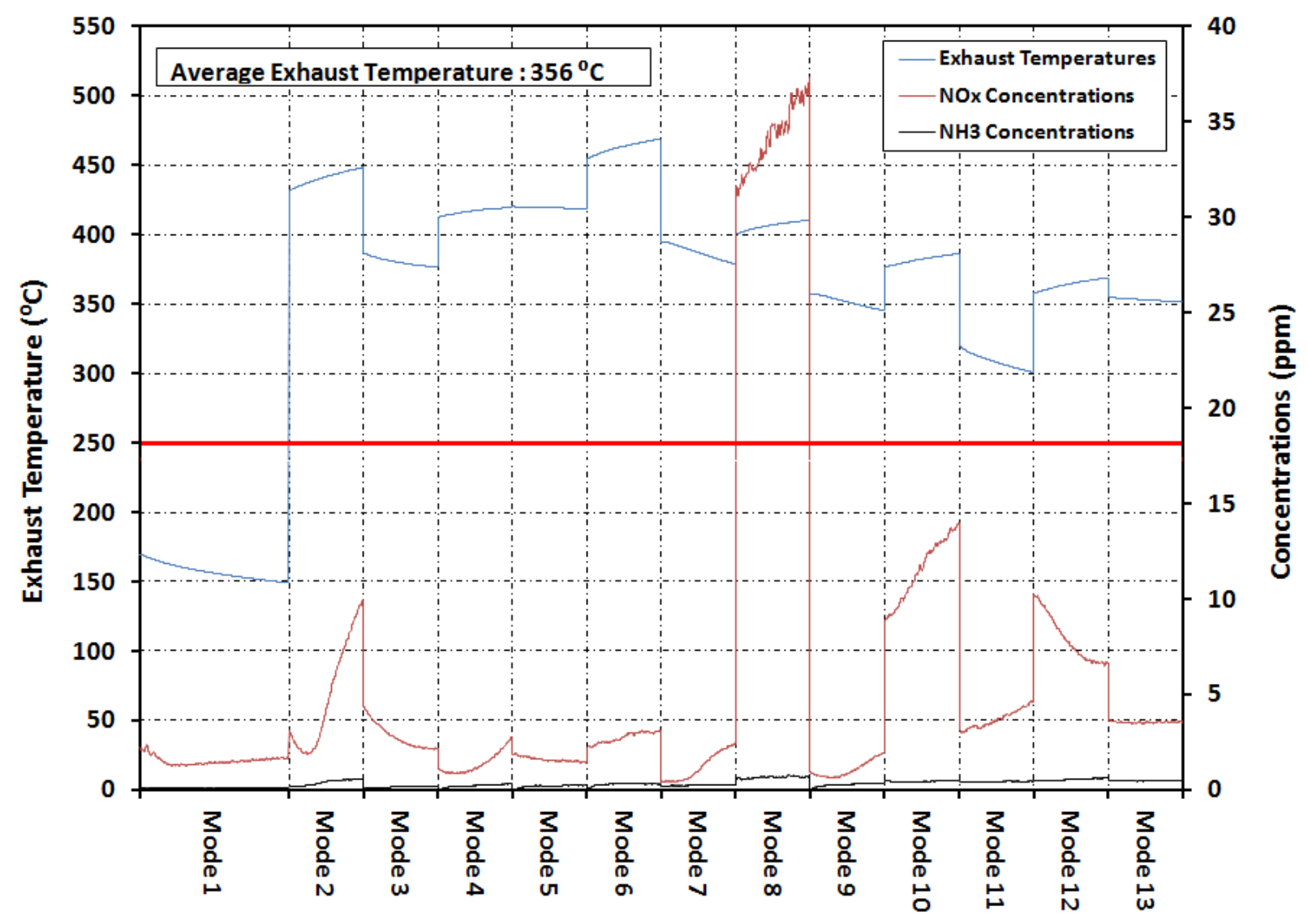

Figure 46: Exhaust temperature $\mathrm{Vs} \mathrm{NO}_{\mathrm{x}}$ and $\mathrm{NH}_{3}$ slip concentrations, ESC Cycles

During the FTP cycles the exhaust temperature are low (lower than $250{ }^{\circ} \mathrm{C}$ ). Figure 47 shows that the temperatures are low and the $\mathrm{NO}_{\mathrm{x}}$ concentrations are high. SCR system will start injecting urea only at temperatures higher than $250{ }^{\circ} \mathrm{C}$. The wired mesh substrate hasn't shown any effect on SCR performance because of low exhaust gas temperatures. 


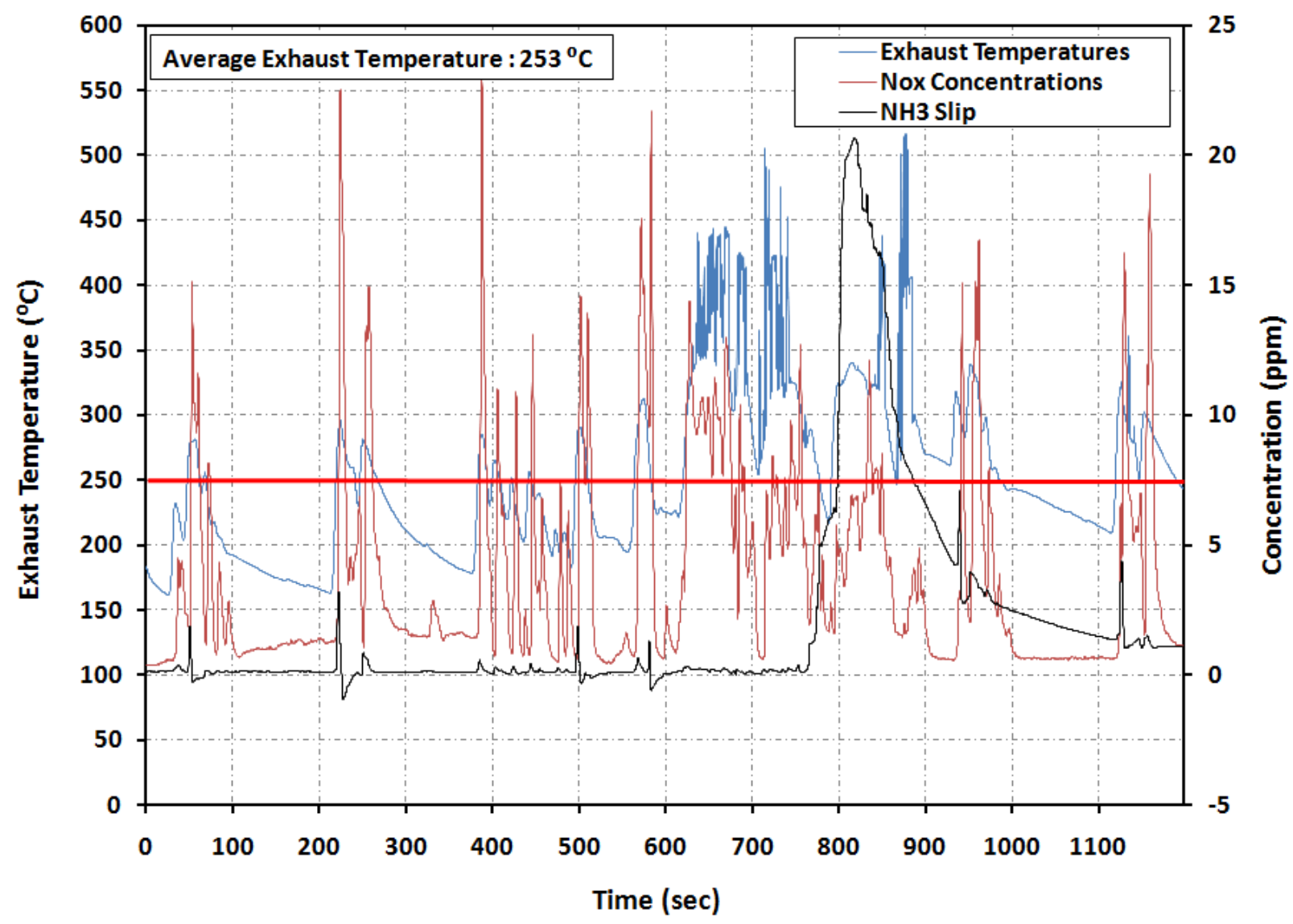

Figure 47: Exhaust temperature Vs $\mathrm{NO}_{x}$ and $\mathrm{NH}_{3}$ slip concentrations, FTP Cycles

\subsection{SCR Efficiency:}

SCR efficiency is the reduction of $\mathrm{NO}_{\mathrm{x}}$ from the engine out concentrations to the SCR out concentrations.

$$
\eta_{S C R}=\frac{\left\lfloor(N O x)_{\text {EngOut }}\right\rfloor-\left[(N O x)_{\text {SCROut }}\right]}{\left\lfloor(N O x)_{\text {EngOut }}\right\rfloor} \times 100
$$

The SCR efficiency for all the modes is calculated. As shown in Figure 48, the SCR efficiency is increased in all modes except modes 10 and 11. Mode 10 which is high load and high speed has less efficiency than other modes and mode 11 is low load mode in which the $\mathrm{NO}_{\mathrm{x}}$ concentrations are as low as 3 ppm. It must be recognized that the concentrations of $\mathrm{NO}_{\mathrm{x}}$ is low in mode 11 . Considerable efficiency increase in the remaining modes shows a clear indication of the mixing effect of mesh substrate. 


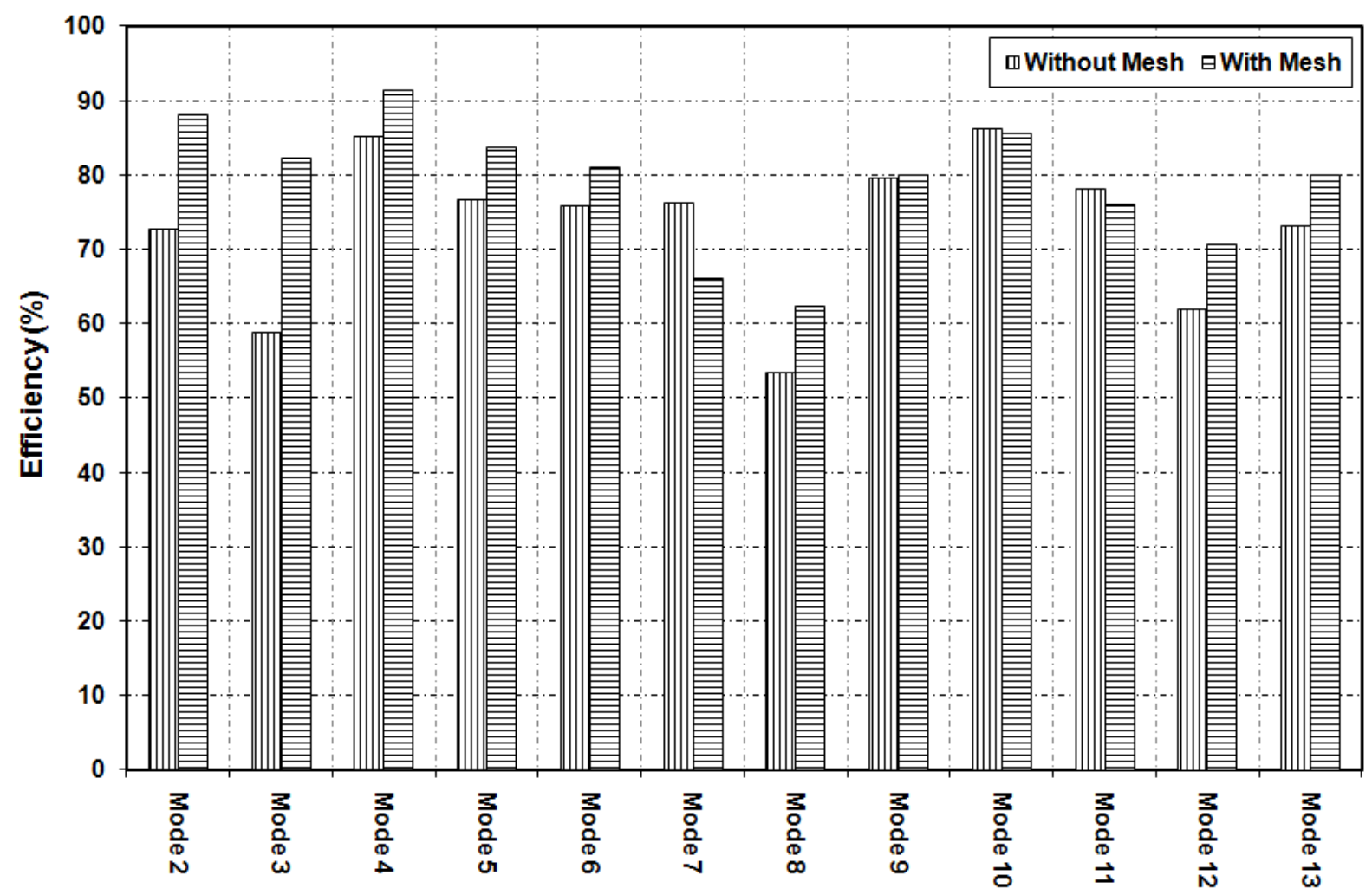

Figure 48: Comparison of SCR efficiency with and without mesh

\subsection{Back Pressure Comparisons:}

Using a wired mesh substrate in the stream of exhaust gases led to an increase in back pressure. The back pressure increase during the ESC and FTP cycles run with the wired mesh substrates was minimal in comparison to the configuration without the mesh. The backpressure data was taken upstream of the DOC to measure the backpressure caused by DOC, DPF wired mesh substrate, and SCR catalyst.

Back pressure increase was, as expected, slightly higher in the high speed and load modes. During the other modes, the back pressure increase is negligible. Figure 49 and Figure 50 show the comparison of back pressure during the ESC and FTP cycles. There is a slight increase in the back pressure during the FTP cycles as well. This increase is not high and does not affect the normal operation of the engine. 


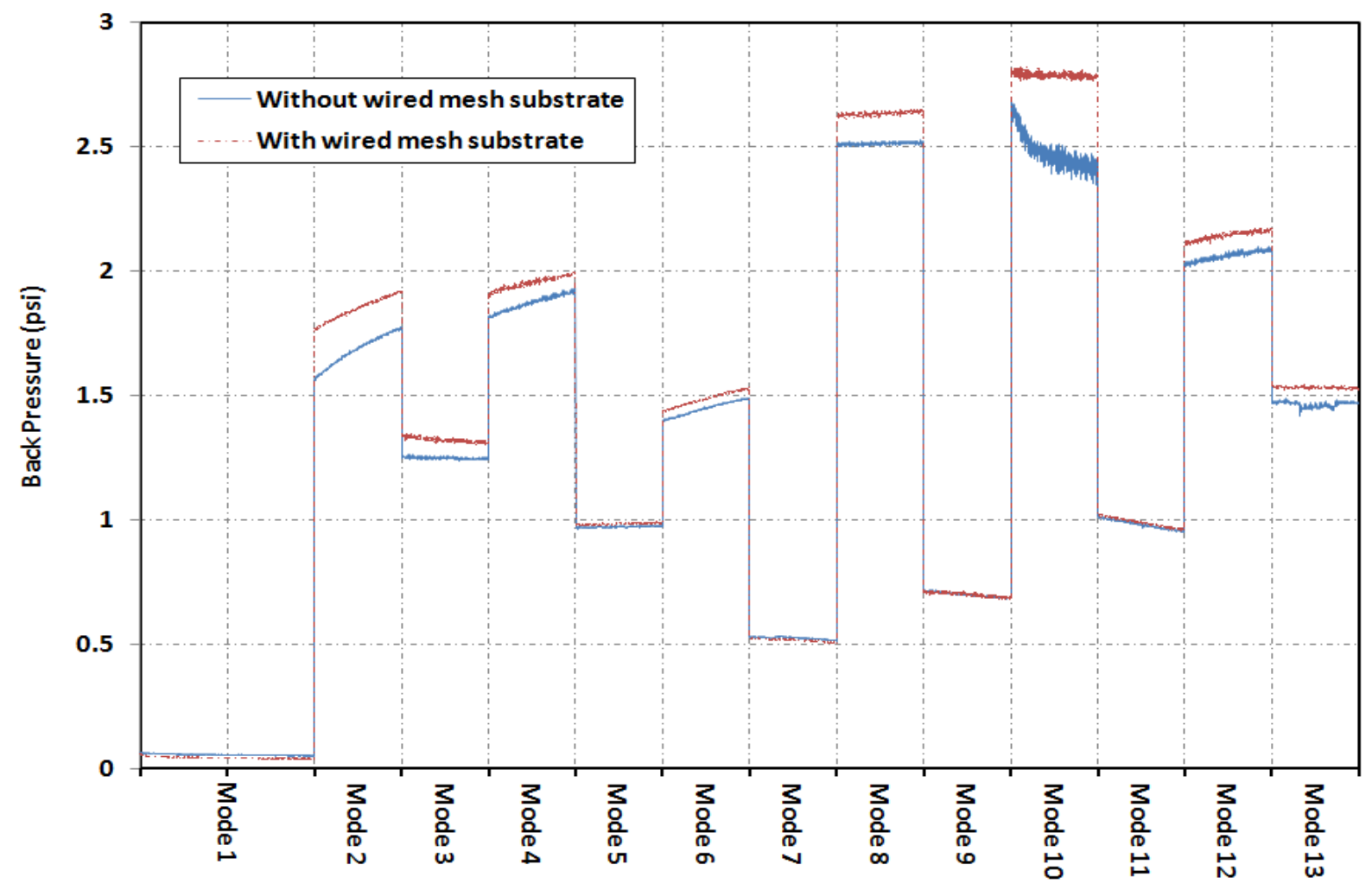

Figure 49: Back pressure comparison between ESC cycles

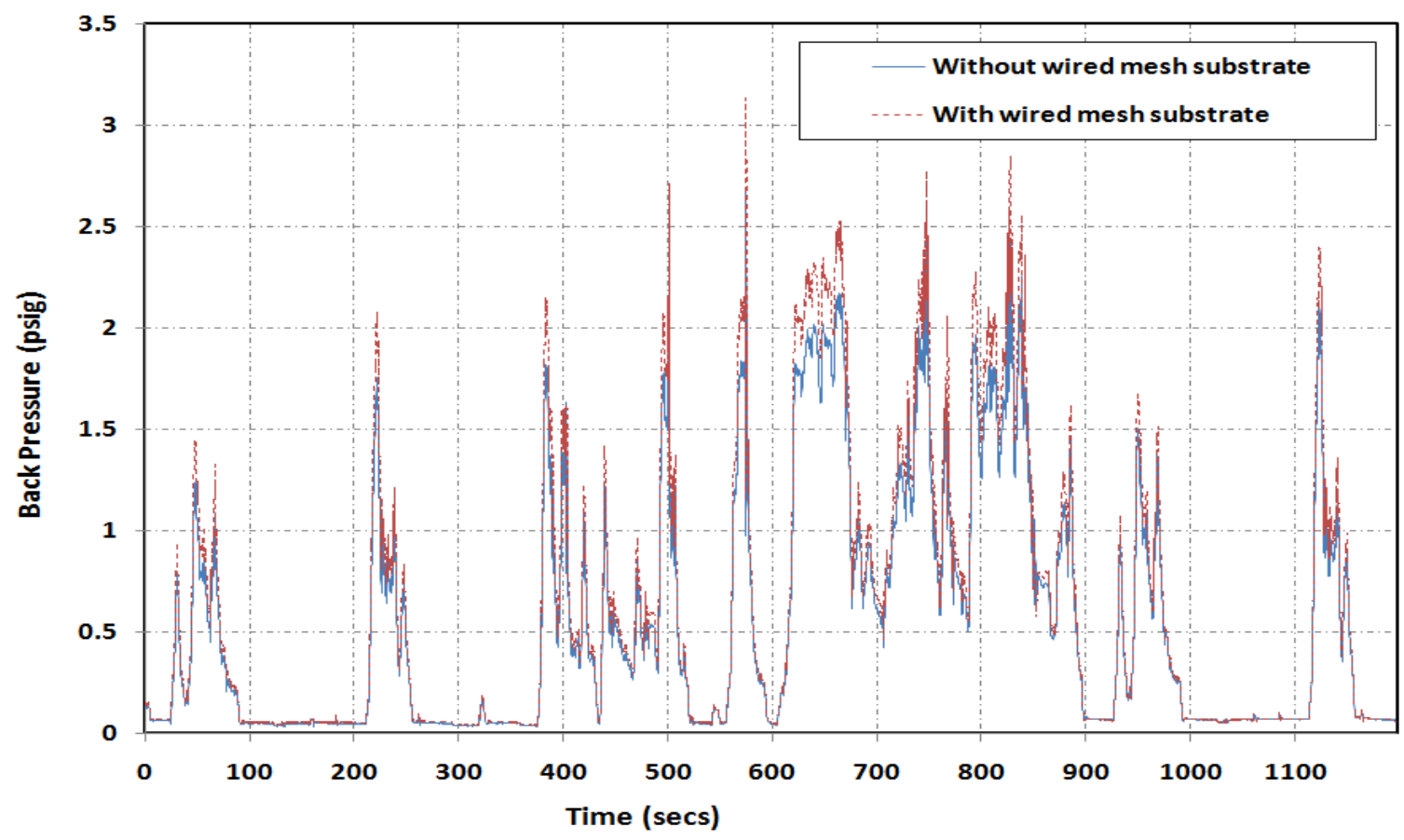

Figure 50: Back pressure comparison between FTP cycles 


\section{Chapter 6: Conclusions:}

The data gathered from the tests conducted on the engine draws the following conclusions:

Introducing the wired mesh substrate in the exhaust stream provides enhanced mixing of urea with the exhaust gases thus providing the thermolysis to take place [1]. $\mathrm{TiO}_{2}$ coating helped in hydrolysis of $\mathrm{HNCO}$ into $\mathrm{NH}_{3}$ and thus gave a further $\mathrm{NO}_{\mathrm{x}}$ reduction than the $\mathrm{ESC}$ ran without wired mesh substrate.

The $\mathrm{TiO}_{2}$ coated wired mesh of 11/2" length placed in the exhaust stream of the engine show considerable effect by reducing the $\mathrm{NO}_{\mathrm{x}}$ emissions by $23 \%$ from the previous SCR out ESC cycles.

Wired mesh substrates has no effect on the $\mathrm{NO}_{\mathrm{x}}$ emissions measured using FTP cycles because of lower temperature profile when compared with the steady state engine operation.

Back pressure increase caused by the wired mesh was insignificant by introducing the wired mesh substrate in the exhaust stream.

\subsection{Recommendations}

This study clearly showed that by installing the $\mathrm{TiO}_{2}$ coated wired mesh in the exhaust stream of the engine after injecting the urea ensured proper mixing of the urea with the exhaust gas and reduced the SCR out $\mathrm{NO}_{\mathrm{x}}$ emissions considerably by $20-25 \%$. The recommendations that can be suggested from this study are:

Results from this study showed that by introducing a wired mesh substrate has no effect on the transient FTP cycle. Effect of wired mesh substrates on different transient cycles with different temperature profiles needs to be evaluated.

The effect of the meshes with different oxidation catalytic coatings needs to be studied. Double and triple wired mesh substrates needs to be tested

Urea injection map can be optimized considering the increased exhaust temperatures because of the wired mesh substrate. This might increase the $\mathrm{NO}_{\mathrm{x}}$ reduction efficiency. 


\section{Chapter 7: References}

1. "Wire Mesh Mixer for Urea SCR System, Reliable Mixing and Thermolysys," ACS Industries, Inc. December 2007.

2. Khalek, I.A., "The Particulars of Diesel Particle Emissions," Southwest Research Institute, Technology Today, 2006.

3. Ardanese, M., "Simple Strategy-Based Technique to Reduce Emissions from SCR-Equipped Heavy-Duty Diesel Engines over Different Engine-Out Calibrations," Ph.D. Dissertation, Dept. of Mechanical and Aerospace Engineering, West Virginia University, August 2008.

4. Ardanese, R., "Control of NOx and PM Emissions from SCR-equipped 2010 Compliant Heavy Duty Diesel Engines over Different Engine-Out Calibrations," Ph.D. Dissertation, Dept. of Mechanical and Aerospace Engineering, West Virginia University, August 2008.

5. Adams, T.R., "Development of an open Loop Fuzzy Logic Urea Dosage Controller for Use with an SCR Equipped HDD Engine," Master's Thesis, Dept. of Mechanical and Aerospace Engineering, West Virginia University, 2008

6. Code of Federal Regulations, Part 86, Section 86.1333, last accessed on Sept 21, 1994.

7. Code of Federal Regulations, Part 1065. January 2008.

8. Ardanese, M., Ardanese, R., Adams, T.R., Besch, M.C., Thiruvengadam, A., Shade, B.C., Gautam, M., "Development of the ADECS to Meet 2010 Emissions Levels - Optimization of $\mathrm{NO}_{\mathrm{x}}, \mathrm{NH}_{3}$ and Fuel Consumption Using High and Low Engine Out $\mathrm{NO}_{\mathrm{x}}$ Calibrations," ASME Fall Technical Conference, September 27-30, 2009.

9. Ardanese, R., Ardanese, M., Besch, M.C., Adams, T.R., Thiruvengadam, A., Shade, B.C., Gautam, M., "PM Concentration and Size Distributions from a Heavy-duty Diesel Engine Programmed with Different Engine-out Calibrations to Meet the 2010 Emission Limits," SAE Paper No. 2009-01-1183, 2009.

10. Geske, D.M., "Mixing it Up for SCR: Online Wire Mesh Mixer Targets Urea SCR Applications; Designed for Higher Gas Flow Uniformity, Shorter Mixing Distance,” Diesel Progress North American, June 2007.

11. Yang, K.S., Mul, G., Choi, J.S., Moulijn, J.A. and Chung, J.S., "Development of $\mathrm{TiO}_{2} / \mathrm{Ti}$ Wire-mesh Honeycomb for Catalytic Combustion of Ethyl Acetate in Air," Applied Catalysis A: General, Volume 313, Issue 1, September 2006, pp 86-93. 
12. "Diesel Exhaust in the United States," Environmental Protection Agency, EPA420-F-03-022 June 2003.

13. Arregle, J., Bermudez, V., Serrano, J.R., and Fuentes, E., "Procedure for Engine Transient Cycle Emissions Testing in Real Time," Experimental Thermal and Fluid Science, Volume 30, Issue 5, May 2006, pp 485-496.

14. "The Federal Test Procedure and Unified Cycle," CARB's Emission Inventory Series, Volume 1, Issue 9, 2002.

15. Emissions Standards: USA - Heavy-Duty FTP transient cycle, www.dieselnet.com, Ecopoint Inc. Revision 1999.03a, last accessed in July, 2008.

16. Emissions Standards: USA - European Stationary cycle, www.dieselnet.com, Ecopoint Inc. Revision 2000.05, last accessed in July, 2008.

17. Code of Federal Regulations Part 1065 Subpart G, 1065.610. January 2008.

18. Andersson, S., Akerlund, C., and Blomquist, M., "Low Pressure EGR Calibration Strategies for Reliable Diesel Particulate Filter Regeneration on HDD Engines," SAE Paper No. 200201-2780.

19. Edgar, B.L., Balakrishnan, K., Zhou, X., and Rumminger, M.D., "Experiments and Analysis of Diesel Particulate Filter Loading and Regeneration,” SAE Paper No. 2000-01-3087.

20. Katsunori, H., Takamasa, S., Toshiyuki, T., and Yukio, M., "Visualization of Combustion Phenomena in Regeneration of Diesel Particulate Filter," SAE Transactions: Journal of Fuels and Lubricants (SAE Paper No. 2003-01-0836), Vol. 112, No 4, pp. 566-573, 2003.

21. Rumminger, M.D., Zhou, X., Balakrishnan, K., and Edgar, B.L., "Regeneration Behavior and Transient Thermal Response of Diesel Particulate Filters," SAE Paper No. 2001-01-1342.

22. Lee, J.S., Baik, D.S., and Lee, S.W., "Evaluation of SCR System in Heavy-Duty Diesel Engine," SAE Paper 2008-01-1320.

23. Walker, A.P., Ronny, A., and Blakeman, P.G., "The Development and Performance of the Compact SCR-Trap System: A 4-Way Diesel Emission Control System," SAE Transactions: Journal of Fuels and Lubricants (SAE Paper No. 2003-01-0778), Vol. 112, No. 3, pp. 11981206, 2003.

24. Emissions Standards: USA - Selective Catalytic Reduction, www.dieselnet.com, Ecopoint Inc. Revision 2005.05d.

25. Gieshoff, J., Pfeifer, M., Schafer-Sindlinger, A., and Spurk, P.C., "Advanced Urea SCR Catalysts for Automotive Applications," SAE Paper No. 2001-01-0514. 
26. Trautwein, W.P., "AdBlue as a Reducing Agent for the Decrease of $\mathrm{NO}_{\mathrm{x}}$ Emissions from Diesel Engines of Commercial Vehicles," DGMK (German Society for Petroleum and Coal Science and Technology) Technical Report 616-1, 2003.

27. Code of Federal Regulations, Part 1065, Subpart B, 1065.140. January 2008.

28. Code of Federal Regulations, Part 1065, Subpart B, 1065.145 and Subpart F, 1065.520. January 2008.

29. "FID Hydrocarbon Analyzer Module," Rosemount Analytical, 2006.

30. “Non-Dispersive Infrared Analyzer (NDIR) Module,” Rosemount Analytical, 1999.

31. “CLD NO/NOx Analyzer Module,” Rosemount Analytical, 2006.

32. http://www.flsmidth.com/FLSmidth+Airloq/English/Product/Measuring+Principles/UV_ND UV/Ultraviolet+Light.htm. Web 29 ${ }^{\text {th }}$ August 2008.

33. Besch, M.C., Thiruvengadam, A., Ardanese, R., Ardanese, M., Gautam, M., "Emissions and Performance Characterization of an SCR DPF Equipped 2010 Complaint Heavy-Duty Diesel Engine,, WVEPSCOR Scientific Paper Conference, 2009.

34. Conrad, B.R., "Evaluation of Diesel Particulate Filter Systems at Stobie Mine," Diesel Emissions Evaluation Program - INCO, May 2006.

35. Thiruvengadam. A., "Evaluation of Exhaust After-Treatment Device Effectiveness in Reducing Regulated and Unregulated Emissions from Natural Gas Fueled Heavy Duty Transit Bus," Master's Thesis, Dept. of Mechanical and Aerospace Engineering, West Virginia University, 2008.

36. Code of Federal Regulations, Part 1065, Subpart D, 1065.301 to 1065.309, January 2008.

37. Walsh, M.P., "Global Trends in Diesel Emissions Regulation - A 2001 Update," SAE Paper No. 2001-01-0183.

38. Gabrielsson, P., Gekas, I., Schoubye, P., Mikkelsen, S., and Fredriksen, S., "Combined Silencers and Urea-SCR Systems for Heavy-Duty Diesel Vehicles for OEM," SAE Paper No. 2002-01-0289.

39. Koebel, M., Madia, G., and Elsener, M., "Selective Catalytic Reduction of $\mathrm{NO}$ and $\mathrm{NO}_{2}$ at Low Temperatures," Catalysis Today, Volume 73, Issues 3-4, 15 April 2002, pp. 239-247.

40. Miller, W.R., "The Development of Urea-SCR Technology for US Heavy Duty Trucks," SAE Paper No. 2000-01-0190.

41. Sluder, C.S., Storey, J.M.E., Lewis, S.A., and Lewis, L.A., "Low Temperature Urea Decomposition and SCR Performance," SAE Paper No. 2005-01-1858. 


\section{Chapter 8: Appendix}

\section{Emission Calculations}

The data from all the test cell parameters and the emissions numbers from the analyzers were recorded and the data was processed to calculate the brake specific emissions of each pollutant in the exhaust. $1 \mathrm{~Hz}$ data collected throughout the cycle was used in the respective equations to calculate the emissions levels according to the 40 CFR Part 1065. The equations that were used to calculate the emissions are shown below. Emissions from series of cycles (Cold start cycle and a sequence of hot start cycles) were calculated.

Calculate brake-specific emissions over each test interval in a duty cycle. Calculate the total mass of emissions and divide it by the total work generated over the test interval

$$
e=\frac{m}{W}
$$

Where:

$m=$ Total mass of emission during the cycle

$W=$ The total work generated over the test interval

To calculate the total mass of an emission, multiply a concentration by its respective flow.

$$
m=M \cdot \sum_{i=1}^{N} x_{i} \cdot \dot{n}_{i} \cdot \Delta t
$$

Where

$M=$ Molecular weight of the exhaust gas

$x_{i}=$ concentration of exhaust gas (1 Hz Data)

$\dot{n}_{i}=$ Flow rate through the Subsonic Venturi 
Subsonic Venturi (SSV) system was used to maintain constant flow rate through the dilution tunnel at all engine operations. SSV system was calibrated according to the regulations from 40 CFR Part 1065.640.

Calculate the flow rate as follows

$$
\dot{n}=C_{d} \cdot C_{f} \cdot \frac{A_{t} \cdot p_{i n}}{\sqrt{Z \cdot M_{\text {mix }} \cdot R \cdot T_{i n}}}
$$

Where:

$C_{\mathrm{d}}=$ Discharge coefficient, determined from the SSV Calibration

$C_{\mathrm{f}}=$ Flow coefficient, determined from the SSV Calibration

$A_{\mathrm{t}}=$ Venturi throat cross-sectional area.

$p_{\text {in }}=$ Venturi inlet absolute static pressure.

$Z=$ Compressibility factor.

$M_{\text {mix }}=$ Molar mass of gas mixture.

$R=$ Molar gas constant.

$T_{\text {in }}=\mathrm{SSV}$ inlet absolute temperature.

To calculate total work from the engine's primary output shaft, numerically integrate feedback power over a test interval.

$$
\begin{aligned}
& W=\sum_{i=1}^{N} P_{i} \cdot \Delta t \\
& P_{i}=f_{n i} \cdot T_{i}
\end{aligned}
$$

Where

$P_{i}=$ Power generated by the engine during the duty cycle.

$f_{n i}=$ Speed of the engine in $\mathrm{rpm}(1 \mathrm{~Hz}$ Data $)$

$T_{i}=$ Torque on the engine $(1 \mathrm{~Hz}$ Data). 
Background emissions correction: Calculate the concentration of different exhaust gases in dilution air.

$$
\begin{aligned}
& m_{b k g n d}=\bar{x}_{d i l / e x h} \cdot m_{b k g n d d e x h} \\
& m_{b k g n d d e x h}=M \cdot \bar{x}_{b k g n d} \cdot \eta_{\text {dexh }}
\end{aligned}
$$

Where

$\bar{x}_{\text {dil/exh }}=$ Flow weighted mean fraction of dilution air in diluted exhaust

$m_{b k g n d d e x h}=$ Total mass of background

$\bar{x}_{b k g n d}=$ Concentration of gas in dilution air

Subtract the mass of background emissions of dilution air from the mass of engine exhaust emissions to get actual mass of emissions produced by the engine. 